\title{
INTERVENÇÃO NUTRICIONAL NO CONTROLE DA DEFICIENNCIA DE FERRO EM GESTANTES DA REDE BÁSICA DE SAÚDE
}

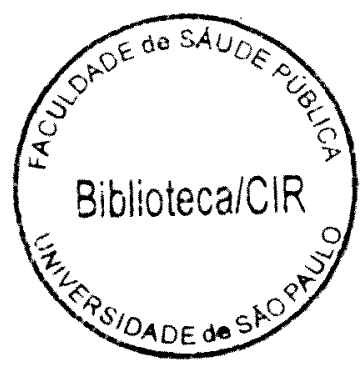

\author{
LUZ MARINA, NÚÑEZ DE CASSANA
}

Tese apresentada ao Departamento de Nutrição da Faculdade de Saúde Pública da Universidade de São Paulo para obtenção do Grau de Doutor.

Orientadora: Prof ${ }^{a}$. Dr ${ }^{a}$. Sophia Cornbluth Szarfarc

São Paulo

1998 
À minha família com quem compartilho as alegrias de hoje,

ao Wilder, meu marido e companheiro constante, por estar sempre ao meu lado, ajudando-me e incentivando-me,

aos meus filhos Edwin Javier, Jean Carlos, José Luis, e Mary Paola, armas desta vitória, pelo amor e carinho,

aos meus pais e irmãos, por compreenderem minha ausência nos momentos difíceis da familia,

eu dedico este trabalho. 
Agradeço a Deus pela vida, pelos meus pais, pela minha família, pelas boas amizades que fiz e pela acolhida que tive neste Pais

Agradeço às mães/gestantes que instigaram o desenvolvimento desta pesquisa, pela solidaridade e paciência 


\section{AGRADECIMENTOS}

À Prof ${ }^{\mathrm{D}} \mathrm{Dr}^{\mathrm{a}}$ Sophia Cornbluth Szarfarc que, como orientadora, transformou o doutorado numa agradável fase de aprendizado, tanto para o desempenho profissional como para a vida, meu muito obrigado pela ajuda neste trabalho e pela grande amizade.

À Prof ${ }^{\mathrm{a}}$. Dr ${ }^{\mathrm{a}}$ Elizabeth Fujimori, meu duplo agradecimento, pela imensa e incessante dedicação e incentivo, essenciais para a confecção deste trabalho, e pela preocupação e cuidado com minha saúde.

À $\mathrm{Dr}^{\mathrm{a}}$. Elvira Maria Guerra-Shinohara, por estar sempre perto do nossos trabalhos e pelo grande carinho e amizade.

À $\operatorname{Dr}^{\mathrm{a}}$ Ida Maria Vianna de Oliveira, colegas e funcionários do Departamento de Enfermagem em Saúde Coletiva da Escola de Enfermagem da USP, pela receptividade e amizade.

Às $\mathrm{Dr}^{\text {as }}$ Alice Lang Simões Santos; Iria Ramos;. Ekatriny Antoine Guerle Tonson, Roseli Monici de Paula Machado e Rosa Maria Pinto de Aguiar, por terem aberto as portas da FAISA para o desenvolvimento do projeto, espero que este trabalho possa de alguma maneira, retribuir 0 respeito e sensibilidade recebida por vocês e por todos os Agentes de Saúde que trabalham na Instituiçâo.

Ao Dro Nairo Massakazu Sumita, do Laboratório Central do Hospital das Clínicas da Faculdade de Medicina da USP e à Eliza.Tieko Okani, do Laboratório de Nutrição da Faculdade de Saúde Pública da USP, pela competente colaboração na análise dos exames laboratoriais. 
Ao $\mathrm{Dr}^{\circ}$ Heitor Franco de Andrade $\mathrm{J}$, pela sua prontidão em nos ajudar sempre.

Aos professores e funcionários do Departamento de Nutrição da Faculdade de Saúde Pública da USP, e do Instituto Adolfo Lutz, pelo carinho e atenção de que sempre fui alvo.

À Patricia, Lubiana, Rosângela, Hosana, Gisele e Érica, alunas de graduação que participaram nas diferentes fases de nosso trabalho, pelo carinho e amizade.

Aos familiares, compatriotas e amigos que fiz no Brasil, pelo calor humano e companheirismo durante minha permanência nesta pais.

À Fundação Kellogg, pelo auxilio financeiro, sem o qual o doutorado não existiria. 
NÚÑEZ de CASSANA , L. M. Intervenção nutricional no controle da deficiência de ferro em gestantes da Rede Básica de Saúde; São Paulo, 1998. [Tese de Doutorado - Faculdade de Saúde Pública da USP]

\section{RESUMO}

A anemia nutricional constitui um importante problema de saúde pública, com sérias repercussões para o grupo materno-fetal. O presente estudo teve como objetivo avaliar a efetividade de diferentes formas de intervenção no controle da deficiência de ferro na gravidez. Foram estudadas 301 gestantes que iniciaram seu controle pré-natal em serviços públicos de saúde, com idade gestacional inferior a 20 semanas e sem uso de medicamentos fontes de ferro. As gestantes selecionadas foram distribuídas em quatro grupos que receberam orientação para a ingestão de diferentes doses de suplemento de ferro: 80 e $120 \mathrm{mg}$ de ferro uma vez por semana; $40 \mathrm{mg}$ diárias, e um grupo denominado "Rotina" que manteve a rotina do serviço em relação à suplementação de ferro. Foram realizadas determinações laboratoriais de hemoglobina $(\mathrm{Hb})$, saturação de transferrina (ST) e ferritina sérica (FS) em momentos distintos do processo gestacional: < 20 semanas, entre 20 e 29 e $\geq 30$ semanas de gestação. Das mulheres estudadas, $14,8 \%$ revelaram-se anêmicas, $13,1 \%$ apresentavam estoques de ferro depletados e $12,7 \%$ apresentavam saturação da transferrina abaixo do normal. Houve uma perda amostral importante devido a abandono ao pré-natal, mudança de endereço e ausência de informação sobre adesão ao programa de suplementação. Destaca-se que, no grupo que recebeu $40 \mathrm{mg}$ de ferro por dia, a justificativa "sabor ruim" foi a mais importante causa de abandono da suplementação $(41,7 \%)$. No grupo "Rotina", destacou-se como principal justificativa "não comprou o medicamento" (35,3\%). Para a totalidade das mulheres que ingeriram o suplemento de ferro pelo tempo mínimo de 13 semanas, verificou-se uma evolução favorável da hemoglobina e da ferritina sérica. No entanto, o aumento da concentração de ferritina sérica no final da gravidez, indicando um aumento das reservas marciais, foi observado somente no grupo que recebeu $120 \mathrm{mg}$ de ferro por semana. Observou-se, ainda, associação positiva entre anemia e ferritina sérica no inicio e no final da gestação, permitindo supor que a evolução dos valores dos indicadores bioquimicos mantêm um sinergismo entre si. Assim, os resultados encontrados indicaram que o fornecimento de $120 \mathrm{mg}$ de ferro, uma vez por semana, pelo periodo mínimo de 3 meses constitui-se em uma estratégia de intervenção efetiva no controle da deficiência de ferro, nos serviços públicos de saúde estudados.

Descritores: gestante, anemia, deficiência de ferro, reserva de ferro, suplementação com ferro 
NUNEZ de CASSANA, L.M. Nutritional intervention concerning iron deficiency control in pregnant women attending the Basic Health Network. São Paulo, SP, Brazil. \{Doctorate Thesis - University of São Paulo School of Public Health\}

\section{Summary}

Nutritional anemia constitutes an important public health problem which brings serious consequences to the maternal-fetal group. The present paper aimed to evaluate the effectiveness of different forms of intervention for controlling iron deficiency in pregnancy. For this purpose, 301 pregnant women, who had started their prenatal control in Public Health Services with gestational age less than 20 weeks and who had not taken iron-source drugs up to then, were studied. The pregnant women selected were distributed into four groups to which orientation as to ingestion of different doses of iron supplement was provided: 80 and $120 \mathrm{mg}$ once a week; $40 \mathrm{mg}$ daily; and, a group, called "Routine", which was kept following the routine of the service concerning iron supplement. Laboratory determinations for hemoglobin ( $\mathrm{Hb}$ ), transferrin saturation (TS) and, seroferritin (SF) were carried out in different moments of the gestational process: < 20; 20-29; and, 30 and more weeks of pregnancy. From the totality of the women studied, $14.8 \%$ were anemic; $13,1 \%$ were iron depleted; and, $12.7 \%$ presented transferrin saturation below the normal pattern. There was an important sample loss due to abandonment of prenatal care, changing of address and absence of information regarding adhesion to the supplementation program. It is worth mentioning that in the group receiving $40 \mathrm{mg}$ iron/day the justification "bad taste" was the most important one, corresponding to $41,7 \%$ of the cases abandoning supplementation. In its turn, the outsdanding justification for the "routine" group was "did not buy the drug", found out in $35.3 \%$ of the reasons given. A favorable evolution of hemoglobin and seroferritin was observed for the totality of the women who took iron supplement for a minimum of 13 weeks. However, the increase in the ferritin concentration at the end of pregnancy, indicating a growth in the martial reserves, was only observed in the group that received $120 \mathrm{mg}$ iron/week. A positive association between anemia and seroferritin, both at the beginning and at the end of pregnancy, was also observed, allowing the supposition that the evolution of the values concerning the biochemical indicators maintained a synergism among themselves. Therefore, the results suggest that the most effective strategy for intervention regarding iron deficiency control in the public health services studied would be to provide pregnant women with $120 \mathrm{mg}$ iron once a week, for a minimum period of 3 months.

Descriptors: Pregnant woman; Anemia; Iron deficiency; Iron reserves; Iron supplement. 


\section{SUMÁRIO}

$\begin{array}{llr}\text { I } & \text { Introdução } & \text { Pág } \\ \text { II } & \text { Objetivos } & 1 \\ \text { III } & \text { Metodologia } & 14 \\ \text { IV } & \text { Resultados e discussão } & 15 \\ \text { V } & \text { Conclusões } & 22 \\ \text { VI } & \text { Recomendações } & 58 \\ & & 61\end{array}$

Anexo 1 Mapa do Município de Santo André: Consultório de higiene pré-natal.

Anexo 2 Declaração do Comitê de ética

Anexo 3 Orientaçōes para iniciar o projeto.

Anexo 4 FAISA: Ordem de serviço $M-222 / 96$

Anexo 5 FAISA: Ficha de Saúde da mulher

Anexo 6 FAISA: Formulário de Higiene Pré-natal

Anexo 7 Impresso do projeto: replica de calendário

Anexo 8 Calendário de uso pela gestante

Anexo 9 Impresso com informações do Kit : Ferritina Sérica

Anexo10 Impresso com informações do Kit: Ferro Sérico e Saturação da Transferrina 


\section{LISTA DE QUADROS}

Quadro 1 Controle da anemia nutricional com base na 5 prevalência da anemia em gestante

Quadro 2 Distribuição dos grupos amostrais, segundo tipo 17 de intervenção

Quadro 3 Programas de intervenção no controle da 37 deficiência de ferro 


\section{LISTA DE TABELAS}

Pág.

Tabela 1 Distribuição das gestantes segundo número de consultas pré-natal.

Tabela 2 Distribuição das gestantes segundo faixa etária.

Tabela 3 Distribuição das gestantes segundo renda familiar.

Tabela 4 Distribuição das gestantes segundo ano de escolaridade.

Tabela 5 Distribuição das gestantes segundo tipo de ocupação.

Tabela 6 Distribuição das gestantes segundo condição de ocupação e presença de companheiro.

Tabela 7 Distribuição das gestantes segundo antecedentes obstétricos.

Tabela 8 Distribuição da freqüência do consumo alimentar segundo grupos de alimentos e origem.

Tabela 9 Distribuição das gestantes segundo altura.

Tabela 10 Distribuição das gestantes segundo o peso no primeiro trimestre.

Tabela 11 Distribuição das gestantes segundo o estado nutricional no primeiro e terceiro trimestre de gestação.

Tabela 12 Concentração de hemoglobina, ferritina sérica e porcentagem de saturação da transferrina, segundo idade gestacional em semanas

Tabela 13 Distribuição das gestantes segundo grupo de intervenção e realização do exame de laboratorial de hemoglobina 
Tabela 14 Médias de hemoglobina, ferritina sérica e porcentagem de saturação da transferrina segundo grupo de intervenção e idade gestacional.

Tabela 15 Anemia e reserva de ferro das gestantes com idade gestacional $<20$ semanas

Tabela 16 Anemia e deficiência de ferro das gestantes com idade gestacional $<20$ semanas

Tabela 17 Anemia e reserva de ferro das gestantes com idade gestacional $>29$ semanas

Tabela 18 Anemia e deficiência de ferro das gestantes com idade gestacional $>29$ semanas

Tabela 19 Avaliação longitudinal dos indicadores de deficiência de ferro segundo tipo de intervenção e idade gestacional inicial ( $<20$ semanas) e final $(>29$ semanas)

Tabela 20 Tempo de ingestão do suplemento de ferro, segundo intervenção

Tabela 21 Causas de interrupção da suplementação com ferro segundo grupo de intervenção

Tabela 22 Distribuição das gestantes segundo presença ou não de anemia $(\mathrm{Hb}<11,0 \mathrm{~g} / \mathrm{dL})$ e ingestão $(\geq 13$ semanas) ou não do suplemento de ferro

Tabela 23 Distribuição das gestantes segundo presença ou não de depleção de ferro ( $F S<12 \mu \mathrm{g} / \mathrm{L}$ ) e ingestão ( $\geq 13$ semanas) ou não do suplemento de ferro 


\section{LISTA DE FIGURAS}

Figura 1 Delineamento do estudo

Figura 2 Necessidade de ferro segundo idade 39

Figura 3 gestacional

Figura 4 Evolução da concentração de hemoglobina 42 na gravidez 


\section{INTRODUÇÃO}

Anemia nutricional é uma condição patológica, na qual o tecido eritropoiético é incapaz de manter as concentrações normais de hemoglobina. Ela resulta de uma ingestão inadequada de alguns nutrientes como proteínas, algumas vitaminas $\left(\mathrm{B}_{12}\right.$, ácido fólico, piridoxina, ácido ascórbico), mas principalmente do ferro. A anemia ferropriva é a mais freqüentemente encontrada e, em saúde pública, anemia nutricional é sinônimo de anemia ferropriva (ORGANIZACION MUNDIAL DE LA SALUD - OMS, 1975a; INTERNATIONAL NUTRITIONAL ANEMIA CONSULTATIVE GROUP - INACG, 1977; DEMAEYER e ADIELSTEGMAN, 1985).

A anemia causada pela deficiência de ferro é o resultado do desequilíbrio entre a quantidade do mineral biologicamente disponível e a necessidade orgânica (FINCH e COOK, 1984; COOK, 1990; BOTHWELL, 1995). Dessa forma, ela afeta principalmente os grupos populacionais em que a demanda do mineral está aumentada, isto é, mulheres em idade fértil, préescolares e gestantes. Estas últimas constituem o grupo de maior risco para essa deficiência nutricional, uma vez que as demandas de ferro aumentam rapidamente, durante $o$ segundo e terceiro trimestre da gestação, devido à expansão do volume plasmático e ao crescimento do feto e da placenta (OMS, 1972; INACG, 1981; SCHWARTZ e THURNAU, 1995). 
Segundo estimativas da Organização Mundial da Saúde (WORLD HEALTH ORGANIZATION - WHO, 1992), cerca de metade das gestantes dos paises em desenvolvimento sofrem de anemia (56\%), mas nos países desenvolvidos sua prevalência é muito menor (15\%).

Na América Latina, os poucos estudos sobre anemia na gestação provêm de grupos populacionais restritos, geralmente referentes a usuários de serviços de saúde que, certamente, não compõem uma amostra representativa da totalidade da população. Tais estudos, no entanto, permitem supor a existência de uma elevada prevalência, uma vez que mostram, por exemplo, no Peru $54,6 \%$ de gestantes com essa deficiência (ZAVALETA e BERLANGA, 1993); 61\% na Argentina, 36 a 41\% na Bolívia, $44 \%$ no Paraguai, 27 a $53 \%$ no Chile, $60 \%$ no Equador e $25 \%$ no Uruguai (ORGANIZACION PANAMERICANA DE LA SALUD-OPS, 1996).

No Brasil, a extensa revisão realizada por VANNUCCHI e cols. (1992), e posteriormente por SZARFARC e cols. (1995), mostram que a prevalência de anemia em gestantes, embora muito diferente nas diversas regiōes do país, apresenta uma tendência crescente no decorrer do tempo ( $28 \%$ a $38 \%$ na década de setenta; $13,7 \%$ a $65,1 \%$ na década de oitenta e $29 \%$ a $52,4 \%$ na década de 90 ), mas sempre muito elevada, constituindo uma das mais importantes deficiências nutricionais ao lado da desnutrição protéico-energética (PINTO e cols., 1975; SALZANO e cols., 1980). 
Não sendo atendidas as necessidades de ferro, as mulheres em idade reprodutiva apresentam, por ocasião da gravidez um risco não desprezível de desenvolver anemia ferropriva, oportunidade em que as necessidades do mineral são notoriamente superiores às de mulheres não grávidas, já bastante elevadas em relação aos outros grupos populacionais.

Independente do fato de que na gravidez a absorção de ferro está aumentada em relação ao normal, os diversos especialistas concordam que a evolução da gestação representa um risco diferenciado para a manifestação de um estado de carência, decorrente da redução dos parâmetros hematológicos, fenômeno observado também em mulheres não ferro-deficientes.

Em nosso meio, a baixa qualidade de vida da maior parte da população determina o consumo de dietas quantitativamente inadequadas em ferro. Como descrito por SZARFARC e cols. (1995), a evolução do consumo de alimentos fontes de ferro, tais como feijões e carnes, vem decaindo desde 1960, determinada em parte pela política agrária, mas, principalmente, pelas mudanças no comportamento alimentar, onde se verifica, cada vez com maior freqüência, a substituição de almoços e/ou jantares por lanches ou os chamados fast foods, nos quais não há espaço para o feijão. O preço, por sua vez, determina uma restrição no consumo de carnes e ovos (ARRUDA, 1978; ACOSTA e cols., 1984; SZARFARC, 1983 ${ }_{\mathrm{a}}$ FUJIMORI e cols., 1987; TRIGO, 1993). 
Segundo THOMSEN cols. (1993) os $30 \mathrm{mg}$ diários de ferro recomendados pelo NATIONAL RESEARCH COUNCIL - NRC (1989) para suprir a necessidade do mineral durante a gestação dificilmente podem ser fornecidos somente com a dieta, mesmo que essa seja adequada em energia e proteína. Sendo assim, tanto a OMS (1975a) como o INACG (1977), estabelecem a obrigatoriedade de ações de controle de anemia, dirigidas ao estrato de gestantes, mesmo em áreas de baixa prevalência, para minimizar o risco reprodutivo.

Realmente, o estudo prospectivo realizado por SZARFARC e cols. (1983) em gestantes não anêmicas que não receberam sulfato ferroso reitera a importância da suplementação medicamentosa de ferro, uma vez que as mulheres estudadas tornavam-se ferro-deficientes e a seguir anêmicas à medida que a idade gestacional avançava.

Considerando que os niveis de hemoglobina da gestante refletem o que está ocorrendo com a população em geral, ou seja, adotando a gestante como Grupo Vulnerável Indicador - GVI da anemia, a OMS (1975 b) e o INACG, (1977) separadamente, propõem o esquema apresentado no Quadro 1, com vistas ao controle da anemia nutricional em populaçōes em geral. Os valores críticos que permitiriam distinguir entre baixo, médio e elevado nível de prevalência de anemia deveriam ser específicos para cada comunidade e por ela fixados. O Instituto Nacional de Alimentação e Nutrição - INAN (1982) estabeleceu, na década de 80, os seguintes valores de prevalência de anemia para o Brasil, diagnosticada a partir de 
valores de hemoglobina inferiores a $11,0 \mathrm{~g} / \mathrm{dL}$ em gestantes: inferior a $10 \%$, baixa prevalência, entre 10 e $30 \%$ média e maior que $30 \%$ elevada prevalência.

Quadro 1 - Propostas de intervenção para o controle da anemia nutricional com base na prevalência da anemia em gestantes

$\begin{array}{ll}\text { BAIXA PREVALÊNCIA } & \text { nenhuma ação exceto para as grávidas } \\ \text { MÉDIA PREVALÊNCIA } & \text { fortificação de alimentos e/ou suplementação profilática } \\ \text { ELEVADA PREVALÊNCIA } & \text { suplementação terapêutica }\end{array}$

Fonte: INACG, 1977

Por conceituar a anemia, a concentração de hemoglobina é o indicador bioquímico adotado obrigatoriamente em Sistemas de Vigilância Epidemiológica Nutricional (OMS, 1975 a). Assim as informações referentes à concentração de hemoglobina são consideradas prioritárias, por destacarem a um só tempo o problema de Saúde Pública e a importância desse indicador bioquímico no diagnóstico da referida deficiência nutricional.

No que se refere à anemia gravidica, esta é prejudicial tanto para a gestante quanto para seu concepto. São inúmeros os trabalhos que observaram a associação entre a presença da deficiência de ferro e o maior risco de morbi-mortalidade materno-fetal. 
A gestante anêmica, além de estar submetida a um maior esforço cardíaco para manter um aporte adequado de oxigênio à placenta e células fetais, tem, como todo indivíduo nessa condição nutricional, menor capacidade de trabalho físico e mental, cansa-se mais facilmente, apresenta maior risco às infecções e menor tolerância à perda de sangue no parto (DALLMAN, 1987; WALLER e HAYMES, 1996).

Em relação ao concepto, quando os niveis de hemoglobina maternos são baixos, há uma redução do abastecimento de oxigênio, fato que favorece a hipóxia fetal e certamente está associado à maior incidência de óbitos neonatais e perinatais, perdas fetais, prematuridade e baixo peso ao nascer (KLEIN, 1962; MACGREGOR, 1963; HARRISON e cols., 1973; KALTREIDER e JOHNSON, 1976; GARN e cols., 1981; MURPHY e cols., 1986; AMAR e cols., 1988; BHARGAVA e cols., 1989; KLEBANOFF e cols., 1991; AGARWAL e cols. 1991; KNOTTNERUS e cols. 1991; SCHOLL e cols., 1992; LARGUIA e cols., 1993). Isso significa, por sua vez, que como repercussão fisiopatológica de níveis deficientes em ferro, o feto fica exposto a uma menor oferta do mineral para a formação de seus próprios tecidos e estoques, tornando-se gradativamente mais propenso à manifestação de um quadro carencial, já no primeiro ano de vida (MARTINS, 1985).

Com o objetivo de diminuir as elevadas proporções com que a anemia ocorre no mundo, a OMS, a partir de meados deste século, tem intensificado os estudos sobre sua prevenção e tratamento. Entre as 
principais medidas propostas pode-se citar a educação para mudança de hábitos alimentares aliada à implementação de programas de fortificação de alimentos e/ou suplementação com sais de ferro, especialmente para as populações de maior risco, das regiōes mais subdesenvolvidas.

No que se refere à prevenção de anemia em gestantes, a OMS (1968), inicialmente, recomenda a suplementação medicamentosa de ferro para a totalidade das grávidas, pelo menos durante a segunda metade da gravidez. Já na década de setenta, tanto a OMS (1975 a) quanto o INACG (1977) estabeleceram a obrigatoriedade da suplementação oral diária com o nutriente em pauta, a partir da $20^{a}$ semana gestacional, ou pelo menos por três meses, mesmo em áreas de baixa prevalência de deficiência de ferro. Paralelamente, medidas de controle da deficiência de ferro adequadas para a população em geral, escolhidas com base no esquema exposto anteriormente (Quadro 1), deveriam ser implantadas com vistas a modificar, permanentemente, os quadros de prevalência de deficiência de ferro e suas conseqüências deletérias.

Vários países do mundo estabeleceram programas de suplementação de ferro a gestantes, em nível dos serviços de atenção primária de saúde, com resultados favoráveis na prevenção da anemia (GILLESPIE e cols., 1991).

No Brasil, em 1977, frente à elevada prevalência de anemia, o INAN e a Sociedade Brasileira de Nutrição recomendaram a suplementação 
terapêutica e profilática com ferro à gestante como uma boa opção para melhorar a situação dessa deficiência nutricional (INAN, 1977). No ano seguinte, o INAN e o INACG sugeriram ao governo brasileiro, a implantação de um programa de suplementação medicamentosa para gestantes (ARRUDA, 1978), proposta que foi incorporada em 1982 ao Programa de Assistência Integral à Saúde da Mulher do Ministério da Saúde (INAN, 1982). No Estado de São Paulo, a Norma Técnica de Anemia Ferropriva para Gestante (SECRETARIA DE ESTADO DA SAÚDE, 1990) determina a prescrição e o fornecimento de suplementação medicamentosa de ferro (um comprimido de $200 \mathrm{mg}$ de sulfato ferroso - 40 $\mathrm{mg}$ de ferro elementar por dia) a todas as gestantes a partir da primeira consulta de pré-natal até o puerpério e periodo de lactação.

Realmente, o sal de ferro mais utilizado nos programas de suplementação tem sido o sulfato ferroso, pelo baixo custo e razoável biodisponibilidade (SOOD e cols, 1975; INACG, 1981). Nos paises industrializados, a dose utilizada varia de 30 a $60 \mathrm{mg}$, enquanto nos paises em desenvolvimento, onde a prevalência de anemia em gestantes é elevada, tem-se preconizado doses de 100 a $200 \mathrm{mg}$ de ferro elementar por dia (HALLBERG e cols., 1967; OMS, 1968; CHAROENLARP e cols., 1988), o que contrasta com o programa nacional de $40 \mathrm{mg}$ de ferro por dia (SECRETARIA DE ESTADO DA SAÚDE, 1990).

Estudos clínicos controlados mostram que a suplementação com sulfato ferroso, além de diminuir a prevalência de anemia durante a gravidez, 
aumenta tanto a reserva materna de ferro quanto a do recém nascido (TAYLOR e cols., 1982; JACKSON e LATHAM, 1982; ROSMLO e cols., 1983; GODEL e cols., 1992; BARTON e cols., 1994; MILMAN e cols., 1994), contribuindo, portanto, para o bem-estar da mãe quer no trabalho quer como membro ativo da comunidade (DODD e cols., 1992; LI e cols., 1994).

Sabe-se, no entanto, que a efetividade dos programas de suplementação tem sido restringida por uma série de fatores que resultam, sobretudo, de um complexo círculo vicioso composto por elementos diversos que envolvem política, administração, planejamento, gestão, organização, disponibilidade de recursos econômicos, materiais e humanos, além do interesse, motivação, crenças e responsabilidade das próprias gestantes (WHO, 1991; GILLESPIE e cols., 1991; US PREVENTIVE SERVICES TASK FORCE, 1993a; GALOWAY e McGUIRE, 1994; CARDOSO e PENTEADO, 1994; MASSAWE e cols., 1995; PAPPAGALLO e BULL, 1996).

É reconhecido que a ineficiência da suplementação decorre, em muitos casos, dos efeitos colaterais provocados pelo uso oral de ferro associados ao mal estar próprio da gravidez (BAKER e DEMAEYER, 1978; CHAROENLARP e cols., 1988). Para MASSAWE e cols. (1995), a dificuldade de se manter a motivação da mulher para o seguimento correto da suplementação, possivelmente se deve também à ausência de uma sintomatologia específica para a deficiência de ferro. 
Dessa forma, estudos vêm sendo realizados no sentido de esclarecer a problemática que envolve a ineficiência dos programas de suplementação de ferro em gestantes. Extensa revisão sobre suplementação rotineira com ferro durante a gestação revela a existência de poucos estudos que avaliam a efetividade dos programas (US PREVENTIVE SERVICES TASK FORCE, 1993b). Apesar de obter a mesma evidência revisando dados norte-americanos, ALLEN (1994) supõe que a aparente ineficácia dos programas de suplementação se deve à baixa adesão das mulheres ao programa. GILLESPIE e cols. (1991) analisando programas operacionais na Índia relatam que o índice médio de abandono ao programa nacional de suplementação com ferro variou de 9 a $87 \%$, sendo que mais de $80 \%$ deles foram decorrentes da falta do suplemento como motivo para desistência. SCHULTINK e cols. (1993), em estudo realizado com 45 gestantes suplementadas com $60 \mathrm{mg}$ de ferro por 2 meses, obtiveram adesão de dois terços do grupo e resultado positivo em apenas $36 \%$ dessas grávidas. Da mesma forma, SCHOLL e HEIDER (1994), estudando gestantes anêmicas e não anêmicas verificaram dificuldade de adesão ao programa, uma vez que a não utilização rotineira do suplemento de ferro variou de $62 \%$ a $76,5 \%$. THORAND e cols. (1994) buscando avaliar a eficiência do programa de suplementação na Indonésia verificou que somente $72 \%$ das gestantes receberam sulfato ferroso e dessas apenas $32,7 \%$ ingeriram o medicamento, resultado que levou o autor a 
recomendar melhoria na cobertura do programa, além de estímulo e conscientização das gestantes.

A dificuldade de adesão a programas que envolvem a suplementação com ferro não é verificada somente em gestantes. SZARFARC e cols. (1996) verificaram uso inexpressivo do suplemento de ferro entre infantes atendidos na Rede Pública de Saúde de Santo André, mesmo quando o medicamente era fornecido pelo pediatra, acompanhado de folheto educativo.

Apesar da magnitude e do longo periodo de existência de alguns programas de suplementação medicamentosa com ferro e da comprovada eficácia na saúde materno-infantil, a prevalência da anemia continua sendo um importante problema de saúde pública, especialmente nos paises em desenvolvimento (WHO,1991). Esse fato torna urgente a busca de alternativas para melhorar a efetividade dos programas de suplementação, no sentido de prevenir e/ou tratar a anemia gestacional.

Segundo MASSEY (1992), os efeitos colaterais gastrointestinais, tais como náuseas, cólicas abdominais, obstipação e/ou diarréia são observados em $15 \%$ a $20 \%$ de pacientes tratados com ferro oral. Esse autor propõe a redução da dose como alternativa para atenuar os efeitos indesejáveis, embora essa medida prolongue o tratamento.

Outras perspectivas profiláticas tais como aumento da concentração de substâncias facilitadoras da absorção do mineral em cada refeição e 
destruição de substâncias inibidoras da absorção do ferro, também presentes nas refeições, têm sido estudadas para melhorar o aproveitamento biológico do nutriente (OMS, 1975a; BOTHWELL e cols., 1989; PIZARRO e cols., 1994).

Também o uso de diferentes formas de ferro oral, tais como cápsulas de sulfato ferroso de liberação gástrica lenta (COOK e cols., 1990; SIMMONS e cols., 1993) e ferro micro encapsulado, como molécula orgânica a

exemplo do ferrochel (PINEDA e cols., 1994), tem sido estudado na busca da redução dos efeitos colaterais e aumento da eficácia do programa de controle da deficiência de ferro.

Recentemente vários estudos clínicos controlados baseados na suplementação intermitente com ferro, isto é doses menos freqüentes que as diárias, vêm demonstrando melhora na adesão ao programa, com diminuição significativa de efeitos colaterais (GROSS e cols., 1994; SCHULTINK e cols., 1995; LIU e cols., 1995; RIDWAN e cols., 1996; QUINTERO-GUTIERREZ e cols., 1997). A efetividade similar na restauração dos niveis de hemoglobina, a partir de doses intermitentes, possivelmente se deve ao fato do mineral ficar retido na célula da mucosa intestinal, que por sua vez se renova somente a cada seis dias.

SZARFARC (1985), já na década de 80 ressaltava a importância da implantação de um sistema de vigilância, com vistas a obter maior eficácia e efetividade do programa de combate à anemia na gravidez. No entanto, 
ainda inexistem, em nosso meio, estudos que avaliem a resposta obtida com a suplementação de ferro durante a gestação (CARDOSO e PENTEADO, 1994)

Toda a problemática que envolve o programa de suplementação com ferro e o maior risco de morbi-mortalidade materno-fetal associada à anemia gravídica destaca a necessidade de se avaliar tal programa e propor meios para melhorar sua efetividade. Tendo em vista que os principais problemas relacionados à baixa eficiência e efetividade dos programas de suplementação da rede básica de saúde tem sido relacionado à dificuldade de adesão ao programa, planejou-se o presente estudo, com a finalidade de verificar o efeito da suplementação semanal de diferentes doses de ferro oral, buscando diminuir tanto o custo (melhor abastecimento e cobertura), quanto os efeitos colaterais indesejáveis (maior adesão). 


\section{OBJETIVOS}

GERAL

Avaliar a efetividade de diferentes formas de intervenção no controle da deficiência de ferro na gravidez, no Programa de Atendimento à Gestante da Rede Pública de Saúde de Santo André.

\section{ESPECÍFICOS}

Determinar a evolução dos indicadores laboratoriais do estado nutricional de ferro, em gestantes submetidas a diferentes formas de suplementação com ferro.

Descrever a freqüência das causas de interrupção e a adesão de gestantes submetidas a diferentes formas de suplementação com ferro. 
III. METODOLOGIA 


\section{METODOLOGIA}

O estudo foi desenvolvido em Santo André, município que compõem a Região Metropolitana de São Paulo. Localizada a sudeste da Capital do Estado, a uma altitude de $760 \mathrm{~m}$, possui uma área de extensão de $181 \mathrm{~km}^{2}$ e em 1991 sua população era de 617 mil habitantes (FUNDAÇÃO IBGE, 1993). Sua base econômica caracteriza-se pela alta predominância de indústrias de transformação que absorvem cerca de $45 \%$ do total da mão de obra ativa do municipio (FAISA, 1986)

A FAISA - Fundação de Assistência à Infância de Santo André - é responsável pelos serviços básicos de saúde destinados às crianças e adolescentes de Santo André. Essa Fundação foi criada em 1966 por iniciativa do Lions Clube e tem como meta a melhoria do nivel de saúde da população materno-infantil do municipio. A FAISA conta atualmente com 20 Postos de Puericultura e Pediatria em funcionamento (Anexo 1), 13 dos quais atendem as gestantes através do Programa de Assistência Integral à Saúde da Mulher. A grande maioria dos postos de saúde da FAISA está localizada em bairros periféricos, próximos da população mais carente (FAISA, 1986).

O presente estudo foi precedido pela aprovação do projeto pela Comissão de Ética da FAISA (Anexo 2). Para a divulgação dos objetivos e metas, do modelo amostral e das atividades a serem desenvolvidas, foram realizadas 
reuniões com a totalidade dos médicos que atendem ao pré natal, frisando-se a importância de sua participação na avaliação do controle da anemia. Nessa ocasião foram distribuídos os impressos de orientação para intervenção no controle da deficiência de ferro, específica para cada posto de saúde (Anexo 3 e 4). Ainda no que toca aos procedimentos éticolegais, há que se salientar que ficou assegurado à gestante o direito à participação ou não na pesquisa, isto é, somente foi admitida no estudo a gestante que após ter sido cientificada dos objetivos do projeto, concordou em participar do mesmo.

Para atender os objetivos propostos, optou-se por um estudo longitudinal. A escolha deste delineamento foi determinada por possibilitar o estudo dos múltiplos aspectos que envolvem um programa de intervenção nutricional com ferro no período gravídico, permitindo avaliar a evolução dos indicadores da deficiência de ferro e a adesão ao programa durante toda a gestação.

A amostra deste projeto, foi constituida por um conjunto de 301 gestantes, atendidas em consultas rotineiras de pré-natal, com os seguintes pré requisitos:

- idade gestacional inferior a 20 semanas na $1^{\text {a }}$ consulta de pré-natal;

- baixo risco obstétrico;

- não ter feito uso de suplemento de ferro até o momento da $1^{a}$ consulta. 
As gestantes selecionadas receberam orientação para tomar o suplemento de ferro na quantidade e freqüência previstas para cada posto de saúde, definida como unidade amostral, a partir da vigésima semana de gravidez, de acordo com a Norma Técnica da Secretaria de Saúde do Estado de São Paulo (SECRETARIA DE ESTADO DA SAÚDE, 1990).

A população de estudo foi distribuída em 4 grupos, como descrito no Quadro 2

Quadro 2 - Distribuição dos grupos amostrais, segundo tipo de intervenção.

\begin{tabular}{|ccccc|}
\hline Grupo & $\begin{array}{c}\text { No de Postos }_{\text {de Saúde }} \\
\text { amostral }\end{array}$ & $\begin{array}{c}\text { Tamanho } \\
\text { suplementaçãa da }\end{array}$ & $\begin{array}{c}\text { Fe elementar } \\
(\mathrm{mg})\end{array}$ \\
\hline 1 & 3 & 78 & Semanal & 120 \\
2 & 3 & 74 & Semanal & 80 \\
3 & 3 & 74 & Diária & 40 \\
4 & 2 & 75 & "Rotina do Serviço" & \\
\hline
\end{tabular}

A utilização de $120 \mathrm{mg}$ e $80 \mathrm{mg}$ de ferro elementar pelos grupos 1 e 2 , se deveu à proposta de se testar a administração semanal de três ou duas vezes, respectivamente, a dose de $40 \mathrm{mg}$ recomendada pela SECRETARIA DE ESTADO DA SAÚDE (1990).

A diferença entre o grupo 3 e 4 foi o fornecimento garantido do suplemento de ferro ao grupo 3, enquanto as mulheres do grupo 4 recebiam apenas a 
prescrição médica do suplemento, não se garantindo o seu fornecimento, a não ser quando este era disponivel no Serviço.

Com exceção da distribuição de sulfato ferroso às gestantes dos grupos 1 , 2 e 3 , a rotina do pré-natal foi mantida. Assim, para a coleta dos dados de caracterização da população, antecedentes familiares e ginecológicos, história obstétrica pregressa e evolução da gravidez atual, foram utilizados os próprios formulários do serviço (Anexos 5 e 6).

Para a obtenção dos dados de prática alimentar e escolaridade da gestante e do chefe da familia, inexistentes nos formulários da FAISA, mas necessários para atender aos objetivos da pesquisa, acrescentou-se ao prontuário das gestantes, o Anexo 7. Além daqueles dados, o impresso continha a reprodução de um calendário que deveria ser preenchido pelos técnicos, a cada retorno da mulher ao pré-natal, a partir da cópia de calendário similar que as gestantes recebiam após a $20^{\mathrm{a}}$ semana (Anexo 8), a fim de indicar a data em que efetivamente ingeria o suplemento e registrar as justificativas para a não ingestão e as manifestações indesejáveis. O mesmo impresso permitia identificar os prontuários das gestantes cadastradas no estudo, facilitando ao serviço, o repasse das orientações especificas.

As orientações para o uso do suplemento de ferro diária ou semanal eram feitas pelo próprio médico responsável pelo pré-natal, durante as consultas. Na mesma oportunidade as gestantes recebiam orientação para 
que comparecessem ao Laboratório Central da FAISA, situado na sede da Instituição, em jejum, para a colheita de sangue, nas datas previstas pelo estudo e indicadas pelo médico.

Para avaliar a evolução da anemia e da deficiência de ferro durante a gestação foram realizadas três colheitas de sangue, a primeira delas antes do início da suplementação (< 20 semanas), a segunda entre a $20^{a}$ e a $29^{a}$ semana gestacional e a terceira da $30^{a}$ à $40^{a}$ semana de gestação (Figura 1).

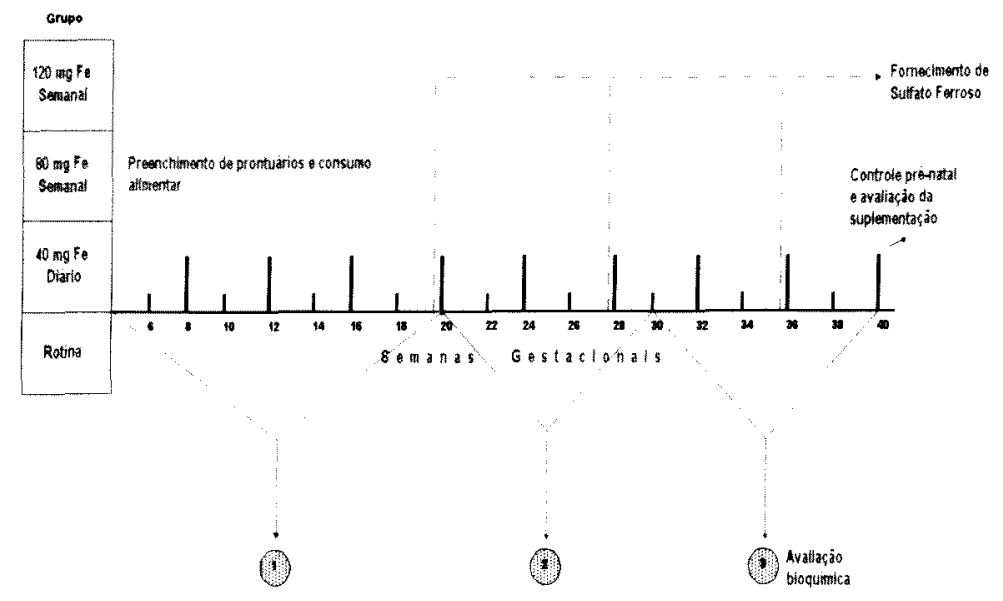

Figura 1 - Delineamento do estudo

Para a determinação e a caracterização da deficiência de ferro, o sangue foi colhido, por punção venosa, em 2 tubos "vacutainer", um sem anticoagulante e outro contendo ácido etileno diamino tetraacético - EDTA. Para a obtenção do soro, o sangue sem anticoagulante foi centrifugado e dividido em dois tubos de ensaio antes de ser congelado, segundo as 
recomendações do INACG (1985). As análises laboratoriais foram realizadas no próprio Laboratório Central da FAISA, no Laboratório Central do Hospital das Clínicas da Faculdade de Medicina da USP e no Laboratório de Nutrição do Departamento de Nutrição da Faculdade de Saúde Pública da Universidade de São Paulo.

A hemoglobina $(\mathrm{Hb})$ foi determinada pelo método colorimétrico da cianometahemoglobina (DACIE e LEWIS, 1984). Para a definição da anemia, utilizou-se o valor $11,0 \mathrm{~g} / \mathrm{dL}$ como valor crítico, conforme proposto pela OMS (1968).

A ferritina sérica (FS) foi determinada através do "kit" N Látex Ferritina da Behring (Anexo 9). A metodologia do "kit" baseia-se no seguinte, a ferritina sérica liga-se a micropartículas de poliestireno sensibilizadas com anticorpos policlonais anti-ferritina. Os microagregados formados desviam a luz que incidem sobre o tubo-reação, e a dispersão da luz é medida por nefelômetro. Foram consideradas ferro-depletadas todas as gestantes que apresentaram valores de ferritina sérica inferiores a $12 \mu \mathrm{g} / \mathrm{L}$, apesar da hemodiluição caracteristica nessa situação fisiológica, conforme sugerem FENTON e cols. (1977).

A porcentagem de saturação da transferrina (ST) foi calculada a partir da relação percentual entre as concentrações de ferro sérico (FeS) e de capacidade total de ligação de ferro (CTLFe). As determinações de ferro sérico ( $F e S$ ) e da capacidade total de ligação de ferro (CTLFe) foram 
feitas através de método colorimétrico de Ponto Final, utilizando os "kits" da Laborlab (Anexo 10). Foram considerados ferro deficientes as gestantes com valores de porcentagem de saturação da transferrina inferiores a $16 \%$, conforme proposto pelo INACG (1985) para maiores de 10 anos. Chama a atenção, os valores de referência citados no catálogo da Laborlab, $20 \%$ a $55 \%$, baseados nos valores aceitos como normais para FeS (entre 60 $\mu \mathrm{g} / \mathrm{dL}$ e $160 \mu \mathrm{g} / \mathrm{dL}$ ) e para CTLFe (entre $250 \mu \mathrm{g} / \mathrm{dL}$ e $400 \mu \mathrm{g} / \mathrm{dL})$.

As análises estatisticas foram realizadas utilizando-se o programa EpiInfo6 (DEAN, 1994). Os resultados obtidos na forma de freqüências, médias e porcentagens são apresentados em tabelas e gráficos. O qui quadrado foi utilizado para analisar a associação da adesão aos tratamentos, entre os grupos de estudo. Para todos os testes estatisticos usados na análise dos resultados, o nivel de significância estabelecido foi sempre de alpha igual ou inferior a $5 \%$. 


\section{RESULTADOS E DISCUSSÃO}

Cerca de $15 \%$ das gestantes do município de Santo André recebem atenção pré-natal nos postos de saúde da FAISA. Isto significa que compete àquela Instituição prestar assistência pré-natal a cerca de 1200 novas gestantes por ano, através do Programa de Atendimento à Gestante, realizando, paralelamente à orientação de rotina, a identificação, prevenção e/ou controle de fatores de risco que possam comprometer a qualidade do processo reprodutivo.

Para a OPS (1986), os fatores de risco que podem comprometer a qualidade do processo reprodutivo estão relacionados a antecedentes vitais, à gestação em curso e à condição social. ALVARENGA (1994), discutindo a importância da abordagem de risco para a priorização de fatores a serem controlados, propõe que a análise das relações do risco gravídico e perinatal avance para além da dimensão biológica, abordando também a natureza psicológica e social da questão, em termos de uma abordagem interdisciplinar.

O atendimento pré-natal é a oportunidade ímpar para prevenir ou controlar o conjunto de fatores de risco, de natureza biológica, especialmente, aqueles relacionados à insuficiência ponderal e prematuridade, principais causas do óbito infantil no primeiro ano de vida.

BENICIO e cols. (1985), estudando fatores associados ao risco de baixo peso ao nascer entre recém nascidos vivos no municipio de São Paulo, 
identificaram a ausência de pré-natal (número de consultas inferior a 3) como o fator de maior relevância, seguido de baixo peso materno prégestacional (inferior a $50 \mathrm{~kg}$ ) e gestação na adolescência (idade materna inferior a 20 anos), além da baixa escolaridade materna (inferior a $1^{\circ} \mathrm{grau}$ completo), quando simultânea à ausência de pré-natal.

A Tabela 1 apresenta a distribuição da população estudada segundo freqüência ao pré-natal. Por tratar-se de um estudo longitudinal, desenvolvido durante o processo gestacional de mulheres que procuraram um serviço de atenção pré-natal durante o primeiro trimestre de gravidez, chama a atenção, a elevada proporção daquelas com número de consultas inferior a $6(30,6 \%)$, valor mínimo considerado adequado pelo Ministério da Saúde (1986).

Tabela 1 - Distribuição das gestantes segundo número de consultas de pré-natal. FAISA, 1997.

\begin{tabular}{ccc}
\hline$N^{0}$ de consultas & $N^{0}$ de Gestantes & \% de Gestantes \\
\hline$<3$ & 37 & 12,3 \\
$3-5$ & 55 & 18,3 \\
$\geq 6$ & 209 & 69,4 \\
\hline TOTAL & 301 & 100,0 \\
\hline
\end{tabular}

A idade materna é outro fator identificado como de risco para baixo peso ao nascer, uma vez que, se a gravidez ocorre na adolescência, à necessidade já aumentada pela demanda do crescimento de um organismo jovem, soma-se aquela relacionada ao processo gestacional, 
especialmente entre menores de 17 anos. Nesses casos, a privação energética pode gerar competição entre gestante e feto o que, certamente, redundará em desnutrição materna e conseqüentemente no baixo peso ao nascer (COSTA, 1996). Outro fator que possivelmente concorre para a maior incidência de baixo peso ao nascer entre adolescentes, é a prematuridade, que acomete com maior freqüência crianças nascidas da primeira gestação, realidade da maioria das adolescentes (MARTINEZ e cols., 1992). Como ocorre em relação a outras variáveis biológicas, o risco derivado dessa situação, pode e deve ser controlado no atendimento prénatal (SZARFARC e cols., 1980).

No presente estudo, a idade média foi de $25,3 \pm 6,1$ anos, variando de 14 a 42 anos. A Tabela 2 mostra a distribuição das gestantes segundo faixa etária. O percentual observado de $21,6 \%$ de gestantes adolescentes, mostrou-se inferior aos $26 \%$ encontrados por BATISTA FILHO e cols. (1993) entre parturientes atendidas na maternidade do Instituto Materno Infantil de Pernambuco, Instituição que atende à população mais carente da Grande Recife. No entanto, a proporção encontrada na FAISA, é bastante superior aos $12,1 \%$ de adolescentes com história de gravidez atual ou pregressa verificados para o Brasil, a partir de dados da Pesquisa Nacional de Saúde e Nutrição (RAPOSO e cols., 1997). 
Tabela 2 - Distribuição das gestantes segundo faixa etária. FAISA, 1997

\begin{tabular}{ccc}
\hline Faixa etária (anos) & $\mathrm{N}^{0}$ de Gestantes & \% de Gestantes \\
\hline$<17$ & 14 & 4,7 \\
$17-19$ & 52 & 16,9 \\
$\geq 20$ & 235 & 78,4 \\
\hline TOTAL & 301 & 100,0 \\
\hline
\end{tabular}

Sabe-se que a proporção de gestantes adolescentes tem aumentado consideravelmente. Concorre para tal, a modificação no padrão do comportamento sexual das últimas décadas, que vem antecipando o início da atividade sexual entre os jovens, fato que aumenta o risco de uma gravidez precoce e geralmente indesejada, com todas as suas conseqüências deletérias. Nesse sentido, vale a pena ressaltar o aumento da participação das mulheres adolescentes na fecundidade total verificada para o Brasil, que passou de 6,5\% em 1970 para 10,5\% em cerca de quinze anos (SIMŌES e OLIVEIRA, 1988). Assim, justifica-se que as complicações da gestação, parto e puerpério constituam uma das principais causas de óbito entre adolescentes (SIQUEIRA e cols., 1996).

Normalmente, a maioria da população que freqüenta os serviços públicos de saúde, como os oferecidos pela FAISA, é aquela que não tem outra opção de assistência. Essa situação pode ser confirmada quando se avalia a variável renda familiar das gestantes estudadas (Tabela 3). 
Tabela 3 - Distribuição das gestantes segundo renda familiar. FAISA, 1997.

\begin{tabular}{ccc}
\hline Renda familiar $\left(\mathrm{SM}^{*}\right)$ & $\mathrm{N}^{0}$ de Gestantes & \% de Gestantes \\
\hline$<1$ & 41 & 38,3 \\
$1-2$ & 26 & 24,3 \\
$3-4$ & 30 & 28,0 \\
$\geq 5$ & 10 & 9,3 \\
\hline TOTAL & 107 & 100,0
\end{tabular}

* $S M=$ Salário minimo

Variaçäo do SM no periodo em dólares americanos: US\$107,10 a 109,85

De acordo com o DEPARTAMENTO INTERSINDICAL DE ESTATISTICA E ESTADO SÓCIO-ECONÓMICO (1997), a renda familiar mínima suficiente para atender às necessidades vitais básicas de uma familia, calculada para o mês de outubro de 1997 , seria de 6,5 salários mínimos. Dessa forma, somente $9 \%$ da população estudada teria condições adequadas para o atendimento de necessidades, tais como despesas com alimentação, moradia, vestuário, etc.

CAMPINO (1986), ao estudar os aspetos sócio-econômicos da desnutrição no Brasil, assinala a importância da variável renda, não só como fator isolado mais importante na determinação do estado nutricional, mas também como uma informação fundamental na implementação ou orientação de programas coletivos de interesse à Saúde Pública, relacionados à nutrição da população.

As informações sobre renda familiar, além de apresentarem problemas de fidedignidade, parecem não ser de conhecimento da população feminina, uma vez que cerca de dois terços $(64,5 \%)$ dos prontuários não continham 
- registro desse dado. Assim, considerando-se que o nível de escolaridade das gestantes poderia constituir uma alternativa interessante para se determinar a condição social, e o fato dessa variável constituir um dos quatro principais fatores de risco associado ao baixo peso ao nascer (BENÍCIO e cols., 1985), apresenta-se na Tabela 4, a distribuição das gestantes segundo o ano de escolaridade.

Tabela 4 - Distribuiçăo das gestantes segundo ano de escolaridade. FAISA, 1997.

\begin{tabular}{ccc}
\hline Anos de escolaridade & $N^{0}$ de Gestantes & \% de Gestantes \\
\hline$<4$ & 28 & 10.1 \\
4 & 33 & 12,0 \\
$5-7$ & 113 & 40.9 \\
8 & 56 & 20.3 \\
$>8$ & 46 & 16.7 \\
\hline TOTAL & 276 & 100 \\
\hline
\end{tabular}

A educação formal, expressa em anos de escolaridade, tem sido valorizada, em estudos epidemiológicos bem consistentes, como um indicador de risco de primeira ordem no que se refere às condições de saúde e nutrição (MONTEIRO e cols., 1992, VIGOLVINO e cols., 1997). Como destaca MONTEIRO e cols. (1986), a atuação da escolaridade na situação de saúde decorre, por um lado, da eficiência com que o indivíduo se insere na sociedade, modificando suas oportunidades de acesso a empregos e, portanto, de salários, e por outro lado, da capacidade de entendimento de problemas de saúde e, em conseqüência, de cuidados especificos necessários para controlar ou evitar situações desfavoráveis 
de saúde. Dessa forma, pode-se afirmar que esta variável está relacionada tanto à condição econômica quanto à condição de vida das pessoas.

A Tabela 4 permite confirmar a precariedade do nivel educacional das gestantes estudadas. Verifica-se que $63,0 \%$ da população tinha menos que 8 anos de estudo, sendo que $10,1 \%$ não tinha sequer o primário completo ( $<4$ anos de estudo).

A baixa escolaridade, cuja média de anos estudados foi de $6,5 \pm 2,5$ anos, tem reflexos, por sua vez, na ocupação que as gestantes informaram exercer. Verificou-se, entre a pequena fração da população que referiu exercer atividade remunerada $(19,3 \%)$, que o perfil de ocupação era bastante modesto, composto de serviços não especializados, distribuindose entre serviços gerais (balconista, atendentes, etc.) e serviços domésticos (diaristas, faxineiras e empregadas domésticas) (Tabela 5).

Tabela 5 - Distribuição das gestantes segundo tipo de ocupação. FAISA, 997.

\begin{tabular}{lcc}
\hline Ocupação & No de Gestantes & \% de Gestantes \\
\hline Não & 192 & 80,7 \\
Sim & & \\
Serviços gerais & 14 & 5,9 \\
Trabalho doméstico & 32 & 13,4 \\
\hline \multicolumn{1}{c}{ TOTAL } & 238 & 100,0 \\
\hline
\end{tabular}


No presente estudo, o trabalho feminino não se mostrou indicativo de melhor renda familiar. Nenhuma das mulheres que trabalhavam estavam incluidas entre aquelas que referiram rendimento familiar igual ou superior a 5 salários mínimos mensais. A hipótese aventada para explicar esse quadro, e que não foi confirmada (Tabela 6), era que a mulher que trabalhava era aquela que não tinha companheiro e portanto seu trabalho constituiria o principal rendimento da casa.

Tabela 6 - Distribuição das gestantes segundo condição de ocupação e presença de companheiro. FAISA, 1997.

\begin{tabular}{lccc}
\hline & \multicolumn{2}{c}{ Companheiro } & \\
Ocupação & Sim & Não & TOTAL \\
\hline Sim & 36 & 6 & 157 \\
Não & 121 & 34 & 40 \\
\hline TOTAL & 157 & 40 & 197 \\
\hline
\end{tabular}

Com relação ao preenchimento das fichas de pré-natal (Anexos 5 e 6) que compõem o prontuário da gestante, três aspectos merecem ser destacados. O primeiro diz respeito à heterogeneidade no preenchimento dos dados. Como não havia padronização, a variável "ocupação", podia ser preenchida como doméstica, referindo-se tanto à mulher do lar, que não trabalhava fora, como também à empregada doméstica, diarista ou faxineira, que trabalha fora de casa, com atividade remunerada, porém nem sempre com seus direitos trabalhistas assegurados pelo registro de vínculo empregatício na Instituição Nacional de Seguridade Social. 
O segundo aspecto diz respeito ao preenchimento incompleto das fichas. Observou-se que, rotineiramente, muitos dados das fichas não eram preenchidos na sua totalidade, o que resultava em muitos espaços em branco, gerando dúvidas em relação àquele dado, cuja conotação poderia ser o não levantamento do dado ou resposta negativa àquela informação. Assim, considerando o exemplo anterior, a variável "ocupação" sem resposta, poderia significar que o dado não havia sido levantado, ou que a mulher realmente não trabalhasse fora de casa.

O terceiro aspecto, e tão importante quanto aos anteriores, diz respeito à atualização das informações. Como a "Ficha de Saúde da Mulher" (Anexo 5) é o mesmo para qualquer atendimento relacionado à saúde da mulher, independente da data em que ela se matriculou na Instituição, os dados a seu respeito poderiam estar, eventualmente, defasados por terem sido colhidas durante consultas ginecológicas ou gestações anteriores.

A precariedade dos registros de assistência pré-natal não constitui particularidade da Instituição onde se desenvolve o presente estudo. OBA e TAVARES (1998) analisando os registros de assistência prestada a gestantes em uma Unidade Básica de Saúde relatam situações de inexistência da informação em até $100 \%$ da amostra.

Tendo em vista a deficiência nos registros, e considerando a importância das informaçōes relacionadas aos antecedentes obstétricos no fornecimento de diretrizes para a orientação da qualidade do processo 
reprodutivo, apresenta-se na Tabela 7 , os dados mais consistentes que puderam ser obtidos.

Tabela 7 - Distribuição das gestantes segundo antecedentes obstétricos. FAISA, 1997.

\begin{tabular}{lcc}
\hline Antecedentes Obstétricos & $N^{0}$ de Gestantes & \% de Gestantes \\
\hline $\begin{array}{l}\text { Ordem da Gravidez } \\
1^{\mathrm{a}}\end{array}$ & 112 & 37,2 \\
$2^{\mathrm{a}}$ ou 3 & 114 & 37,9 \\
$4^{\mathrm{a}}$ ou mais & 38 & 12,6 \\
Sem informação & 37 & 12,3 \\
Abortos & & \\
0 & 126 & 41,9 \\
1 & 19 & 6,3 \\
2 ou mais & 8 & 2,6 \\
Sem informação & 148 & 49,2 \\
\hline
\end{tabular}

Há que se destacar que o preenchimento incompleto dos formulários, especialmente aquele relacionado à anamnese obstétrica pregressa, para a obtenção de informações relacionadas à ocorrência anterior de natimortalidade e/ou baixo peso ao nascer, número de gestações anteriores e intervalo interpartal, certamente impedem o diagnóstico e tratamento precoce de patologias, que prejudicam a boa qualidade do atendimento à saúde, além de impossibilitar o cumprimento dos objetivos propostos pelo Programa de Assistência Integral à Saúde da Mulher da SECRETARIA DE ESTADO DA SAÚDE DE SÃO PAULO (1986).

Considerando a importância da situação nutricional materna na qualidade reprodutiva, especialmente sua relevância como fator de risco gravídico, 
analisam-se a seguir, os dados relacionados ao consumo alimentar e ao estado nutricional das gestantes estudadas.

Com relação à alimentação, obteve-se o levantamento do consumo alimentar de 94,3\% ( $n=284)$ das gestantes, através do "recordatório de 24h", método adequado para se avaliar a freqüência do consumo (TRIGO, 1993). Desse total, verificou-se que $96,1 \%(n=273)$ ingeriam cereais (pão, arroz e/ou macarrão) diariamente, seguido do grupo das carnes, referido por $89,1 \%(n=253)$, leguminosas $77,1 \%(n=219)$, laticinios $64,8 \%(n=184)$, frutas $59,8 \%(n=170)$ e hortaliças $49,6 \%(n=141)$.

Tabela 8 - Distribuição da freqüência do consumo alimentar segundo grupos de alimentos e origem. FAISA, 1997

\begin{tabular}{cccc}
\hline \multicolumn{2}{c}{ De origem animal } & \multicolumn{2}{c}{ De origem vegetal } \\
Alimentos & $n(\%)$ & Alimentos & $n(\%)$ \\
\hline Cames e ovos: & $253(100,0)$ & Cereais: & $273(100,0)$ \\
Bovina & $170(67,2)$ & Arroz & $240(87,9)$ \\
Frango & $77(30,4)$ & Pão & $211(77,3)$ \\
Frios & $64(25,3)$ & Macarrão & $106(38,8)$ \\
Peixe & $50(19,8)$ & Leguminosas: & $284(100,0)$ \\
Fígado & $31(12,3)$ & feijão & $219(77,1)$ \\
Ovos & $51(20,2)$ & Hortaliças: & $141(100,0$ \\
Laticinios: & $184(100,0)$ & folhas verdes & $129(91,5)$ \\
Leite & $163(88,6)$ & em geral & $126(89,4)$ \\
Queijo & $53(28,8)$ & Fruta: & $170(100,0)$ \\
\hline
\end{tabular}

A tabela 8 mostra a distribuição da freqüência dos alimentos ingeridos, segundo os grupos de alimentos e sua origem, considerando-se como total, o número de gestantes que referiram ingerir aquele grupo de 
alimento. Observa-se que dentre as gestantes que referiram ingerir o grupo das carnes, a carne bovina, fazia parte da prática alimentar de dois terços do grupo estudado $(67,2 \%)$. O leite $(88,6 \%)$ foi o alimento mais consumido por aquelas que referiram ingerir laticinios. O arroz foi o cereal mais consumido $(87,9 \%)$, seguido do pão $(77,3 \%)$. A totalidade daquelas que informaram ingerir o grupo das leguminosas ingeriam o feijão, enquanto das que consumiam hortaliças, $91,5 \%$ ingeriam folhas verdes.

Com relação ao estado nutricional das gestantes, analisaram-se no presente estudo, os dados da altura*, obtidos para $77,7 \%(n=234)$ das gestantes, do peso corporal no primeiro trimestre da gestação, verificados para $67,1 \%(n=202)$ e a classificação do estado nutricional, no primeiro e terceiro trimestres da gestação, determinados para $59,1 \% \quad(n=178)$ da população.

A estatura materna, que se constitui num indicador da história nutricional da mãe, isto é, desnutrição pregressa, tem sido associada com o risco de baixo peso ao nascer (CIARI e cols., 1975; VICTORA e cols., 1988; TOMASI e cols., 1996). A proporção de gestantes com altura inferior a $1,50 \mathrm{~m}$, e portanto com maior risco obstétrico, verificada neste estudo, foi similar aos $10,8 \%$ observados por VICTORA e cols. (1988) em estudo epidemiológico desenvolvido em Pelotas, RS, na década de 80 . NÓBREGA (1989), por sua vez, em estudo de 101 mil mulheres que deram

- Embora faça parte dos formulários da FAISA a medida da altura não é feita rotineiramente em todos os Postos de Saúde da Instituicão. Com bastante freqüencia, essa medida foi verificada posteriormente, por solicitação dos pesquisadores 
à luz em hospitais das capitais brasileiras no ano de 1978, relata proporção cerca de duas vezes maior $(20,0 \%)$ de mulheres com altura inferior a $1,50 \mathrm{~m}$ na região norte do Brasil, enquanto no sudeste a porcentagem foi praticamente a metade $(6,0 \%)$ da encontrada no presente estudo. Considerando a tendência secular do crescimento (INAN, 1990), essa proporção deveria ser menor, da mesma forma que o verificado em estudo similar, repetido década mais tarde em Pelotas, que revelou diminuição daquela proporção para 4,6\% (TOMASI e cols., 1996).

Tabela 9 - Distribuição das gestantes segundo altura. FAISA, 1997.

\begin{tabular}{ccc}
\hline Altura $(\mathrm{m})$ & No de Gestantes $^{\circ}$ & \% de Gestantes \\
\hline$\leq 1,50$ & 25 & 10,7 \\
$>1,50$ & 209 & 89,3 \\
\hline TOTAL & 234 & 100,0 \\
\hline
\end{tabular}

A distribuição do peso corporal no primeiro trimestre gestacional está apresentado na Tabela 10. Peso pré-gestacional inferior a $50,0 \mathrm{Kg}$ apresenta uma forte associação com a ocorrência de baixo peso ao nascer, como demonstram os estudos de BENÍCIO e cols. (1985) e VICTORA e cols. (1988). A proporção de $22,4 \%$ de gestantes com essa situaçāo nutricional de risco, verificada no presente estudo, encontra-se na faixa intermediária entre aquelas verificadas por BENICIO (1983) e VICTORA e cols (1988) nas décadas de $70(29 \%)$ e $80(27,9 \%)$, nos municipios de São Paulo e Pelotas, respectivamente, e os 15,7\%, também registrados em Pelotas, RS, na década de 90 (TOMASI e cols., 1996). 
Tabela 10 - Distribuição das gestantes segundo o peso no primeiro trimestre. FAISA, 1997.

\begin{tabular}{ccc}
\hline Peso $(\mathrm{kg})$ & $\mathrm{N}^{\circ}$ de Gestantes & \% de Gestantes \\
\hline$\leq 50$ & 41 & 22,4 \\
$>50$ & 142 & 77,6 \\
\hline TOTAL & 183 & 100,0 \\
\hline
\end{tabular}

A relação entre peso e altura permite caracterizar o estado nutricional durante a gestação. Utilizando essas duas medidas antropométricas, SIQUEIRA e cols. (1975) e ROSSO (1985) desenvolveram curvas de referência para a identificação da adequação do ganho de peso de acordo com a idade gestacional. A "curva" de ROSSO (1985), validada por TADDEl e cols. (1991), foi adotada pelo Ministério da Saúde para compor as ações a serem desenvolvidas nos Programas de Assistência Integral à Saúde da Mulher durante o acompanhamento pré-natal. A Tabela 11 apresenta o estado nutricional das gestantes no $1^{\circ}$ e $3^{\circ}$ trimestres da gestação, usando como parâmetro, o critério recomendado pelo Ministério da Saúde (TADDEl e cols., 1991).

Tabela 11 - Distribuição das gestantes segundo o estado nutricional no primeiro e terceiro trimestres da gestação. FAISA, 1997.

\begin{tabular}{lccc}
\hline $3^{\circ}$ Trimestre & $\begin{array}{c}\text { Desnutrida } \\
\mathrm{n}(\%)\end{array}$ & $\begin{array}{c}1^{\circ} \text { Trimestre } \\
\text { Não desnutrida } \\
\mathrm{n}(\%)\end{array}$ & TOTAL \\
\hline Desnutrida & $40(75,5)$ & $13(24,5)$ & $53(100,0)$ \\
Não desnutrida & $17(13,6)$ & $108(86,4)$ & $125(100,0)$ \\
\hline TOTAL & $57(32,0)$ & $121(68,0)$ & $178(100,0)$ \\
\hline
\end{tabular}

$x^{2} 65,0 \quad p<0.0001$ 
A associação entre desnutrição no início e no final da gravidez mostra, de forma irrefutável, a manutenção de uma situação indesejável, onde mais de dos terços das gestantes desnutridas permaneceram nesse estado. SINISTERRA e cols. (1991) verificaram que a recuperação de mulheres desnutridas até o final da gravidez diminui o risco de baixo peso ao nascer ao nivel encontrado entre mulheres eutróficas em relação ao estado nutricional.

Confirma-se, portanto, uma vez mais, a importância da verificação das medidas de estatura e peso corporal, para que se possa classificar o estado nutricional no inicio da gravidez e acompanhar sua evolução durante toda a gestação. Esse controle certamente possibilita monitorizar nutricionalmente as gestantes, prevenindo e/ou controlando a ocorrência de condições materno-fetais indesejáveis. Há que se destacar, também, a importância da implantação e utilização do gráfico de ROSSO, recomendado pelo Ministério da Saúde.

Mundialmente, o consumo inadequado e/ou insuficiente de ferro constitui a principal causa da anemia nutricional. Segundo DEMAYER (1989), 59\% das gestantes dos paises em desenvolvimento são anêmicas.

A preocupação com o consumo dietético de ferro vem reunindo, sob o patrocínio da International Life Sciences Institute (ILSI), um grupo de especialistas em micronutrientes, com o objetivo de definir atividades a serem implementadas no controle das deficiências nutricionais específicas 
como a do ferro. Com relação à prática alimentar do brasileiro, os estudos que vêm sendo desenvolvidos, têm como finalidade eleger os alimentos mais viáveis para serem enriquecidos com os micronutrientes responsáveis pelas deficiências nutricionais em nível endêmico. No que se refere ao ferro, têm sido considerados os alimentos tais como farinha de trigo (uso doméstico e panificação), açúcar e leite, este último, considerando-se a elevada prevalência de anemia na infância. O controle da deficiência de ferro através da fortificação de alimentos, intervenção que certamente beneficiará a grande maioria de população brasileira, vem ao encontro de honrar o compromisso brasileiro firmado junto às Nações Unidas, de reduzir a prevalência de anemia, a um terço, até o ano 2000. (VITAL, 1993)

Há que se mencionar, no entanto, que a fortificação é uma estratégia de intervenção profilática, cujos efeitos somente se fazem sentir a médio prazo, ou seja, entre um e dois anos. Assim sendo, gestantes não beneficiadas pela fortificação de alimentos requerem medidas de curto prazo, justificando a utilização da suplementação medicamentosa, conforme pode-se observar no Quadro 3.

Quadro 3 - Programas de intervenção no controle da deficiência de ferro.

\begin{tabular}{|l|l|l|l|}
\hline TIPO & COBERTURA & PRAZO DO BENEFICIO & COMPLEXIDADE \\
\hline Suplementação & Individual & Curto (meses) & Difícil \\
\hline Fortificação & Geral; grupos especificos & Médio (1 a 2 anos) & Simples \\
\hline Educação alimentar & Geral & Longo & Dificil \\
\hline
\end{tabular}

Fonte: INACG (1977). 
A gravidez é caracterizada por mudanças fisiológicas e metabólicas que alteram os parâmetros bioquímicos e hematológicos maternos, resultando em diminuição ou aumento destes parâmetros (KNIGHT e cols., 1994).

Por essa razão, para diversos especialistas, a evolução da gestação representa um risco diferenciado para a manifestação de um estado de carência de ferro, observado mesmo entre gestantes que iniciam a gravidez sem anemia (MICOZZI, 1980; SZARFARC e cols, 1983; LAMPARELLI e cols., 1988).

A demanda suplementar de ferro durante o processo gravídico é extremamente elevada e ocorre de forma não homogênea no decorrer do período. Como pode se observar na Figura 2, a necessidade suplementar de ferro durante os três primeiros meses da gestação é praticamente nula, pouco se diferenciando da necessidade basal pré-gestacional, podendo até mesmo ser compensada pela ausência da menstruação.

Como assinalado, a anemia nutricional é um problema de grande importância no âmbito da saúde pública, e portanto, seu diagnóstico e prevenção constituem prioridade mundial desde a década de 70 (OMS 1972). Estudos controlados, realizados com gestantes, sugerem que quando a anemia é diagnosticada no início da gravidez e tratada, os riscos de parto prematuro e baixo peso ao nascer tendem a diminuir (AGARWAL e cols. 1991; SCHOLL e cols., 1992). 


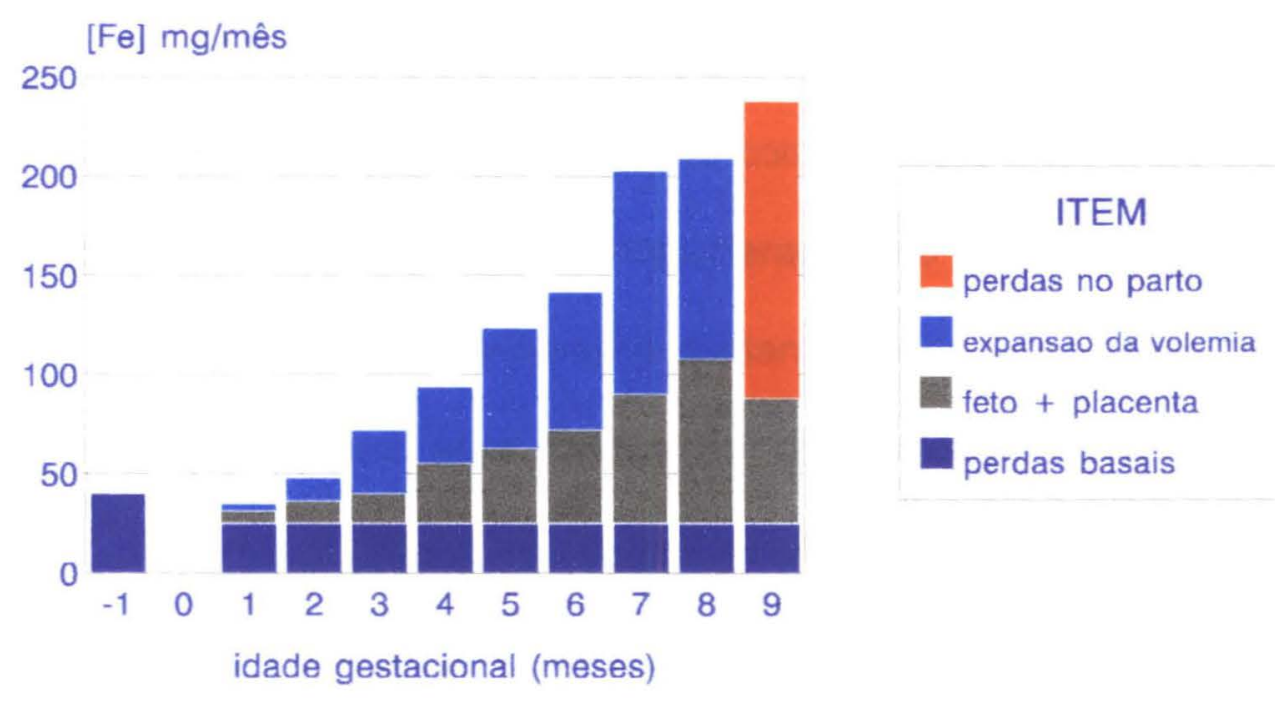

Adapatado de Hitten \& Leitch, 1964

FIGURA 2

Utilizando-se o critério proposto pela OMS (1968), que considera anêmica toda gestante com concentração de hemoglobina menor do que $11 \mathrm{~g} / \mathrm{dL}$, verificou-se a ocorrência de $14,8 \%$ de anemia na primeira metade da gestação, isto é, antes da $20^{\mathrm{a}}$ semana gestacional. Essa freqüência é menor que a esperada para uma população com as características sócioeconômicas anteriormente mencionadas. No entanto, comparada à prevalência encontrada em alguns outros estudos pontuais realizados no Brasil, ela se mostra similar e até mesmo superior. GUERRA e cols. (1990) relatam a ocorrência de $12,4 \%$ de anemia entre gestantes de primeira consulta em Centros de Saúde de um subdistrito paulistano. FUJIMORI (1994) encontrou $14,3 \%$ de anemia entre gestantes adolescentes e NACUL e cols. (1990) relatam prevalência de apenas $7,6 \%$ de anemia no início da gravidez em Pernambuco. 
Tendo em vista a proposta do Instituto Nacional de Alimentação e Nutrição (INAN, 1982) em classificar a anemia gravídica como indicador para propostas de intervenção, verifica-se que com a freqüência de anemia encontrada na população de estudo, considerada pelo INAN (1982) como de médio prevalência, recomenda-se a implantação de um programa de suplementação profilática e/ou fortificação de alimentos para toda a população. Entretanto, programas de intervenção devem ser considerado para mulheres grávidas, mesmo quando a prevalência de anemia entre as gestantes for inferior a 10\% (INACG, 1977).

Considerando que a idade gestacional média no primeiro exame laboratorial foi de apenas $12,8 \pm 8$, semanas, período em que a necessidade orgânica de ferro ainda é similar à da mulher não grávida (Figura 2), estimou-se a ocorrência de anemia, utilizando-se como nível crítico o valor de hemoglobina inferior a $12,0 \mathrm{~g} / \mathrm{dL}$, preconizado pela OMS (1968) para mulheres em idade reprodutiva. Conforme pode ser observado na Figura 3, avaliada dessa forma, a anemia atingia $38,5 \%$ das mulheres estudadas com menos de 20 semanas de gestação. 


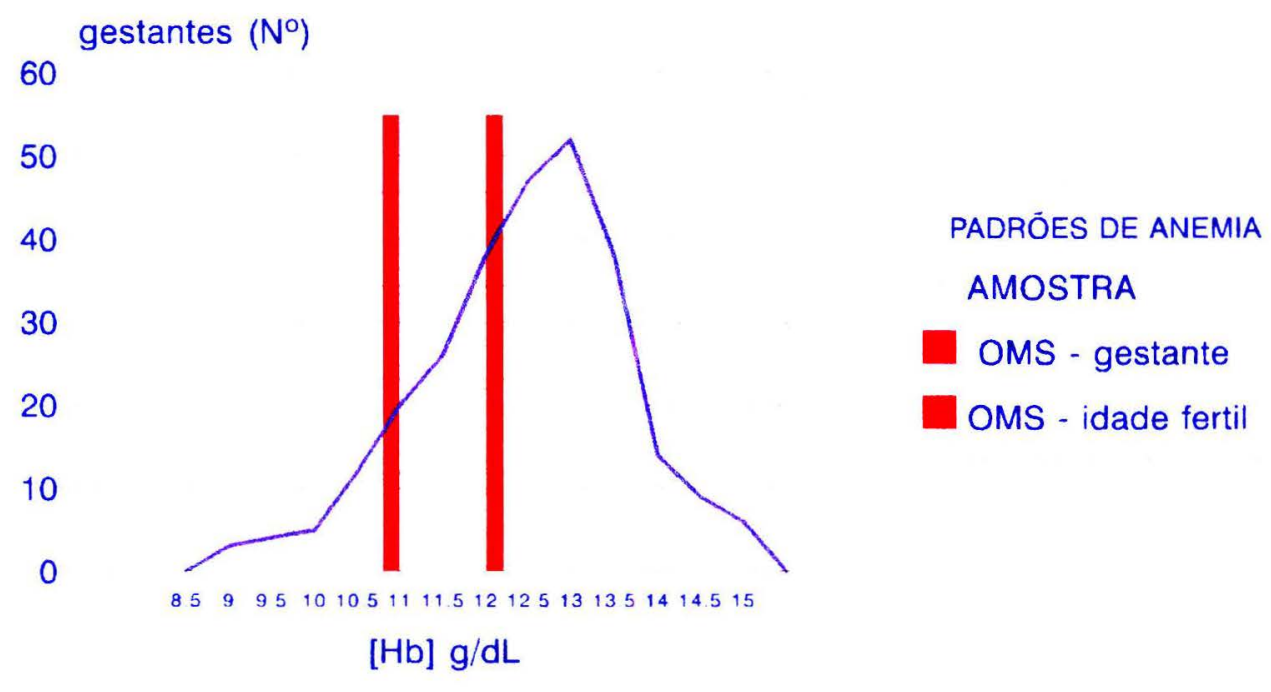

FAISA, 1997

\section{FIGURA 3}

A partir da segunda metade da gestação, dois novos processos metabólicos passam a onerar a necessidade de ferro, quais sejam, a formação do feto e a formação da placenta. Até que atinjam o equilíbrio, que ocorre ao redor do $8^{\circ}$ mês de gestação, os dois processos terão prioridades em relação à captação do nutriente em pauta. A partir de então, conforme a oferta do mineral, a distribuição do ferro será dependente das constantes de equilíbrio e do tempo de meia vida dos metabólitos de ferro (BOTHWELL, 1995). O aumento da volemia, e conseqüente diluição da hemoglobina no sangue, leva a uma diminuição fisiológica da sua concentração. Assim, justifica-se a curva da concentração de hemoglobina obtida no presente estudo (Figura 4), a qual segue o mesmo modelo observado por SZARFARC e cols. (1985) entre a 
população de gestantes atendidas em serviços de saúde do Estado de São Paulo, que por sua vez, é similar àquela elaborada com valores de referência obtidos a partir de um estudo longitudinal entre gestantes não anêmicas e não ferro deficientes (SZARFARC, e cols., 1983).

\section{EVOLUÇÃO DA CONCENTRAÇÃO DE HEMOGLOBINA NA GRAVIDEZ}

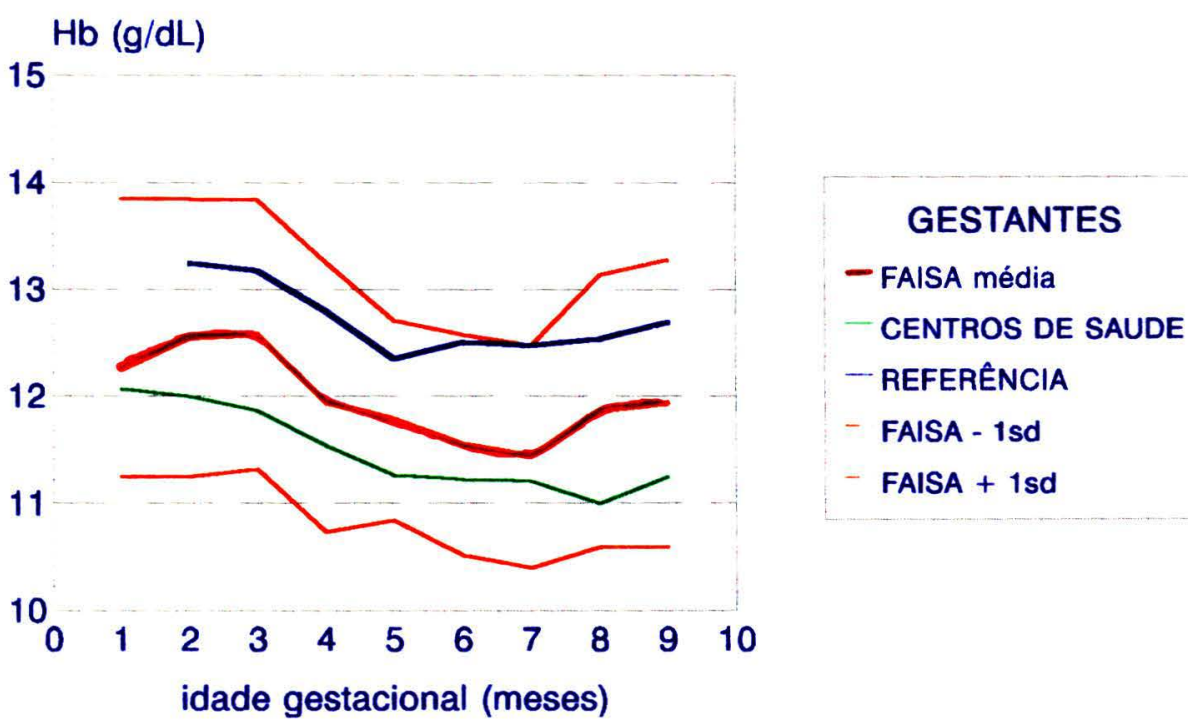

\section{FIGURA 4}

O nivel das curvas dependem de três fatores, quais sejam, da concentração de hemoglobina na mulher não grávida, das reservas de ferro possivelmente nulas, uma vez que segundo a OMS (1970) $40 \%$ a 99\% das gestantes são ferro deficientes, e por último, do ferro exógeno.

Durante os nove meses de uma gravidez normal são necessários pouco mais de $1000 \mathrm{mg}$ de ferro para compensar as perdas basais, para suprir a demanda do mineral para o desenvolvimento do feto e da placenta e para fazer face ao aumento do volume sangüíneo materno e à perda de sangue 
no parto. Cerca de $90 \%$ da demanda total de ferro é utilizada somente nos últimos 150 dias da gestação, o que significa que cerca de $6 \mathrm{mg}$ de ferro deverão ser absorvidos por dia nesse período. Assim sendo, conclui-se que o ferro da dieta somado ao mineral da reserva, praticamente nula, são insuficientes para suprir a necessidade do nutriente, tornando-se, portanto, indispensável a suplementação de ferro.

A inclusão da suplementação de ferro no Programa de Assistência Integral à Saúde da Mulher, que inclui o atendimento à gestante, elaborado pelo Ministério da Saúde e incorporado pela SECRETARIA DE ESTADO DA SAÚDE (1986), representa o reconhecimento da incompetência orgânica da mulher em suprir a demanda marcial de ferro, na ausência de um fornecimento extra do mineral, para a manutenção de uma boa qualidade reprodutiva.

SZARFARC e cols. (1983), estudando gestantes atendidas em um Centro de Saúde Escola, demonstrou que a anemia, diagnosticada precocemente através da concentração de hemoglobina, constituia valor preditivo do risco de peso inadequado ao nascer. Realmente, diversos estudos mostram que a correção da anemia diminui o risco de baixo peso ao nascer, tornando-o similar ao de gestantes não anêmicas e diminuindo, assim, os efeitos deletérios à saúde da criança (MURPHY e cols., 1986; NOTTNERUS e cols., 1990; SCHOLL e cols., 1992; HALLBERG e cols., 1993: SHOLL e HEDIGER, 1994). 
A evolução dos indicadores de anemia e deficiência de ferro nas gestantes estudadas é inicialmente apresentada para a totalidade da população. Assim, construiu-se a Tabela 12 que mostra os valores médios dos indicadores, determinados nos três momentos do processo gravídico, conforme previsto no delineamento do estudo.

Tabela 12. Concentração de hemoglobina [Hb], ferritina sérica [FS], e porcentagem de saturação da transferrina [ST], segundo idade gestacional em semanas FAISA, 1997.

\begin{tabular}{ccccc}
\hline $\begin{array}{c}\text { Idade } \\
\text { Gestacional }\end{array}$ & [Hb] & $\begin{array}{c}{[\mathrm{FS}]} \\
\mathrm{g} / \mathrm{dL}\end{array}$ & $\begin{array}{c}{[\mathrm{ST}]} \\
(\%)\end{array}$ \\
\hline$<20$ semanas & $X(\mathrm{dp})$ & $12,2(1,2)$ & $42,1(33,9)$ & $30,8(13,6)$ \\
& $n$ & 270 & 229 & 252 \\
$20-29$ semanas & $X(\mathrm{dp})$ & $11,6(1,0)$ & $18,9(14,8)$ & $24,2(12,6)$ \\
& $n$ & 175 & 152 & 168 \\
$>29$ semanas & $X(\mathrm{dp})$ & $11,8(1,3)$ & $19,2(16,4)$ & $21,8(12,1)$ \\
& $\mathrm{n}$ & 101 & 84 & 102 \\
\hline
\end{tabular}

O diagnóstico da deficiência de ferro durante a gestação apresenta algumas dificuldades. Segundo ROODENBURG (1995), a considerável variação intra-individual diária de alguns parâmetros, associada à expansão fisiológica do volume plasmático própria da gravidez, aumenta a variabilidade dos parâmetros dependentes da concentração. Assim, justifica-se a grande variabilidade observada nos indicadores estudados, conforme pode se observar na Tabela 12

A concentração de $\mathrm{Hb}$, indicador que conceitua a anemia (OMS, 1972; INACG, 1977), apesar de sua baixa sensibilidade (KRAUFER e cols 
1988), apresenta variabilidade média em torno de $10 \%$, como o obtido na maioria dos estudos que determinam a patologia.

A concentração de ferritina sérica (FS), que reflete os estoques de ferro, constitui também o indicador bioquímico que confirma a etiologia da anemia nutricional (KELLY, 1977; KANESHIGE, 1981). De acordo com MILNE e cols. (1990), a ferritina é a medida mais sensivel na identificação das reservas de ferro. Entretanto, os niveis de FS variam largamente em uma dada população, e sua padronização é bastante difícil (INACG, 1985). Também GUERRA-SHINOHARA e cols. (1998) destacam que existe diferença significativa entre os valores de FS obtidos a partir de dois métodos imunológicos automatizados diferentes, havendo a necessidade do estabelecimento de valores de referência, específicos para cada metodologia.

A porcentagem de saturação da transferrina (ST), por sua vez, tem a capacidade de quantificar a adequação do suprimento de ferro para a produção de células vermelhas, sem identificar, no entanto, a origem da carência (INACG, 1985). Sua variabilidade em torno da média reflete as variabilidades do ferro sérico circulante e da capacidade total de ligação do ferro, sendo importante lembrar que a concentração de ferro sérico depende do fornecimento do ferro exógeno, isto é, do ferro absorvido (da dieta ou da suplementação). 
Outro aspecto a ser destacado com relação à Tabela 12, é que as gestantes, mesmo quando compareceram regularmente às consultas de pré natal, não o fizeram com a regularidade planejada à consulta laboratorial. Assim, como se observa na Tabela 13, construida a partir dos resultados de hemoglobina segundo grupo de intervenção, já no primeiro exame laboratorial, a perda amostral foi de cerca de $10 \%$.

Tabela 13. Distribuição das gestantes segundo grupo de intervenção e realização do exame laboratorial de hemoglobina. FAISA, 1997

\begin{tabular}{|c|c|c|c|c|}
\hline \multirow{2}{*}{$\begin{array}{c}\text { Grupos } \\
\text { De } \\
\text { Intervenção }\end{array}$} & \multirow[b]{2}{*}{$\begin{array}{c}\text { Gestantes } \\
\mathrm{n}\end{array}$} & \multicolumn{3}{|c|}{$\begin{array}{l}\text { Realização do exame laboratorial de }[\mathrm{Hb}] \\
\text { (semanas gestacionais) }\end{array}$} \\
\hline & & $\begin{array}{c}<20 \\
n\end{array}$ & $20 \vdash 30$ & $\begin{array}{c}30+40 \\
n\end{array}$ \\
\hline $120 \mathrm{mg} / \mathrm{semana}$ & 78 & 72 & 44 & 21 \\
\hline $80 \mathrm{mg} / \mathrm{semana}$ & 74 & 67 & 40 & 19 \\
\hline $40 \mathrm{mg}$ diário & 74 & 65 & 40 & 30 \\
\hline "Rotina" & 75 & 66 & 51 & 31 \\
\hline Total & 301 & 270 & 175 & 101 \\
\hline
\end{tabular}

PAPPAGALLO e BULL (1996), referindo-se ao seguimento de gestantes e problemas operacionais na avaliação da suplementação com ferro, também relatam baixa aderência para a realização dos exames laboratoriais de hemoglobina.

No decorrer do presente estudo, ocorreram mudanças na administração da FAISA, com o intuito de melhorar o atendimento à população. Nesse sentido, a colheita do material, inicialmente centralizado, passou a ser realizado nos próprios Postos de Saúde. Com a descentralização, a coleta 
de sangue passou a ser semanal em alguns Postos, isto é, a atividade era desenvolvida em apenas um único dia da semana, fato que pode ter contribuído para a perda amostral.

A Tabela 14, apresenta a evolução dos indicadores laboratoriais de anemia $(\mathrm{Hb})$, reserva de ferro (FS) e deficiência de ferro (ST) durante o processo gestacional, considerando o tipo de intervenção à qual a gestante foi submetida.

Tabela 14 - Médias de hemoglobina [Hb], ferritina sérica [FS] e porcentagem de saturação de transferrina [ST], segundo grupo de intervenção e idade gestacional. Faisa, 1997.

\begin{tabular}{ccccc}
\hline Idade gestacional & $\begin{array}{c}\text { Intervenção } \\
{[\mathrm{Fe}] \mathrm{mg}}\end{array}$ & $\begin{array}{c}{[\mathrm{Hb}]} \\
\mathrm{g} / \mathrm{dL}\end{array}$ & $\begin{array}{c}{[\mathrm{FS}]} \\
\mu \mathrm{g} / \mathrm{L}\end{array}$ & $\begin{array}{c}{[\mathrm{ST}]} \\
(\%)\end{array}$ \\
\hline \multirow{2}{*}{$<$ 20semanas } & s/intervernção & $12,2(1,2)$ & $42,1(33,9)$ & $30,8(13,6)$ \\
\hline \multirow{3}{*}{$20-29$ semanas } & $120 /$ semana & $11,8(1,3)$ & $12,6(5,9)$ & $30,2(9,0)$ \\
& $80 /$ semana & $11,3(1,2)$ & $25,7(25,8)$ & $28,1(12,2)$ \\
& $40 /$ dia & $11,4(0,7)$ & $14,7(10,5)$ & $23,4(13,0)$ \\
& "Rotina" & $11,8(1,0)$ & $23,8(16,0)$ & $19,8(8,2)$ \\
\hline \multirow{5}{*}{29 semanas } & 120/semana & $11,6(1,7)$ & $18,6(15,1)$ & $16,5(6,7)$ \\
& $80 /$ semana & $11,7(1,5)$ & $13,1(10,9)$ & $20,0(9,4)$ \\
& $40 /$ dia & $11,6(1,3)$ & $10,8(8,1)$ & $17,7(11,1)$ \\
& "Rotina" & $12,0(1,3)$ & $24,0(18,0)$ & $20,1(7,8)$ \\
\hline
\end{tabular}

A tabela 14 mostra que a concentração de hemoglobina apresenta queda seguida de um ligeiro aumento no final da gestação, da mesma forma que o observado para o total das gestantes (Tabela 12), independente do grupo de intervenção. Os valores médios de FS encontrados sugeram que 
o grupo que recebeu $120 \mathrm{mg}$ de ferro por semana tendeu a aumentar a reserva de ferro no final da gravidez, o grupo "Rotina" não mostrou alteração, enquanto os outros dois grupos apresentaram depleção da reserva do mineral. Em todos os grupos de intervenção, os valores de ST tenderam a diminuir com a evolução da gravidez, exceto no grupo "Rotina"

POULAKKA e cols. (1980), estudando grávidas suplementadas com ferro, encontraram diminuição da concentração de ferritina sérica desde a $1^{\mathrm{a}}$ até a $32^{\mathrm{a}}$ semana de gestação, quando se iniciaram a recuperação dos valores, que retornaram aos niveis pré-gestacionais somente cerca de dois meses após o parto. Os autores justificam a queda como conseqüência da diluição do volume sangüíneo e da rápida mobilização dos depósitos marciais de ferro, que se esgotam no final da gestação, mesmo na ausência de anemia. Como os niveis de ferritina refletem os estoques do mineral, os autores destacam que a suplementação com ferro durante a gestação permite uma melhor recuperação da mulher.

ROMSLO e cols. (1983) e TAYLOR e cols. (1982) também verificaram a mesma tendência de queda e recuperação dos níveis de ferritina sérica em gestantes suplementadas com ferro.

Estudando gestantes não suplementadas com ferro, FORADORI e cols. (1978) no Chile, KANESHIGE (1981) no Japão e NESE e cols. (1989) no Uruguai, relatam, por sua vez, diminuição consideravelmente maior nas 
taxas de ferritina sérica no decorrer da gestação, sem a recuperação observada a partir da $32^{\mathrm{a}}$ semana, indicando uma depleção maior dos depósitos de ferro, que praticamente se extinguiram no terceiro trimestre.

En relação ao comportamento dos niveis da saturação de transferrina, verificou-se que os dados obtidos no presente estudo são similares àqueles relatados por LIRA e cols. (1984), CALLE e cols. (1986), GUERRA e cols. (1992) e FUJIMORI (1994).

A concentração de hemoglobina é capaz de diagnosticar apenas o resultado final da deficiência de ferro, isto é, a anemia, sem determinar sua etiologia, não sendo, portanto especifica para o diagnóstico da deficiência de ferro. Sua associação com os parâmetros que avaliam o transporte e a reserva de ferro indicam, entretanto, a proporção de gestantes anêmicas ferro-deficientes ou ferro-depletadas no inicio (Tabelas 15 e 16) e final (Tabelas 17 e 18).

\section{Tabela 15. - Anemia e reserva de ferro das gestantes com idade gestacional} $<20$ semanas. FAISA, 1997.

\begin{tabular}{cccc}
\hline & \multicolumn{3}{c}{ Reserva de ferro } \\
Anemia & $\begin{array}{c}\text { FS }<12 \mu \mathrm{g} / \mathrm{L} \\
\mathrm{n}(\%)\end{array}$ & $\begin{array}{c}\mathrm{FS} \geq 12 \mu \mathrm{g} / \mathrm{L} \\
\mathrm{n}(\%)\end{array}$ & $\begin{array}{c}\text { TOTAL } \\
\mathrm{n}(\%)\end{array}$ \\
\hline $\mathrm{Hb}<11 \mathrm{~g} / \mathrm{dl}$ & $9(28,0)$ & $23(72,0)$ & $32(100,0)$ \\
$\mathrm{Hb} \geq 11 \mathrm{~g} / \mathrm{dl}$ & $21(10,7)$ & $176(89,3)$ & $197(100,0)$ \\
\hline TOTAL & $30(13,1)$ & $199(86,9)$ & $229(100,0)$ \\
\hline$x^{2}=7,38 \quad \mathrm{p}<0.01$ & & &
\end{tabular}


Tabela 16 - Anemia e deficiência de ferro das gestantes com idade gestacional $<20$ semanas. FAISA, 1997

\begin{tabular}{|c|c|c|c|}
\hline \multirow[b]{2}{*}{ Anemia } & \multicolumn{3}{|c|}{ Deficiência de ferro } \\
\hline & $\begin{array}{c}S T<16 \% \\
n(\%)\end{array}$ & $\begin{array}{c}\text { ST } \geq 16 \% \\
n(\%)\end{array}$ & $\begin{array}{c}\text { TOTAL } \\
n(\%)\end{array}$ \\
\hline $\mathrm{Hb}<11,0 \mathrm{~g} / \mathrm{dL}$ & $8(21,6)$ & $29(78,4)$ & $37(100,0)$ \\
\hline $\mathrm{Hb} \geq 11,0 \mathrm{~g} / \mathrm{dl}$ & $24(11,2)$ & $191(88,8)$ & $215(100,0)$ \\
\hline TOTAL & $32(12,7)$ & $220(87,3)$ & $252(100,0)$ \\
\hline
\end{tabular}

Tabela 17 - Anemia e reserva de ferro das gestantes com idade gestacional $>29$ semanas. FAISA, 1997.

\begin{tabular}{|c|c|c|c|}
\hline \multirow[b]{2}{*}{ Anemia } & \multicolumn{3}{|c|}{ Reservas de ferro } \\
\hline & $\begin{array}{c}\mathrm{FS}<12 \mu \mathrm{g} / \mathrm{L} \\
\mathrm{n}(\%)\end{array}$ & $\begin{array}{c}\mathrm{FS} \geq 12 \mu \mathrm{g} / \mathrm{L} \\
\mathrm{n}(\%)\end{array}$ & $\begin{array}{c}\text { TOTAL } \\
\mathbf{n}(\%)\end{array}$ \\
\hline$H b<11 \mathrm{~g} / \mathrm{dl}$ & $13(68,4)$ & $6(31,6)$ & $19(100,0)$ \\
\hline $\mathrm{Hb} \geq 11 \mathrm{~g} / \mathrm{dl}$ & $24(38,7)$ & $38(61,3)$ & $62(100,0)$ \\
\hline TOTAL & $37(45,7)$ & $44(54,3)$ & $81(100,0)$ \\
\hline
\end{tabular}

Tabela 18 - Anemia e deficiência de ferro das gestantes com idade gestacional $>29$ semanas. FAISA, 1997.

\begin{tabular}{cccc}
\hline Anemia & \multicolumn{3}{c}{ Deficiência de ferro } \\
& $\mathrm{n}(\%)$ & $\begin{array}{c}\mathrm{ST} \geq 16 \% \\
\mathrm{n}(\%)\end{array}$ & $\begin{array}{c}\text { TOTAL } \\
\mathrm{n}(\%)\end{array}$ \\
\hline $\mathrm{Hb}<11,0 \mathrm{~g} / \mathrm{dL}$ & $11(52,4)$ & $10(47,6)$ & $21(100,0)$ \\
$\mathrm{Hb} \geq 11,0 \mathrm{~g} / \mathrm{dl}$ & $17(18,1)$ & $77(81,9)$ & $94(100,0)$ \\
\hline TOTAL & $28(24,3)$ & $87(75,7)$ & $115(100,0)$ \\
\hline$x^{2}=10.96 \quad \mathrm{p}<0,0001$ & & &
\end{tabular}


Confirma-se, uma vez mais, que o ferro circulante é uma medida bioquímica que depende de fatores que se modificam muito rapidamente. Assim, não surpreende, a não associação encontrada entre a prevalência de anemia e níveis inadequados de ST no início da gestação (Tabela 16). À medida que evolui a gestação, no entanto, a associação entre reserva de ferro, ferro circulante e anemia torna-se clara (Tabelas 17 e 18).

Considerando que a análise longitudinal dos dados possibilita caracterizar a evolução dos indicadores laboratoriais durante o processo gestacional, elaborou-se a Tabela 19, que apresenta, exclusivamente, os dados das gestantes acompanhadas durante a totalidade do processo gravídico, ou seja, somente daquelas para as quais foram realizadas as três dosagens bioquímicas previstas. Das 301 gestantes, apenas $66 \quad(21,9 \%)$ submeteram-se às três análises laboratoriais, fato que possibilitou analisar o estado nutricional de ferro apenas no início ( $<20$ semanas) e no final (>29 semanas) da gestação.

Como a ferritina sérica e a hemoglobina constituem moléculas que refletem, em primeira e última instância, o efeito de um fornecimento inadequado de ferro, julgou-se imprescindivel, apresentar nesta análise, suas respectivas concentrações. 
Tabela 19 - Avaliação longitudinal dos indicadores do estado nutricional de ferro segundo tipo de intervenção e idade gestacional inicial $(<20 \mathrm{sem}) \mathrm{e}$ final (>29 sem). FAISA, 1997.

\begin{tabular}{|c|c|c|c|c|c|}
\hline \multirow{2}{*}{$\begin{array}{c}\text { Grupo } \\
\text { De } \\
\text { Intervenção }\end{array}$} & \multirow[b]{2}{*}{$n$} & \multicolumn{2}{|c|}{$[\mathrm{Hb}] \mathrm{g} / \mathrm{dL}$} & \multicolumn{2}{|c|}{$[F S] \mu \mathrm{g} / \mathrm{L}$} \\
\hline & & $\begin{array}{l}\text { Início } \\
X(d p)\end{array}$ & $\begin{array}{l}\text { Final } \\
X(d p)\end{array}$ & $\begin{array}{l}\text { Início } \\
\text { X (dp) }\end{array}$ & $\begin{array}{l}\text { Final } \\
X(d p)\end{array}$ \\
\hline $120 \mathrm{mg} / \mathrm{semana}$ & 14 & $12,1(1,2)$ & $11,6(1,7)$ & $41,9(32,4)$ & $18,6(15,1)$ \\
\hline $80 \mathrm{mg} / \mathrm{semana}$ & 11 & $12,1(1,8)$ & $11,7(1,5)$ & $50,8(37,5)$ & $13,1(10,9)$ \\
\hline $40 \mathrm{mg} / \mathrm{dia}$ & 23 & $12,3(1,1)$ & $11,6(1,3)$ & $41,7(34,2)$ & $10,8(8,1)$ \\
\hline "Rotina" & 18 & $11,9(1,2)$ & $12,0(1,3)$ & $29,0(20,0)$ & $24,0(18,0)$ \\
\hline TOTAL & 66 & $12,1(1,3)$ & $11,7(1,4)$ & $40,0(31,4)$ & $17,3(14,7)$ \\
\hline
\end{tabular}

Observa-se que a reserva de ferro diminuiu em todos os grupos de intervenção, da mesma forma que a concentração de hemoglobina. $O$ grupo "Rotina", que praticamente manteve a taxa de hemoglobina constante, parece ter apresentado uma melhor eficácia do suplemento de ferro, quando se comparam as concentrações iniciais e finais de FS dos diferentes grupos de intervenção (Tabela 19).

A qualidade da dose semanal no controle da deficiência de ferro tem sido relatada em vário estudos, em diferentes grupos populacionais: préescolares (SHULTINK e cols., 1995 e LIU e cols., 1995), mulheres em idade fértil (GROSS e cols., 1,994) e gestantes (RIDWAN. cols., 1996, QUINTERO-GUTIERREZ e cols., 1997). Todos demostraram que o comportamento dos indicadores da deficiência de ferro com a suplementação semanal foi similar ao comportamento desses indicadores com a suplementação com doses diárias. 
A Tabela 20 apresenta a distribuição do total de gestantes estudadas que informaram a ingestão ou não do suplemento de ferro, segundo o tempo de ingestão e o grupo de intervenção.

Tabela 20 - Tempo de ingestão do suplemento de ferro, segundo intervenção. FAISA, 1997.

\begin{tabular}{ccccc}
\hline \multirow{2}{*}{$\begin{array}{c}\text { Drupo } \\
\text { De }\end{array}$} & 0 a 6 & 7 a 12 & 13 e mais & Total \\
\cline { 2 - 5 } Intervenção & $n(\%)$ & $n(\%)$ & $n(\%)$ & $n(\%)$ \\
\hline $120 \mathrm{mg} /$ semana & $5(10,0)$ & $11(22,0)$ & $34(68,0)$ & $50(100,0)$ \\
$80 \mathrm{mg} / \mathrm{semana}$ & $11(23,9)$ & $9(19,6)$ & $26(56,5)$ & $46(100,0)$ \\
$40 \mathrm{mg} /$ dia & $14(29,8)$ & $7(14,9)$ & $26(55,3)$ & $47(100,0)$ \\
"Rotina" & $14(23.0)$ & $6(9,8)$ & $41(67,2)$ & $61(100,0)$ \\
\hline Total & $44(21,6)$ & $33(16,2)$ & $127(62,2)$ & $204(100,0)$ \\
\hline
\end{tabular}

Observa-se que a adesão ao programa aumentou proporcionalmente com o tempo em todos os grupos de intervenção. Entretanto o grupo que recebeu $120 \mathrm{mg}$ semanais de ferro e o grupo "Rotina" apresentaram proporção ligeiramente maior de gestantes ingerindo o suplemento por mais de 3 meses (13 ou mais semanas). Destaca-se que a adesão ao programa foi menor para o grupo que recebeu orientação para ingestão de $40 \mathrm{mg}$ diárias de ferro $(55,3 \%)$, grupo que apresentou a maior proporção de gestantes $(29,8 \%)$ ingerindo o suplemento por menos de 7 semanas.

Conforme recomendação da OMS (1975a), a gestante deve ser suplementada com ferro por pelo menos três meses consecutivos (13 e mais semanas) para a obtenção de algum resultado satisfatório. Dessa 
forma, os dados da Tabela 20 indicam que menos de dois terços do total das gestantes estudadas $(62,3 \%)$ estariam obtendo resultado positivo com o tratamento profilático da anemia.

As causas da interrupção e/ou abandono ao programa de suplementação, do total de gestantes, estão apresentadas na Tabela 21

Tabela 21. Causas da interrupção da suplementação (ingestão $<13$ semanas) com ferro segundo grupo de intervenção. FAISA, 1997.

\begin{tabular}{lccccc}
\hline & \multicolumn{5}{c}{ Grupos de intervenção [Fe] } \\
\cline { 2 - 6 } Causas de interrupção & 120 /semana & $80 /$ semana & $40 /$ dia & Rotina & Total \\
\hline Transferência & 3 & 2 & 3 & 1 & 9 \\
Desapareceu & 19 & 12 & 10 & 4 & 45 \\
Abortou & 1 & 2 & 1 & 2 & 6 \\
Morte fetal & 0 & 0 & 0 & 1 & 1 \\
Esquecimento & 1 & 1 & 1 & 3 & 6 \\
Dor de estômago & 0 & 0 & 0 & 2 & 2 \\
Diarréia & 0 & 2 & 1 & 3 & 6 \\
Náuseas & 0 & 1 & 4 & 1 & 6 \\
Sabor ruim & 1 & 13 & 20 & 1 & 35 \\
Não comprou & 0 & 0 & 0 & 12 & 12 \\
Sem informação & 19 & 15 & 8 & 4 & 46 \\
\hline Total & 44 & 48 & 48 & 34 & 174 \\
\hline
\end{tabular}

A maior proporção de mulheres que informaram interrupção do tratamento em decorrência do sabor ruim do suplemento foi verificada no grupo que recebia $40 \mathrm{mg}$ diárias de ferro. Surpreende o não aparecimento dessa causa no grupo de "Rotina", que apresentou, no entanto, como esperado, 
a não aquisição do medicamento como principal causa de abandono ou não aderência ao tratamento, além de causas como diarréia e mal estar e esquecimento, que apareceram com maior freqüência nesse grupo Queixas tais como náuseas e vômitos foram praticamente inexistentes nos 4 grupos de intervenção

LOPS e cols. (1995) e YIP (1996) assinalam que a efetividade de um programa de intervenção no controle da deficiência de ferro será tanto maior quanto maior ênfase se der na orientaçāo precisa da importância da suplementação e no aconselhando alimentar, além da conscientização da gestante quanto aos riscos da instalação de um quadro de anemia.

A prevalência de anemia e de depleção da reserva de ferro entre as mulheres que se submeteram às três análises laboratoriais (estudo longitudinal), segundo ingestão ou não do suplemento de ferro por pelo menos 3 meses consecutivos estão apresentadas nas Tabelas 22 e 23 
Tabela 22 - Distribuição das gestantes segundo presença ou não de anemia ( $\mathrm{Hb}<11,0 \mathrm{~g} / \mathrm{dL}$ ) e ingestão ( $\geq 13$ semanas) ou não do suplemento de ferro. FAISA, 1997.

\begin{tabular}{ccccc}
\hline $\begin{array}{c}\text { Grupo de } \\
\text { Intervenção }\end{array}$ & $\begin{array}{c}\text { Ingestão de } \\
\mathrm{FeSO}_{4}\end{array}$ & $\begin{array}{c}\text { Anêmica } \\
\mathrm{n}(\%)\end{array}$ & $\begin{array}{c}\text { Não anêmica } \\
\mathrm{n}(\%)\end{array}$ & $\begin{array}{c}\text { TOTAL } \\
\mathrm{n}(\%)\end{array}$ \\
\hline $120 \mathrm{mg} /$ semana & Tomou & $0(0,0)$ & $9(100,0)$ & $9(100,0)$ \\
& Não tomou & $5(100,0)$ & $0(0,0)$ & $5(100,0)$ \\
$80 \mathrm{mg} / \mathrm{semana}$ & Tomou & $0(0,0)$ & $8(100,0)$ & $8(100,0)$ \\
& Não tomou & $3(100,0)$ & $0(0,0)$ & $3(100,0)$ \\
$40 \mathrm{mg}$ diário & Tomou & $2(33,3)$ & $4(66,7)$ & $6(100,0)$ \\
& Não tomou & $6(35,3)$ & $11(64,7)$ & $17(100,0)$ \\
"Rotina" & Tomou & $3(75,0)$ & $1(25,0)$ & $4(100,0)$ \\
& Não tomou & $1(7,1)$ & $13(92,9)$ & $14(100,0)$ \\
\hline \multirow{2}{*}{ TOTAL } & Tomou & $5(18,5)$ & $22(81,5)$ & $27(100,0)$ \\
& Não tomou & $15(38,5)$ & $24(61,5)$ & $39(100,0)$ \\
\hline
\end{tabular}

Embora para o total da amostra, a proporção de anêmicas tenha sido maior entre as que não ingeriram o suplemento medicamentoso, não se verificou associação estatisticamente significativa entre ingestão de ferro e ocorrência de anemia (Tabela 22). No entanto, essa associação foi significativa para o total da amostra, em relação à reserva de ferro, quando se observou que a ingestão do mineral por um período mínimo de 13 semanas resultou em proporção significativamente menor de gestantes com reservas de ferro exauridas (Tabela 23). 
Tabela 23 - Distribuição das gestantes segundo presença ou não de depleção da reserva de ferro (FS $<12 \mu \mathrm{g} / \mathrm{L})$ e ingestão $(\geq 13$ semanas) ou não do suplemento de ferro. FAISA, 1997.

\begin{tabular}{ccccc}
\hline $\begin{array}{c}\text { Grupo de } \\
\text { Intervenção }\end{array}$ & $\begin{array}{c}\text { Ingestão do } \\
\mathrm{FeSO}_{4}\end{array}$ & $\begin{array}{c}\text { Ferro } \\
\text { depletada } \\
\mathrm{n}(\%)\end{array}$ & $\begin{array}{c}\text { Não ferro } \\
\text { depletada } \\
\mathrm{n}(\%)\end{array}$ & $\begin{array}{c}\text { TOTAL } \\
\mathrm{n}(\%)^{*}\end{array}$ \\
\hline 120mg/semana & Tomou & $2(25,0)$ & $6(75,0)$ & $8(100,0)$ \\
& Não tomou & $4(66,7)$ & $2(33.3)$ & $6(100,0)$ \\
$80 \mathrm{mg} /$ semana & Tomou & $1(33,3)$ & $2(66,7)$ & $3(100,0)$ \\
& Não tomou & $3(75,0)$ & $1(25,0)$ & $4(100,0)$ \\
$40 \mathrm{mg}$ diário & Tomou & $4(44,4)$ & $5(55,6)$ & $9(100,0)$ \\
& Não tomou & $7(87,5)$ & $1(12,5)$ & $8(100,0)$ \\
"Rotina" & Tomou & $2(13,3)$ & $13(86,7)$ & $15(100,0)$ \\
& Não tomou & $2(66,7)$ & $1(33,3)$ & $3(100,0)$ \\
\hline \multirow{2}{*}{ TOTAL } & Tomou & $9(25,7)$ & $26(74,3)$ & $35(100,0)$ \\
& Não tomou & $16(76,2)$ & $5(23,8)$ & $21(100,0)$ \\
\hline
\end{tabular}

* sem informaçăo - 10

$x^{2}=13,53 \quad p<0,001$

A análise individual de cada grupo de intervenção, em relação à ingestão ou não do suplemento de ferro, revela uma tendência mais marcante de distinção entre a ocorrência ou não de anemia $(H b<11,0 g / d L)$ elou depleção da reserva de ferro, nos grupos com suplementação semanal de ferro. 


\section{CONCLUSÕES.}

O estudo "Intervenção nutricional no controle da deficiência de ferro em gestantes da rede básica de saúde" permitiu extrair as seguintes conclusões:

- verificou-se associação positiva entre a ocorrência de desnutrição no início e no final da gestação;

- a evolução da concentração de hemoglobina, indicador da anemia, apresentou curva similar à da população de referência, formada por gestantes não anêmicas e não ferro deficientes;

- independente da forma de suplementação, a concentração inicial e final da hemoglobina e da ferritina sérica, apresentaram diminuição, comportamento indicativo de um processo de depleção do mineral em pauta;

- verificou-se associação positiva entre anemia e reserva de ferro no início e no final da gestação;

- verificou-se associação positiva entre transporte de ferro (avaliado através da saturação de transferrina) e anemia, somente no final da gestação; 
- verificou-se que os valores médios de Hb, FS e ST tenderam a diminuir durante o processo gestacional, com tendência de elevação da concentração de $\mathrm{Hb}$ no final da gestação;

- tanto o fornecimento de $80 \mathrm{mg}$ semanais de ferro, quanto o fornecimento de $40 \mathrm{mg}$ diárias de ferro não resultaram em aumento da reserva de ferro no final da gravidez;

- o aumento da concentração da ferritina sérica resultante da ingestão de $120 \mathrm{mg}$ de ferro por semana sugere estar havendo aumento na reserva de ferro;

- a perda amostral não permitiu distinguir se houve diferença de adesão às diferentes formas de intervenção no fornecimento do ferro. No entanto, as manifestações que motivaram a interrupção na ingestão do suplemento de ferro concentraram-se no grupo que recebeu $40 \mathrm{mg}$ diárias de ferro (sabor ruim) e no grupo de "rotina" (não aquisição do suplemento). Náuseas e vômitos não foram referidos com freqüências relevantes.

- o acompanhamento longitudinal das gestantes estudadas mostrou que a ingestão de ferro pelo período mínimo de 13 semanas ( 3 meses) resulta em diminuição significativa na prevalência de anemia e associação positiva com reserva de ferro. 
- Os resultados encontrados sugerem que o fornecimento de $120 \mathrm{mg}$ de ferro, uma vez por semana, pelo periodo mínimo de 3 meses, foi a estratégia de intervenção mais efetiva no controle da deficiência de ferro, nos serviços públicos de saúde. 
V. RECOMENDAÇÖES 


\section{RECOMENDAÇÕES}

Com relação à prática da intervenção no controle da deficiência de ferro, recomenda-se:

- que o medicamento esteja disponível nos serviços, para a totalidade das gestantes atendidas;

- que a partir de um diagnóstico positivo da anemia, através do exame laboratorial, estabeleça-se uma monitoração especial a fim de se evitar os riscos decorrentes dessa deficiência nutricional;

- avaliação precoce da depleção da reserva de ferro, através da dosagem da ferritina sérica, para minimizar o risco gravidico;

- possibilidade da utilização de $120 \mathrm{mg}$ semanais de ferro, a partir da $20^{\mathrm{a}}$ semana de gestação, para todas as grávidas não anêmicas, considerando sua importância na manutenção da reserva de ferro no decorrer do processo gestacional e seu menor custo, frente aos $280 \mathrm{mg}$ semanais, correspondente a $40 \mathrm{mg}$ por dia de ferro, conforme proposto pelo Ministério da Saúde; 
Levando em conta a experiência de acompanhar o desenvolvimento de um estudo longitudinal, recomenda-se sensibilizar os trabalhadores de saúde que prestam assistência pré-natal, para a importância:

- do preenchimento correto, completo e atualizado do prontuário da gestante, considerando a importância das informações para a identificação do risco gravídico, ponto de partida para a quantificação do risco reprodutivo;

- de cumprir integralmente as ações propostas no Programa de Atendimento à Gestante, que inclui a avaliação do estado nutricional da gestante, através da curva de ROSSO;

- do retorno da mulher à consulta puerperal, como parte integrante das atividades do Programa de Atendimento à Gestante

- a implementação de um programa de educação para a saúde, com vistas à conscientização das gestantes quanto aos riscos e às conseqüências das deficiências nutricionais, tais como a desnutrição e a anemia gestacional, enfatizando a importância de sua profilaxia;

- o desenvolvimento de estudos multicêntricos com vistas ao estabelecimento de valores criticos para os indicadores laboratoriais do estado nutricional de ferro no decorrer do processo gestacional, dada a sua inexistência. 


\section{REFERÊNCIAS BIBLIOGRÁFICAS}

ACOSTA, A.; AMAR, M.; SZARFARC, S.C.; DALLMAN, E.; FOSIL, M.; BIACHI, R.G.; GREBE, G.; HERTRAMPF, E.; KREMENCHUZKY, S.; LAYRISSE, M.; MARTINEZ-TORRES, C.; MORON, C.; PIZARRO, F.; REYNAFARJE, C.; STEKEL, A.; VILLAVICENCIO, D.; ZUNIGA, H. Iron absorption from typical Latin American. Am. J. Clin. Nutr., $\underline{39}$ : 953-62, 1984.

AGARWAL, K.N.; AGARWAL, D.K.; MISHRA, K.P. Impact of anaemia prophylaxis in pregnancy on maternal haemoglobin, serum ferritin \& birth weight. Ind. J. Med. Res., 94: 277-80, 1991.

ALLEN, L. H. Nutritional supplementation for the pregnant woman. Clin. Obstet. Gynecol., 37: 587-95, 1994.

ALVARENGA, A.T. de. Risco gravídico e risco perinatal: implicações metodológicas, teóricas e técnicas, das propostas de mensuração. Rev. Bras. Cres. Desenvol. Hum., 4 41-8, 1994.

AMAR, I.; SOARES, M.M.O.; CREPO, S.G.M. Anemia carencial e peso e vitalidade do concepto. Arq. Bras. Med., 62: 451-4, 1988.

ARRUDA, B. Programa de prevenção das anemias ferroprivas no Brasil. Brasília, Ministério da Saúde-INAN, 1978. [Apresentado no encontro do INACG, Campinas, S.P, 1978]. 
BAKER, S.J. \& DEMAEYER, E.M. Nutritional anemia: its understanding and control with special reference to the work of the health organization. Am. J. Clin. Nutr., 32: 368-417, 1978.

BARTON, D.P.J.; JOY, M.T.; LAPPIN, T.R.J.; AFRASIABI, M.; MOREL, J.G.; O'RIORDAN, J.F.; MURPHY, J.; O'HERLIHY, C. Maternal erythropoietin in single pregnancies: a randomized trial on the effect of oral hematinic supplementation. Am. J. Obstet. Gynecol., 170: 896-901, 1994.

BATISTA FILHO, M; BARROS, L.F. de; NÁCUL, L.C. O perímetro braquial como método de avaliação do estado nutricional das gestantes. Rev. IMIP., $\mathbf{7}: 12-5,1993$

BENICIO, M.H.D'A. Fatores de risco de baixo peso ao nascer em recémnascidos vivos: município de São Paulo, 1978. São Paulo, 1983. [Tese de Doutorado - Faculdade de Saúde Pública da USP].

BENICIO, M.H.D'A; MONTEIRO, C.A.; PACHECO, J.M. de S.; CASTILHO, E..A. de; LAMONICA, I.M.R. Análise multivariada de fatores de risco de baixo peso ao nascer em nascidos vivos- Municipio de São Paulo, Rev. Saúde Pública, 19: 311-20,1985.

BHARGAVA, M.; KUMAR, R.; IYER, P.; RAMJI, S.; KAPANI, V.; BHARGAVA, S. Effect of maternal anaemia and iron depletation on 
fetal iron stores, birthweight and gestation. Acta Paedriatr. Scand., 78: $321-2,1989$.

BOTHWELL, T.H.; BAYNES, R.D.; MacFARLANE, B.J.; MacPHALL, A.P Nutritional iron requirements and food iron absorption. J. Inter. Med., 226: $357-65,1989$.

BOTHWELL, T.H. Overview and mechanisms of iron regulation. Nutr. Rev.; 53: $237-45,1995$.

CAMPINO, A.C.C. Aspectos sócio-econômicos da desnutrição no Brasil Rev. Saúde Pública, 20: 83-101, 1986.

CARDOSO, M.A. \& PENTEADO, M. de V.C. Intervenções nutricionais na anemia ferropriva. Cad. Saúde Pública, 10: 231-40, 1994.

CHARLOENLARP, P.; DHANAMITTA, S.; KAEWVICHIT R.; SILPROSERT, A.; SUWANARADD, C.; NA-NAKORN, S.; PRAWATMUANG, P.; VATANAVICHARN, S.; NUTCHARAS, U.; POOTRAKUL, P.; TANPHAICHITR, V.; TANANGKUL, O.; VANIYAPONG, T.; TOE T.; VALYASERVI, A.; BAKER, S.; COOK, J.; DEMAEYER, E.M.; GARBY, L.; HALLBERG, L. A WHO collaborative study on iron supplementation in Burna and Tailand. Am. J. Clin. Nutr., 47: 280-97, 1988.

CIARI-JUNIOR, C.; ALMEIDA, P. A. M. de; SIQUEIRA, A. A. F. de. Relação entre peso da criança ao nascer, altura materna, idade 
gestacional e restrição alimentar em gestantes normais. Rev. Saúde Pública, 9: 33-42,1975.

COOK, J.D. Adaptation in iron metabolism. Am. J. Clin. Nutr. 51: 301-8, 1990.

COOK, J. D.; CARRIAGA, M.; KHAN, S.G; SCHALCH, W.; SKIKNE, B.S. Gastric delivery system for iron supplementation. Lancet, 335: 1136$9,1990$.

COSTA, C. E. O peso ao nascer e a declaração de nascidos vivos: um estudo epidemiológico, São Paulo, 1996. [Disertação de Mestrado Faculdade de Saúde Pública da USP].

CRICHTON, R.R. Ferritin structure, synthesis and function. N. Engl. J. Med., 284: 1413-22, 1971.

DACIE, J.V. \& LEWIS, S.M. Practical hematology. Churchil Livingstone, 1984.

DALLMAN, P. Iron deficiency and the innune response. Am. J. Clin. Nutr., 46. $329-34.1987$

DEAN, A.G.; DEAN, J.A.COULOMBIER, D.; BRENDEL, K.A.; SMITH, D.C.; BURTON, A.H.; DICKER, R.C.; SULLIVAN, K.; FAGAN, R.F.; ARNER, T.G.; Epi-Info, versión 6: a word processing database, and statistics program for epidemiology on microcomputers, Atlanta, Centers of Disease Control and Prevention, 1994. 
DEMAEYER, E.M. \& ADIELS-TEGMAN, M. The prevalence of anaemia in the World. World Health Stat. Q., 38: 302-16, 1985.

DEMAEYER, E.M; DALLMAN, P.; GURNEY, J.M.; HALLBERG, L.; SOOD, S.K.; SRIKANTIA, S.G. Preventing and controlling iron deficiency anaemia through primary health care. Geneval World Health Organization, 1989

DEPARTAMENTO INTERSINDICAL DE ESTATISTICA E ESTADO SÓCIO-ECONÔMICO (DIEESE). Cesta básica nacional. Bol. DIEESE., (199) 85-96, 1997.

DODD, N.S.; SHEELA, T.S.; SHARMA, U.k. Effect of different levels of iron supplementation on the iron status and physical work capacity of anaemic Indian women. Ind. J. Med. Sci., $\underline{46}$ : 33-42, 1992.

FENTON, V:; CAVILL, I.; FISHER, J. Iron stores in pregnancy. Bri. J. Haematol., 37: 145-9, 1977.

FINCH, C.A. \& COOK, J.D. Iron deficiency. Am. J. Clin. Nutr., 39: 471-7, 1984.

FORADORI C., A.; LIRA V., P; GREBE B., G.; LEGUES S., M.E; MUÑOZ V., B.; VELA, P. Evaluación de la ferritina sérica en embarazadas y su correlación con otros parámetros hematológicos, Rev. Med. Chil. 106: $350-3,1978$. 
FUJIMORI, E. Gravidez na adolescência: estado nutricional referente ao ferro, São Paulo, 1994. [Tese de Doutorado - Faculdade de Saúde Pública da USP].

FUJIMORI, E.; SALUM, M.J.L.; SHIMA, H. Avaliação do estado nutricional de ferro em estudantes universitários do sexo feminino. Rev. Esc. Enferm. USP., 21: 17-22, 1987.

FUNDAÇÃO DE ASSISTÊNCIA À INFÂNCIA DE SANTO ANDRÉ. Relatório dos primeiros vinte anos 1967 - 1986. São Paulo, 1986.

FUNDAÇÃO IBGE. Anuário estatístico do Estado de São Paulo. Rio de Janeiro. 1993, v.1. p. 9-12.

GALLOWAY, R. \& McGUIRRE, J. Determinants of compliance with iron supplementation : supplies, side effects, or psychology?. Soc. Sci. Med., 39: 381-90, 1994.

GARN, S.M.; RIDELLA, S.A; PETZOLD, A.S; FALKNER, F. Maternal hematologic levels and pregnancy outcomes. Sem. Perinatol., $\underline{5}$ : $155-62,1981$

GILLESPIE, S.; KEVANY, J.; MASON, J. Controlling iron deficiency: a report based on an ACC/SCN workshop. Geneva, United Nations Administrative Committee on Coordination-Subcommitte on Nutrition, 1991. 
GODEL, J.C.; PABST, H.F.; HODGES, P.E; JOHNSON, K.E. Iron status and pregnancy in a Northern Canadian population: relationship to diet and iron supplementation. Can. J. Public. Health., 83: 339-43, 1992.

GROSS, R.; SCHULTINK, W.; JULIAWATI. Treatment of anaemia with weekly iron supplementation. Lancet., 344: 821, 1994.

GUERRA, E.M.; BARRETO, O.C. de O, PINTO, A.V.; SILVEIRITA, M.B. Prevalência de anemia em gestantes de primeira consulta en Centros de Saúde do Área Metropolitana, Brasil. Rev. Saúde Pública, 24: $380-86,1990$

GUERRA, E.M; BARRETO, O.C. de O.; PINTO, A.V.; CATELLÄO, K.G.; GOMES, K. Prevalência de deficiência de ferro em gestantes de primeira consulta em Centros de Saúde de Área metropolitana, Brasil: etiologia da anemia. Rev. Saúde Pública, 26: 88-95, 1992.

GUERRA-SHINOHARA, E.M.; PAIVA, R.P.; SANTOS, H.G.; SUMITA, N.; MENDES, M.E.; NUÑEZ, L.M.; SZARFARC, S.C.; VAZ, A.J.; Determinação da ferritina por dois métodos inmunológicos automatizados. Rev. Bras. Anál. Clin., 30: 39-40, 1998.

HALLBERG, L.; RYTTINGER, L.; SOLVELL, S. Side effects oral therapy: a double-blind study of different iron compounds in tablet form. Acta Med. Scand., $\underline{459}$ (suppl): 3-10, 1967. 
HALLBERG, L.; BEENGGTSSON,C.; LAPIDUS, L.; LINDSTEDT, G.; LUNDBERG, P.A.; HULTEN, L. Screening for iron deficiency: an analysis based on bone-marrow examinations and serum ferritin determinations in a population sample of women. Br. J. Haematol., 85: 9787-98, 1993.

HARRISON, K.A.; LECTURER, K.A.H.S.; LECTURER, P.A.I. Maternal anaemia and fetal birthweight. J. Obstet. Gynaecol. Br. Commonw., 80: 798-804, 1973.

HYTTEN, F. \& LEITCH, I. The physiology of human pregnancy. London Blackwell, 1964.

INSTITUTO NACIONAL DE ALIMENTAÇÃO E NUTRIÇÃO. Seminário sobre Anemias Nutricionais no Brasil, Brasilia 1977. Relatório final. Brasilia, INAN/MS, 1977.

INSTITUTO NACIONAL DE ALIMENTAÇÃO E NUTRIÇÃO. Comissão de Estudos para a Anemia Nutricional. 1982. Relatorio. Brasília, 1982. InSTITUTO NACIONAL DE ALIMENTAÇÃO E NUTRIÇÃO. Pesquisa nacional sobre saúde e nutrição: Perfil de crescimento da população brasileira de 0 a 25 anos. Brasilia, INAN, 1990.

INTERNATIONAL NUTRITIONAL ANEMIA CONSULTITAVE GROUP. Guidelines for the eradication of iron deficiency anemia. Washington, D.C. The Nutrition Foundation, 1977 
INTERNATIONAL NUTRITIONAL ANEMIA CONSULTATIVE GROUP. Iron deficiency in women. Washington, D.C. The Nutrition Foundation, 1981.

INTERNATIONAL NUTRITION ANEMIA CONSULTATIVE GROUP. Measurements of iron status. Washington, D.C., The Nutrition Foundation, 1985

JACKSON, R.T. \& LATHAM, M.C. Anemia of pregnancy in Liberia, West Africa: a terapeutic trial. Am. J. Clin. Nutr., 35: 710-4, 1982.

KALTREIDER, D.F. \& JOHNSON, J.W.C. Patients at high risk for lowbirth- weight delivery. Am. J. Obstet. Gynecol., 124: 251-6, 1976.

KANESHIGE, E. Serum ferritin as an assessment of iron stores and other hematologic parameters during pregnancy. Obstet. Gynecol. 57: 238-42, 1981.

KELLY, A. M.; MACDONALD, D.J.; MCNAY, M. B. Ferritin as an assessment of iron stores in normal pregnancy. $\mathrm{Br}$. J. Obstet. Gynecol., 84: 434-8, 1977.

KLEBANOFF, M.A.; SHIONO, P.H.; SELBY, J.V.; TRACHTENBERG, A.I.; GRAUBARD, B.I. Anemia and spontaneous preterm birth. Am. J. Obstet. Gynecol., 164: 59-63, 1991.

KLEIN, L. Premature birth and maternal, prenatal anemia. Am. J. Obstet. Gynecol., 83: 588-90, 1962. 
KNIGHT, E.M.; SPURLOCK, B.G.; EDWARDS, C.H.; JOHNSON, A.A.; OYEMADE, U.J.; COLE, O.J.; WEST, W.L.; MANNING, M.; JAMES, H.; LARYEA, $H_{\text {; }}$; WESTNEY, O.; JONES, $\mathrm{S}$; WESTNEY, L. Biochemical profile of African American women during three trimesters of pregnancy and at delivery. J. Nutr., 124: 943S53S,1994.

KNOTTNERUS, J.A.; DELGADO, L.R.; KNIPSCHILD, P.G.; ESSED, G.G.; SMITS, F. Haematologic parameters and pregnancy outcome. J.Clin. Epidemiol., 43: 461-6, 1991

KRAUFER, M.; CASANUEVA, E.; ARROYO, P; LORIA, A. Detección de deficiencia de hierro: el embarazo como modelo. Rev. Salud Púbica. 30: $6-13,1988$.

LAMPARELLI, R.D; $\quad$ BOTHWELL,T.H; MACPHAL, A.P; WANDER,W,J;BAYNES, R.D; MACFARLANE, B.J. Nutritional anaemia in pregnant coloured women in Johannesburg. S. Afr. Med. J., 73: 447-87, 1988.

LARGUIA, M.; SAN PEDRO, M.; LUJAN, S. Mortalidad fetal y mortalidad neonatal según patologia materna asociada. Rev. Hosp. Matern. Infant. Rámon Sardá, 12: 40-2, 1993.

LI, R.; CHEN, X.; YAN, H.; DEURENBERG, P.; GARBY, L.; HAUTUAST, J.G. Functional consequences of iron supplementation in iron- 
deficient female cotton mill workers in Beijing, China. Am. J. Clin. Nutr., 59: 908-13, 1994

LIU, XU-NIAN; KANG, J.; ZHAO, L.; VITERI, E. Intermittent iron supplementation in Chinese preschool children is efficient and safe. Food Nutr. Bull., 16: 139-47, 1995.

LOPS, V.R.; HUNTER, L.P.; DIXON, L.R. Anemia in pregnancy. Am. Fam. Physican, 51:1189-97, 1995.

MAcGREGOR, M.W. Maternal anaemia as a fator in prematurity and perinatal mortality. Scott. Med. J., $\underline{8}$ : 134-40, 1963

MARTINEZ, J.; ANDINA, E.; POMATA, J.; COLOMBO, A.; GONZALES,, M.E.; FENUCCI, C.; LUCIEN, E. Programa asistencial para la madre adolescente. PROAMA. Rev. Hosp. Matern. Infant. Ramón Sardá, 11: $7-23,1992$

MARTINS, C.S.M. Conduta na anemia ferropriva da gravidez. Rev. Cient. CASL, Porto Alegre, 43: 18-22, 1985

MASSAWE, S.; URASSA, E.; LINDMARK, G.; NYSTROM, L. Anaemia in pregnancy: perceptions of patients in Dar-Es-Salaam, East. African Med. J., 72: 498-503, 1995.

MASSEY, A. Microcytic anemia. Differential diagnosis and management of iron deficiency anemia. Med. Clin. North Am., 76: 549-66, 1992. 
MICOZZI, M. Sobre la definición de anemia del embarazo, Bol. Oficina Sanit. Panam., 89: 597-603, 1980.

MILMAN, N.; AGGER, O.; NIELSEN, O. Iron status markers and serum erythropoietin in 120 mothers and newborn infants, effect of iron supplementation in normal pregnancy. Acta Obstet. Gynecol. Scand., 73: 200-4, 1994.

MILNE, D.B.; GALLAGHER, S.K.; NIELSEN, F.H. Response of various indices of iron status to acute iron depletion produced in menstruating women by low iron status intake and phlebotomy. Clin. Chem., $\underline{36}$ : 487-91, 1990.

MONTEIRO, C.A.; ZUÑIGA, H.P.; BENICIO, D'A.M.H.; SZARFARC, S.C. Estudo das condições de saúde das crianças do municipio de São Paulo, Brasil, 1984-1985. Rev. Saúde Pública, 20: 435-45, 1986.

MURPHY, J.F.; O'RIORDAN, J.; NEWCOMBE, R.G; COLES, E.C.; PEARSON, J.F. Relation of haemoglobin levels in first and second trimesters outcome of pregnancy. Lancet, 1: 992-5, 1986.

NACUL, L.C.; LIRA, P.I.; BATISTA FILHO, M. Anemia em gestantes atendidas no pré-natal do IMIP: I- levantamento preliminar. Rev. IMIP., 4: 104-6, 1990.

NATIONAL RESEARCH COUNCIL. Recommended dietary allowances. $10^{\text {th }}$. ed. Washigton, D.C. National Academy Press, 1989. 
NESE, M.; BELLIS, R. de; PIRIZ, B.; BASOA, E.; SERE, C.; ALMEIDA, C. de; CUADRO, J.C. Anemia y embarazo, valor de la ferritina sérica en la detección de una población de riesgo. Arch. Med. Inter., 19: 5-7, 1989.

NÓBREGA, F.J. de Coord. Antropometria do recém-nascido. Nestlé, São Paulo, 1989

NOTTNERUS, J.A; DELGADO, L.R; KNIPSCHILD, P.G.; ESSED, G.G.; SMITS, F. Haematologic parameters and pregnancy outcome. J. Clin. Epidemiol., 43: 461-6, 1990.

OBA, M. das D. V. \& TAVARES, M. S. A precariedade dos registros de assistência pré-natal em uma unidade básica de saúde do município de Ribeirão Preto - SP. Rev. Latinoam. Emferm., ㅁ: 53-61, 1998.

ORGANIZACION MUNDIAL DE LA SALUD. Anemias nutricionales, Ginebra, 1968. (OMS-Serie de Informes Técnicos, 405).

ORGANIZACION MUNDIAL DE LA SALUD. Prevención de la mortalidad y la morbilidad perinatal, Ginebra, 1970. (OMS-Serie de Informes Técnicos, 457).

ORGANIZACION MUNDIAL DE LA SALUD. Anemias nutricionales, Ginebra, 1972. (OMS-Serie de Informes Técnicos, 503). 
ORGANIZACION MUNDIAL DE LA SALUD. Lucha contra la anemia nutricional especificamente contra la carencia de hierro. Ginebra, 1975a. (OMS-Serie de Informes Técnicos, 580).

ORGANIZACION MUNDIAL DE LA SALUD. Metodologia de vigilancia nutricional. Ginebra, 1975b. (OMS-Serie Informes Técnicos, 493).

ORGANIZACION PANAMERICANA DE LA SALUD. Manual sobre enfoque de riesgo en la atención materno infantil. OPS, Washigton D.C. Serie Paltex para Ejecutores de Programas de Salud 7, OPS, 1986

ORGANIZACION PANAMERICANA DE LA SALUD. Plan de acción para el control de la anemia por carencia de hierro en las Américas. Washigton D.C. 1996.

PAPPAGALLO, S. \& BULL, D.L. Operational problems of an iron supplementation programme for pregnant women: an assessmemt of UNRWA experience. Bull. World Health Organ., 74: 25-33, 1996.

PINEDA, O.; ASHMEAD, H.D.; PEREZ, J.M.; LEMUS, C. Effectiveness of iron amino acid chelate on the tratament of iron deficiency anemia in adolescents. J. Appl. Nutr., 46: 2-11, 1994.

PINTO, A.V.; PINTO, G.P.; FORMIGA FILHO, J.F.N.; LARA, S.; SANTOS, F. Anemia da gravidez em Sobradinho, cidade satélite de Brasilia. Rev. Bras. Pesq. Med. Biol., ㅁ: 381-5, 1975. 
PIZARRO, F.; OLIVARES, M.; HERTRAMPF, E.; WALTER, T. Factores que modifican el estado de nutrición del hierro: contenido de taninos de infusiones de hierbas. Arch. Latinoam. Nutr., 44: 277-80, 1994.

PUOLAKKA, J.; JANNE, O.; PAKARINEN, A; JARVINEN, P.A.; VIHKO, R. Serum ferritin as a measurements of iron stores during and after normal pregnancy with and without iron supplements. Acta Obstet. Gynecol. Scand., 9 5 (Suppl.): 43-51, 1980.

QUINTERO-GUTIERREZ, A.; RIVERA, D.J.; GONZALES, R.G. Suplementación con hierro en dosis única semanal y dosis diária en la prevención de la anemia ferropriva en la embarazada. XI Congreso de la Sociedad Latinoaméricana de Nutrición, 1997. (código CM-79)

RAPOSO, M.C.; VIGOLVINO, H.A., BATISTA-FILHO, M. Saúde e nutrição de mulheres adolescentes no Brasil. II aspectos de saúde reprodutiva. Rev. IMIP., 11: 11-6, 1997.

RIDWAN, E.; SCHULTINK, W.; DRUPADI, D.; GROSS, R. Effects of weekly iron supplementation of pregnant Indonesian women are similar to those of diary. Am. J. Clin. Nutr., 63: 1-7, 1996.

ROMSLO, I.; HARAM, K.; SAGEN, N.; AUGENSEN, K. Iron requeriment in normal pregnancy as assessed by serum ferritin, serum transferrin saturation and erytrocyte protoporphyrin determinations. Br. J. Obstet. Gynaecol., 90: 101-7, 1983. 
ROODENBURG, A.J.C. Iron suplementation during pregnancy. Eur. J. Obstetr. Reprod., 61: 65-71, 1995.

ROSSO, P. A new chart chart to monitor gain during pregnancy. Am. J. Clin. Nutr., 41: 644-52, 1985.

SALZANO, A. A.; BATISTA FILHO, M.; FLORES, H.; CALADO, C. L. A. de Prevalência de anemia no ciclo gestacional en dois estados do nordeste brasileiro, Pernambuco e Paraíba. Rev. Bras. Pesq. Med. Biol., 13: 211-4, 1980.

SCHOLL, T.O; HEDIGER, M.L.; FISHER., R.L.; SHEARER, J.W. Anemia vs iron deficiency: incresed risk of preterm delivery in propective study. Am. J. Clin. Nutr., 57: 135-9, 1992.

SCHOLL, T.O. \& HEIDER, M.L. Anemia and iron deficiency: compilation of data on pregnancy outocome. Am. J. Clin. Nutr., $\underline{59}$ (Suppl): 492S501S, 1994.

SCHULTINK. W.; VAN DER REE, M.; MATULESSI, P.; GROSS, R. LoW compliance with an iron supplementation program: a study among pregnant women in Jakarta, Indonesia. Am. J. Clin. Nutr., 57: 135-9, 1993.

SCHULTINK, W.; GROSS, R.; GLIWITZKY, M.; KARYADI, D.; MATULESSI, P. Effect of daily vs twice weekly iron supplementation 
in Indonesia preschool children with low iron status. Am. J. Clin. Nutr., 61: 111-5, 1995.

SCHWARTZ, W. J. \& THURNAU, G. R. Iron deficiency anemia in pregnancy. Clin. Obstet. Gynecol., 38: 443-54, 1995.

SECRETARIA DE ESTADO DA SAÚDE. Subprograma de saúde da mulher: subsídios e diretrizes. São Paulo, Grupo de Saúde da Mulher, 1986.

SECRETARIA DE ESTADO DA SAÚDE. Resolução SS 131 de 16 de maio de 1990: establece diretivas e estratégias para combate a anemia ferropriva. Diário Oficial do Estado de São Paulo, São Paulo, 15 maio, 1990. Secção I, p.12.

SIMMONS, W.K.; COOK, J.D.; BINGHAM, K. C.; THOMAS, M.; JACKSON, J.; JACKSON, M.; AHLUWALIA, N.; KAHN, S.G.; PATTERSON, A.W. Evaluation of a gastric delivery system for iron supplementation in pregnancy. Am. J. Clin. Nutr., 58: 622-6, 1993.

SIMÕeS, C. C. da S. \& OlIVEIRA, L. A. P. de. Perfil estatístico de crianças e mães no Brasil: a situação da fecundidade; determinantes gerais e características da transição recente. Rio de Janeiro, Fundação IBGE, 1988. 
SINISTERRA R, O; SZARFARC, S. C.; BENICIO, D'A. M.H. Anemia e desnutrição materna e sua relação com o peso ao nascer. Rev. Saúde Pública., 25: 193-7, 1991.

SIQUEIRA, A; JUNIOR, C; MARCONES, P; TANAKA, A; MONTELONE, P; GONÇALVES, J.; DELASCIO, D. Influência da altura e ganho de peso materno e da idade gestacional sobre o peso do recém-nascido; estudo de 3 grupos de gestantes normais. Rev. Saúde Pública, $\underline{9}$ : $331-42,1975$.

SIQUeIRA, A. A. F de; TANAKA, A. C. D' A.; ALVAREnGA, A. T. de; SCHOR, N. Perfil da mortalidade de mulheres de 10 a 19 anos na região sul do Município de São Paulo. Rev. Bras. Cres. Desenv. Hum., 6: 69-76, 1996.

SOOD, S.; RAMACHANDRAN, K.; MARTHUR, M.; GUPTA, K.; RAMALINGASWAMY, V.; SWARNABAI, C.; PONNIAH, J.; MATHAN, V.; BAKER, J. Word Health Organization sponsored collaborative studies on nutritional anaemia in India. Q. J. Med., 44: 241-58, 1975.

SZARFARC, S. C.; BOEL, C. P.; ANDRADE, J.; CIARI-JUNIOR, C. Caracteristicas vitais como indicadores do risco gravídico. Rev. Saúde Pública, 14: 310-9, 1980.

SZARFARC, S. C. Densidade do ferro biodisponivel em uma dieta habitual no Estado de São Paulo. Rev. Saúde Pública, 17: 290 - 6, 1983a. 
SZARFARC, S. C. Prevalência de anemia nutricional entre gestantes atendidas matriculadas em centros de saúde do estado de São Paulo, 1983 . [Tese de Libre Docência - Faculdade de Saúde Pública da USP]

SZARFARC, S. C.; SIQUEIRA, A.A.F.; MARTINS, I.S. Avaliação de ferro orgânico em uma população de grávidas. Rev. Saúde Pública, 17: $200-7,1983$.

SZARFARC, S. C. Anemia nutricional entre gestantes atendidas em centros de saúde, São Paulo, Brasil. Rev. Saúde Pública., 19: 450-7, 1985

SZARFARC, S.C; STEFANINI, M.E.; LERNER, B.R. Anemia nutricional no Brasil. Cad. Nutr., 9: 5 - 24, 1995.

SZARFARC, S. C.; BERG, G; SANTOS, A.L.S.; SOUZA, S.B.; MONTEIRO C.A. O controle da anemia na infância da rede básica de saúde. J. Pediatr., 72: 329-34, 1996.

TADDEI, J. A. de A. C.; JACOMO, J. A.; ALBURQUERQUE, Z. P.; BENICIO DÁQUINO, M. H.; ATHIAS, S. P.; TORRES, D. H. B.; SEGOVIA, I.; SRIEDES, R. M.; MACHADO, C. Das S.; DOS SANTOS, P. S. M.; CAMPELLO, L. O porcentual do peso para altura da gestante no diagnóstico do baixo peso ao nascer: estudo multicêntrico. Rev. Bras. Ginecol. Obstet., 2: 78-82, 1991. 
TAYLOR, D. J.; MALLEN, C.; MAcDOUGALL, N.; LIND, T. Effect of iron supplementation on serum ferritin levels during and after pregnancy. Br. J. Obstet. Gynaecol., 89: 1011-7, 1982.

THOMSEM, J. K.; PRIEN-LARSE, J. CH.; DEVANTIER, A.; FOGHANDERSEN, N. Low dose iron supplementation does not cover the need for iron during pregnancy. Acta Obstet. Gynecol. Scand., $\underline{72}$ : 93-8, 1993.

THORAND, B.; SCHULTINK, W.; GROSS, R.; SASTROAMIDJOJO, S.; WENTZEL, S. Efficiency of the iron supplementation programme for pregnant women in Jeneponto, Sulawesi, Indonesia. Asia Pac. J. Clin. Nutr., 3: 211-5, 1994.

TOMASI, E.; BARROS, F.C.; VICTORA, CC.G. Situação sócio-econômica e condições de vida: comparação de duas coortes de base populacional no sul do Brasil. Cad. Saúde Pública. 12 (supl 1) 15-9, 1996.

TRIGO, M. Metodologia de inquérito dietético: estudo do método recordatório de 24 horas. São Paulo, 1993. [Tese de Doutorado Faculdade de Saúde Pública da USP].

US PREVENTIVE SERVICES TASK FORCE (USPSTF). Routine iron supplementation during pregnancy: policy statement. JAMA, 270: $2846-8,1993$ 
US PREVENTIVE SERVICES TASK FORCE (USPSTF). Routine iron supplementation during pregnancy: review article. JAMA, 270: 2848$54,1993_{b}$

VANNUCHI, H.; FREITAS, M. L. S.; SZARFARC, S. C. Prevalência de anemia no Brasil. Cad. Nutr., 4: 7-26, 1992.

VICTORA, C. G.; BARROS, F. C.; VAUGHAN, J. P. Epidemiologia da desigualdade. São Paulo, HUCITEC, 1988.

VIGOLVINO, H. A., BATISTA-FILHO, M. RAPOSO, C. Saúde e nutrição de mulheres adolescentes no Brasil. II Aspectos sócio econômicos. Rev. IMIP., 11: 5-10, 1997.

VITAL I OFICINA DE NUTRICION. Tercer Taller Regional: Deficiencia de Vitamina A y otros Micronutrientes en América Latina y el Caribe. Recife, Brasil, agosto, 1993. (Informe IN-14)

WALLER, M.F.\& HAYNES, E.M. Effects of heat and exercise on sweat in loss. Sci. Sports Exerc., 28: 197-203, 1996.

WORLD HEALTH ORGANIZATION. Prevention and management of severe anemia in pregnancy: report of technical working group. Geneva, WHO/MH/SMP, 1991.

WORLD HEALTH ORGANIZATION. The prevalence of anemia in women: a tabulation of available information. Geneva, 1992. 
ZAVALETA, N. \& BERLANGA, R. Prevalencia y determinantes de anemia por deficiencia de hierro en gestantes de Lima Metropolitana. Lima, Oficina Panamericana de la Salud, 1993. (Anemias Nutricionales, Boletín 1) 
ANEXOS

P. 
Anexo 1

\section{MUNICÍPIO DE SANTO ANDRÉ Consultórios de Higiene Pré-natal}

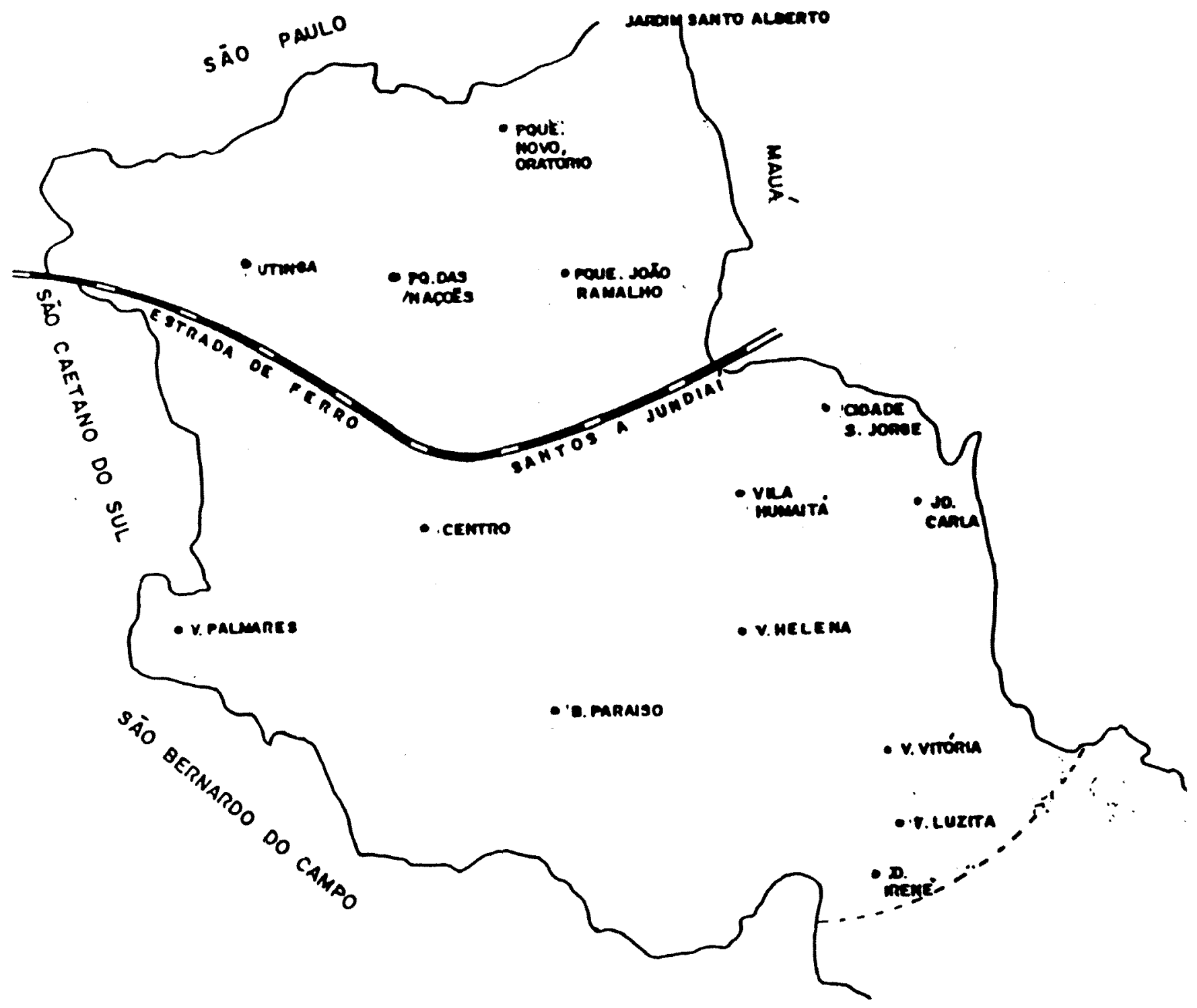

FONTE: FAISA. 1986. 
Declaro que o projeto "Intervenção no Controle de Anemias Nutricionais", que teve como objetivo central o diagnóstico de deficiências nutricionais no decorrer do processo gravídico e identificação de seus determinantes, entre a clientela do Programa de Atendimento à Gestante. com vistas a propor e avaliar intervençóes para o controle das mesmas, foi submetido a este Comitê de Ética, tendo sido aprovado.

Santo André, 19 de maio de 1998.
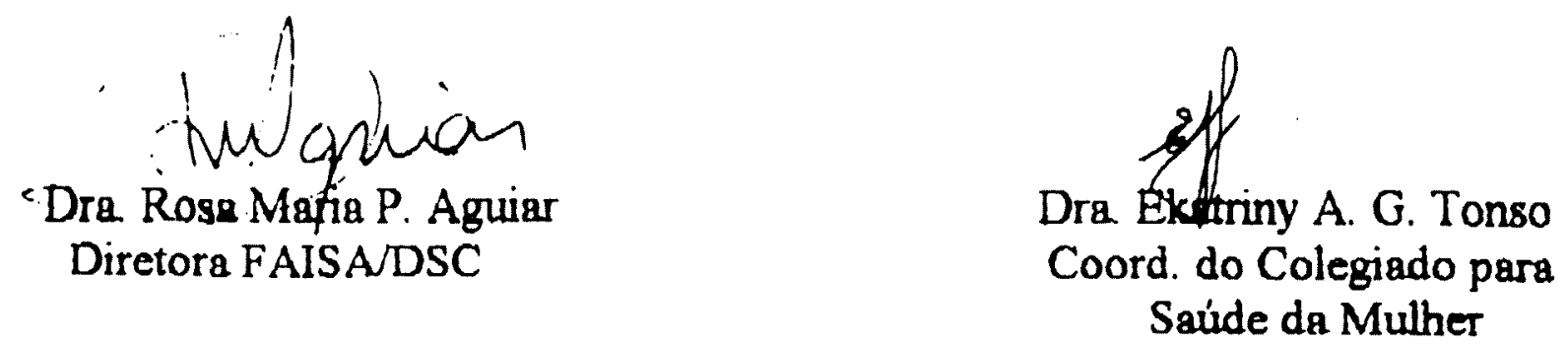
IMPLEMENTAÇÃO E AVALIAÇÃO DO PROGRAMA DE CONTROLE DA DEFICIÊNCIA DE FERRO NA GRAVIDEZ NA REDE BÁSICA DE SAÚDE

\section{METODOLOGIA.}

A população de estudo será constituída pela totalidade de gestantes matriculadas em Postos de Saúde da FAISA (Fundação de Assistência à Infância de Santo André), com idade gestacional inferior a 20 semanas. Considerando que se deseja um número amostral de 50 mulheres para cada grupo ao final do estudo, e, calculando uma perda amostral de $50 \%$ (casos de abandono, perdas fetais, abortos, natimortos), serão cadastradas 75 grávidas por grupo.

Serão formados os seguintes grupos:

GRUPO 1 - $120 \mathrm{mg}$ de $\mathrm{Fe}$ de $\mathrm{FeSO}_{4} / 1$ vez por semana;

GRUPO 2 - $80 \mathrm{mg}$ de $\mathrm{Fe}$ de $\mathrm{FeSO}_{4} / 1$ vez por semana;

GRUPO 3 - $40 \mathrm{mg}$ de $\mathrm{Fe}$ de $\mathrm{FeSO}_{4} /$ diariamente;

GRUPO 4 - orientação habitual.

\section{ATIVIDADES.}

1. diagnóstico de deficiência de ferro: concentração de hemoglobina, saturação de transferrina e ferritina sérica, em diferentes momentos:

- na matricula ao Programa de Atendimento à gestante e;

- a cada dois meses

2. avaliação antropométrica a cada consulta;

3. preenchimento de formulário referente às características gineco-obstétricas, sociais, econômicas e prática alimentar;

4. nas consultas de rotina entrega do suplemento de ferro para gestantes com mais de 20 semanas de gravidez, com orientação para seu uso. As orientações são especificas para cada Posto de Saúde.

5. distribuição de calendários para anotação das datas de ingestão do suplemento, intercorrência quando houver e datas de retorno.

Observação: $O$ grupo 3 corresponderá àquele em que a gestante receberá o suplemento na forma preconizada pelo Programa de Atendimento, diferindo do grupo 4, apenas pela garantia do fornecimento do suplemento de ferro, ao primeiro. 


\section{ANEXO 4.}

Fundação de Assistência à Infância de Santo André

Santo André, 07 de Outubro de 1996

ORDEM DE SERVIÇO M - 222/96

Assunto: Orientação administrativa para a implantação do $\equiv:=:=: 0$ de Pesquisa sobre Deficiência de Ferro na gestação.

01 - População alvo: gestantes.

02 - Critérios de Inclusão: gestantes que iniciem o pré-nazal com menos de 20 semanas.

03 - Critérios de Exclusão: gestantes que iniciem o pré-natá com mais de 20 semanas.

gestantes com patologias não třżंeis na gestação (por exemplo esquistossomose) e que são causa de deficiência de ferro.

gestantes com patologias (anemia falciforme, talassemia, cardiopatas, etc).

04 - Ne de gestantes que serão incluidas no projeto: 25 por ミこsto.

05 - Tempo de acompanhamento das gestantes incluidas: 12 meses

06 - Exames que serão pedidos (dentro do laboratório da FAISA): Ia consulta: aqueles que já são pedidos de rotina sendo cie para a pesquisa será usado somente o Eritrograma, Ferro Sérizo e Transferrina.

07 - Periodicidade para repetição dos exames acima: a cada z -.eses, sendo que a partir do $8 \varrho$ mês os exames serão mensais e o illtimo será pedido no puerpério (mandar a paciente retornan após 30 dias do parto).

08 - As pacientes que pertencem a pesquisa terão seus pedidos de Eri trograma, Ferro Sérico e Transferrina diferenciados da seguinte forma: no campo indicação, escrever PESQUISA, este item $\dot{e}-. . j i t o$ importante para que o laboratório da FAISA possa ider:izizar esta paciente; alguns exames serão feitos no laborató:z z exter no, então a paciente terá uma quantidade de sangue ex:n三 maior volume.

09 - As pacientes que pertencem a pesquisa terão suas fichas (mode1o 289) diferenciadas com uma folha interna (formulário que te rá uma porção externa para identificação, que será montado coñ forme orientação dada). 
10 - Este formulário do item 9 é chamado "Inquérito Alin:.: : : . deverá ser preenchido pela auxiliar de enfermagem nc $\equiv::$ : matricula e o calendário nele contido será preenchici auxiliar, sempre que a gestante retornar.

11 - o calendário citado no ítem 10 é uma replica daquele gue a mãe (folha cor de abóbora), serve para a anotaj

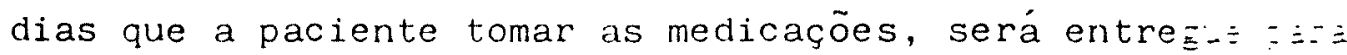
todas as mães da pesquisa.

A mãe deverá ser orientada para trazer o seu calencí:: : pre que vier ao posto para consulta de pré-natal; $s e:=$ is prudente grampear o calendário no cartão de pré-r.j:三:.

\section{2 - Serão formados os seguintes grupos:}

Grupo 1 - $120 \mathrm{mg}$ de Ferro, Sulfato ferroso, 1 vez por $\equiv \equiv=\sum . \equiv$. HPN 1, HPN 2, HPN 4

Grupo 2 - $80 \mathrm{mg}$ de Ferro, Sulfato ferroso, 1 vez por $\equiv \equiv z \equiv .$. HPN 10, HPN 11, HPN 12

Grupo 3 - $40 \mathrm{mg}$ de Ferro, Sulfato ferroso, diariamer:

HPN 13, HPN 15, HPN 20

Grupo 4 - 15 mg de Ferro, Ferrochel, diariamente.

HPN 8, HPN 14, HPN 16

Grupo 5 - Orientação habitual, sem distribuição de Sü:=n:-:. HPN 18, HPN 19

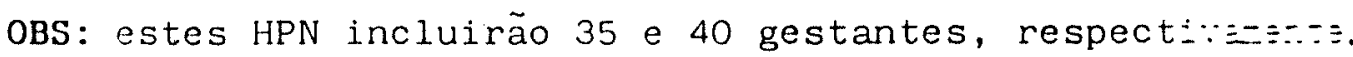
para completar o total da amostra que é de 75 c $\equiv \equiv: \equiv \equiv: z$ grupo.

Enviaremos orientações especificas, para cada grupo, $\vdots-\equiv$ xo.

13 - Naquele grupo chamado "Grupo Controle" a paciente ser entada a tomar "sulfato ferroso" mediante receita mé:i: porém o medicamento não será fornecido, pois daremos $\equiv$ o calendário e cartinha.

14 - Dúvidas ligar para Dra. Ekatriny na FAISA Central ol $\equiv \equiv \equiv \equiv$ Dra. Sofia no número 852-6748.

15 - Observações:

A - Ds exames de Laboratório, para as pacientes da $=\vdots \Xi:-1-$ sa, serão fejtos das 07:00 às 09:00 horas de 2 a a $5 \vdots$ $\vdots:: \vdots$ no laboratório da FAISA Central; orientar as pacien: $\equiv$ anotar nos pedidos de exame. 
B - Pacientes da pesquisa terão seus exames colhidos : : : jum de 8 horas.

Agradecemos a atenção, o espírito de colaboração, e $2:=5:-$ mentamos a todos.

Dra. Ekstrify A. G. Tonso

Atend. à Saúde Mulher

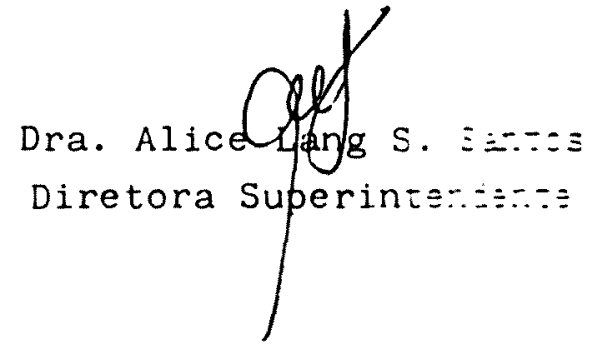

c. c

Todos os Consultórios de HPNG 
ANEXO I

Grupo 1: HPN 01, HPN 02, HPN 04

FORNECIMENTO DE MATERIAL:

- Cartinha cor de abóbora ou azul com calendário e caneta

- Sulfato ferroso: fornecer 02 frascos a cada 2 meses

fornecer 1 colher medida de $5 \mathrm{ml}$, no ins:

da pesquisa.

\section{PRESCRIÇÃO}

\section{USO INTERNO}

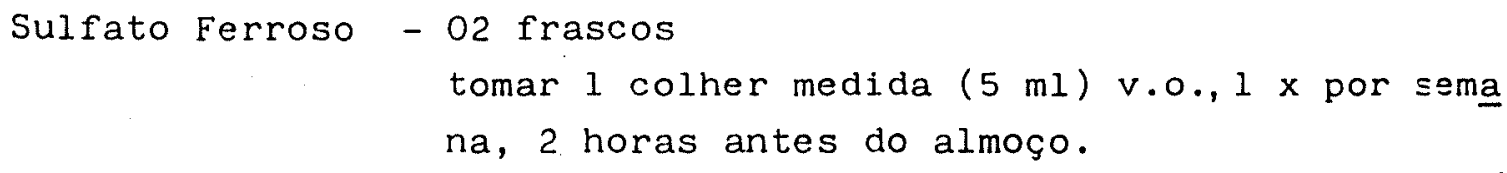


ANEXO II

Grupo 2: HPN 10, HPN 11, HPN 12

FORNECIMENTO DE MATERIAL:

- Cartinha cor de abóbora ou azul com calendário e caneta

- Sulfato Ferroso: fornecer 01 frasco a cada 2 meses

fornecer 01 colher medida de $1,6 \mathrm{ml}$, no $-:: \vdots=10$ da pesquisa

\section{PRESCRIÇÃO :}

\section{USO INTERNO}

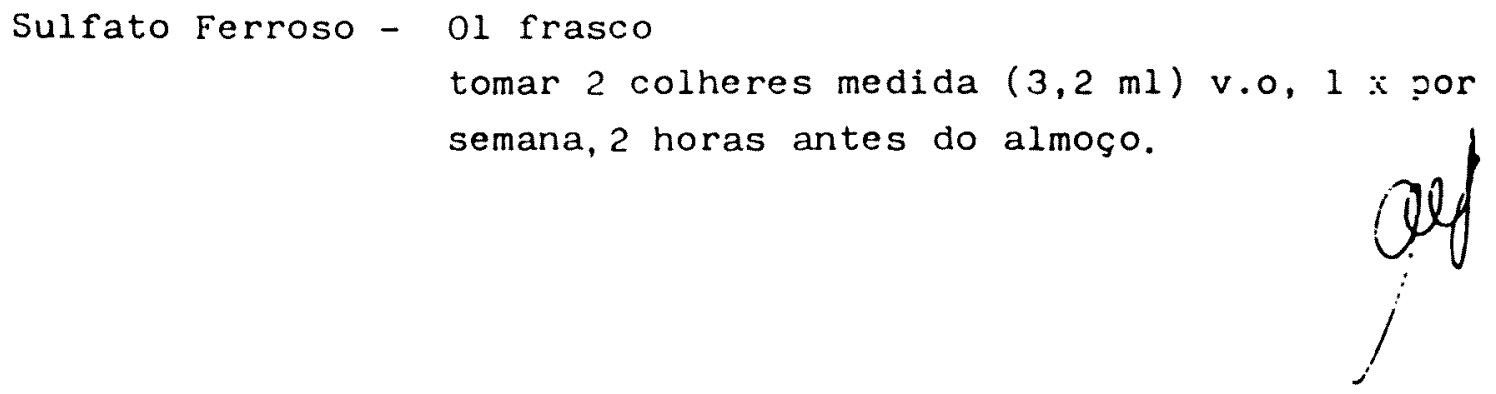


Grupo 3: HPN 13, HPN 15, HPN 20

\section{FORNECIMENTO DE MATERIAL:}

- Cartinha cor de abóbora ou azul com calendário e cane:三

- Sulfato Ferroso: fornecer 04 frascos a cada 2 meses fornecer 1 colher medida de $1,6 \mathrm{ml}, \mathrm{nc}: \therefore:: 2:$ da pesquisa

\section{PRESCRIÇño:}

\section{USO INTERNO}

Sulfato Ferroso - 04 frascos

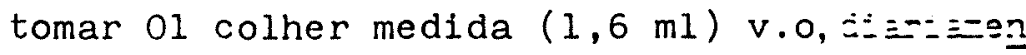
te, 2 horas antes do almoço. 


$$
\text { ANEXO IV }
$$

GRUPO 4: HPN 8, IIPN 14, HPN 16

\section{FORNECIMENTO DE MATERIAL}

- Cartinha cor de abóbora ou azul com calendário e caneta

- Ferro-Que1: 01 frasco a cada 2 meses.

\section{PRESCRIÇÃO}

\section{USO INTERNO}

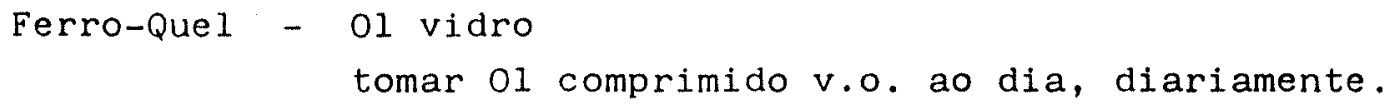


ANEXO $V$

GRUPO 5: HPN 18, HPN 19

\section{FORNECIMENTO DE MATERIAL}

- Cartinha cor de abóbora ou azul com calendário e caneż

OBS: Dar apenas a receita de sulfato ferroso; não será $=: 2 \times:=: \vdots 0$ o medicamento.

\section{PRESCRIÇÃO}

\section{USO INTERNO}

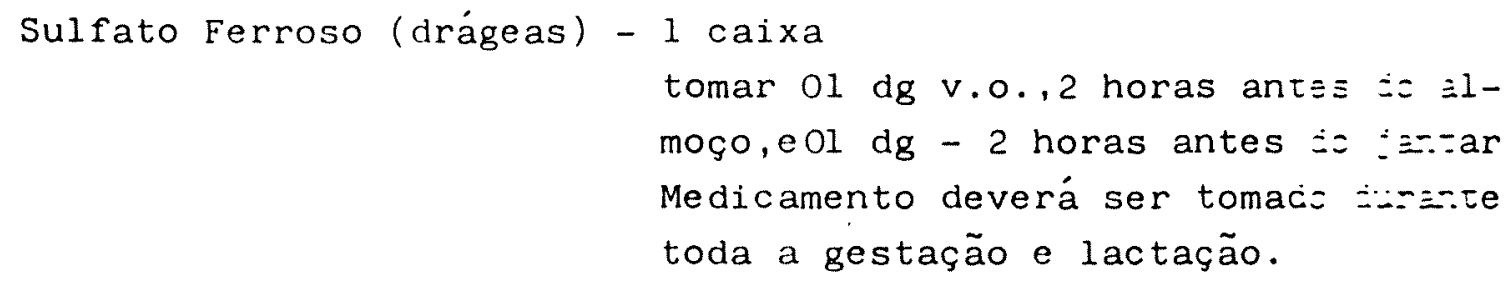


2a a foira das 7 as 9 horas

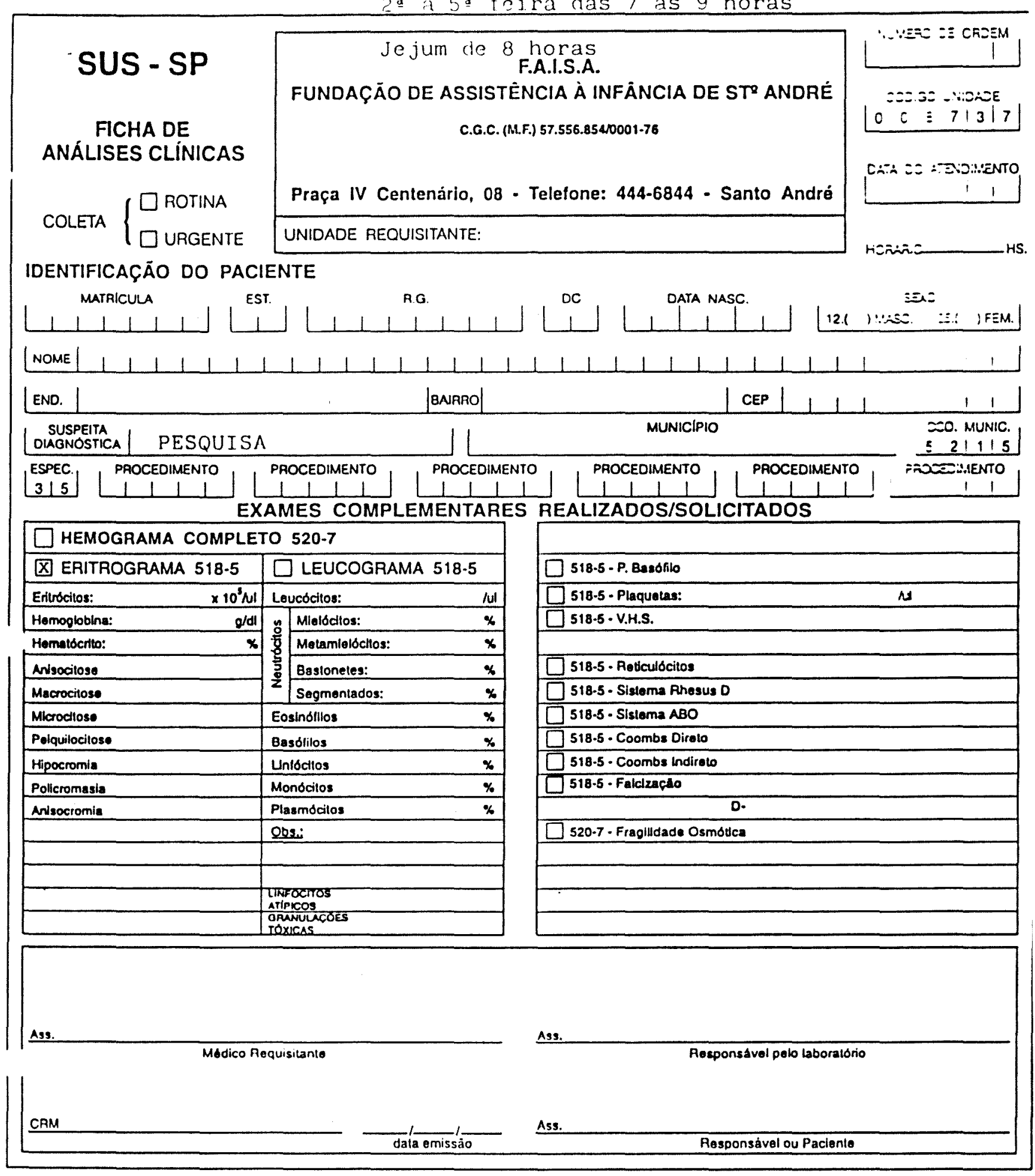


2a a 5a feira das 7 às 9 horas

JEJUM de 8 horas

\section{SUS - SP}

FICHA DE ANÁLISES CLÍNICAS

COLETA $\left\{\begin{array}{l}\square \text { ROTINA } \\ \square \text { URGENTE }\end{array}\right.$
F.A.I.S.A.

FUNDAÇĀO DE ASSISTÉNCIA À INFÃNCIA DE STO. ANDRÉ C.G.C. (M.F.) $57.558 .85410001-76$

Praça IV Centenário, 08 - Telefone: 444-6844 - Santo Andró UNIOADE REQUISITANTE

WEO DE ORDEM

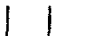

:DSOU UNIDADE

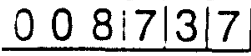

=-^ACATENDIMENTO

IDENTIFICAÇĀO DO PACIENTE

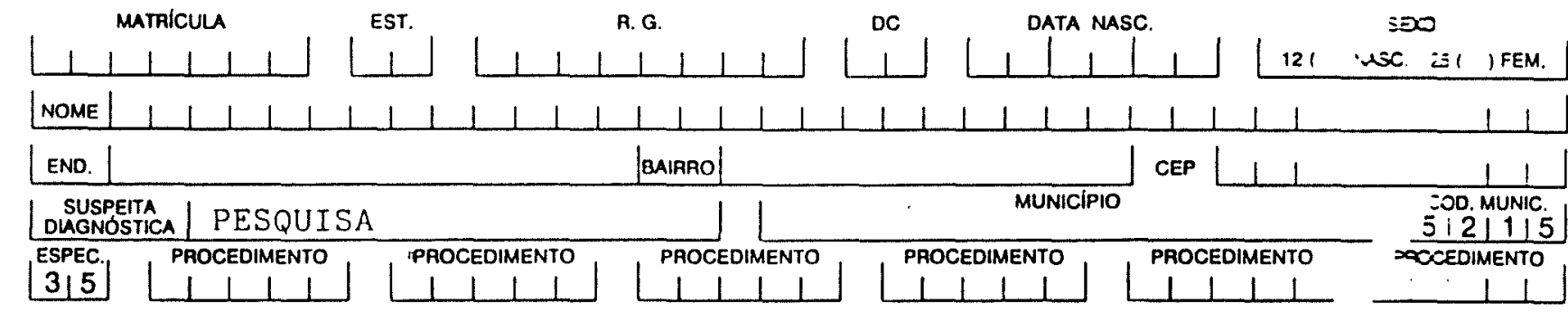

\section{EXAMES COMPLEMENTARES REALIZADOS/SOLICITADOS}

\section{BIOQUÍMICA GERAL}

$500-2$ - Addo úrico

$\left[\begin{array}{l}2.0 \\ \text { Bll. Indireta } \\ \text { Bil. botal }\end{array}\right.$

D500-2. Creatinina

$\square$ 500-2 - Glicose em jejum

500-2. Gllooso pós-prandial

5100 . Curve gicolmica

\begin{tabular}{|c|c|}
\hline \multicolumn{2}{|c|}{ Glloosúria } \\
\hline 1e & ya \\
\hline 2 & 24 \\
\hline 3* & 30 \\
\hline 40 & 44 \\
\hline
\end{tabular}

口500-2 - Urbla

$\square$ 500.2-Cresbinina

500-2 - Sódio

$\square$ 500.2 - Pothesio

D500.2 - Calcto

$\square$ s00-2 - Fostoro

$\square$ 504-5 - Fosfalaee

Ncalina

T4-5 - Trigllotrides

L w - Colestorol

$\square 502-9 \cdot$ TGO

$\square$ 502.9 - TGP

$\square$ 502-9 - Anitase

X] 504.5 - Forro

X] 506-1 - Transioming

$\square$ 500-2 - Cloreto

$\square$ 500-2. Protoina total

Q $500-2\left\{\begin{array}{l}\text { Abumlna } \\ \text { Globulina } \\ \text { Aolactio AV }\end{array}\right.$ $\mathrm{mg} / \mathrm{dl} \square 518.5 \cdot$ Tempo de Sangramento

\section{SOROLOGLA}

seo. SOROLOC

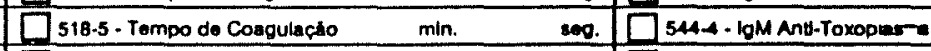

П518-5 - Tempo do Protrombian

518.5 - Tempo de Tromboplastina Parcial

D518-5 - Rolraçio do Codgulo

* $538-0 \cdot V D A L$

nog. D540-1 . Paut-Bunnall-Devasoon

× $\square$ 512-8 - Aublot

D540-1 - Machado Guerrers

\section{Reumatologia}

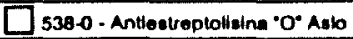

D80-7 - Colules LE

D380 - Fator Reumatoide

$\square 3380$. Protolna ${ }^{\circ} \mathrm{C}$ Reallva

口502.9. Mucoproleinne

L

Exame(s) Solicitado(s) - Justificar

NA UAGÉNCIA 
Anos escolares curnados por: gestante

chere da famllia

O que a senhora comeu ontem?

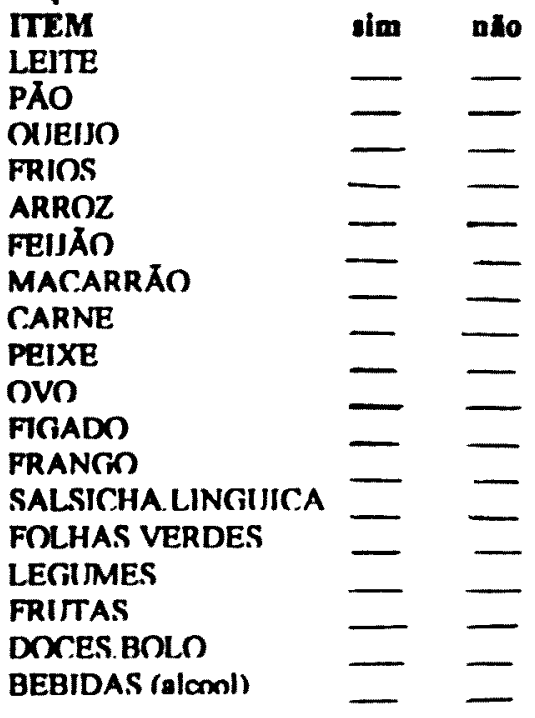

\section{Uso do sup.ilemento de ferro}

\begin{tabular}{|c|c|c|c|c|c|c|c|c|c|c|c|c|c|}
\hline $\begin{array}{l}0 \\
0 \\
01 \\
21\end{array}$ & 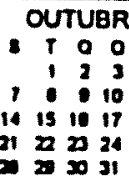 & $\begin{array}{l}10 \\
1 \\
11 \\
10 \\
20\end{array}$ & 12 & $\begin{array}{ll}0 & 1 \\
1 & 1 \\
11 & 11 \\
4 & 2\end{array}$ & 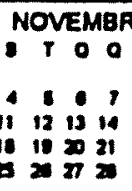 & $\begin{array}{l}\text { Ro } \\
: \\
1 \\
13 \\
2\end{array}$ & $\begin{array}{l}2 \\
2 \\
10 \\
2\end{array}$ & $\begin{array}{ll}0 & 0 \\
1 & 2 \\
1 & 1 \\
11 & 10 \\
0 & 0\end{array}$ & $\begin{array}{ll}\text { DE } \\
1 \\
1 \\
10 \\
11 \\
24 \\
31\end{array}$ & $\begin{array}{ll}2 E M \\
1 & 0 \\
3 & 11 \\
0 & 11 \\
11 & 11\end{array}$ & $\begin{array}{l}\operatorname{len} \\
0 \\
11 \\
11 \\
2\end{array}$ & & $\begin{array}{l}3 \\
11 \\
y \\
21\end{array}$ \\
\hline $\begin{array}{ll}0 & \\
12 & 11 \\
11 & 20 \\
n & n\end{array}$ & 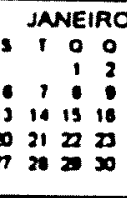 & $\begin{array}{c}3 \\
3 \\
3 \\
10 \\
17 \\
24 \\
31\end{array}$ & $\begin{array}{l}3 \\
11 \\
11 \\
25\end{array}$ & $\begin{array}{ll}0 & 1 \\
0 & 1 \\
1 & 10 \\
14 & 11 \\
12 & 24\end{array}$ & 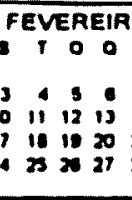 & $\begin{array}{l}30 \\
1 \\
14 \\
21 \\
21\end{array}$ & : & $\begin{array}{cc}0 & 1 \\
1 & 3 \\
11 & 10 \\
11 & 17 \\
13 & 24 \\
30 & 31\end{array}$ & $\begin{array}{ll}1 \\
11 \\
11 \\
11\end{array}$ & $\begin{array}{ll}M & \\
1 & 0 \\
1 & 1 \\
1 & 12 \\
11 & 18\end{array}$ & $\begin{array}{l}00 \\
0 \\
13 \\
0 \\
\pi\end{array}$ & & $\begin{array}{l}1 \\
1 \\
18 \\
2\end{array}$ \\
\hline $\begin{array}{ll}0 & 1 \\
1 & 1 \\
11 & 11 \\
2 & 21 \\
n & x\end{array}$ & 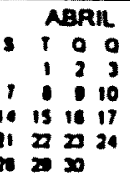 & $\begin{array}{c}3 \\
11 \\
25\end{array}$ & $\begin{array}{l}3 \\
12 \\
13 \\
2\end{array}$ & $\begin{array}{ll}0 & 8 \\
1 & 5 \\
11 & 12 \\
10 & 18 \\
10 & 28\end{array}$ & 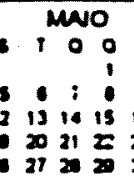 & $\begin{array}{l}3 \\
1 \\
10 \\
20 \\
0\end{array}$ & $\begin{array}{l}3 \\
3 \\
10 \\
11 \\
24 \\
31\end{array}$ & $\begin{array}{cc}0 & 8 \\
1 & 2 \\
1 & 1 \\
10 & 18 \\
0 & 20 \\
20 & 30\end{array}$ & $\begin{array}{l}5 \\
1 \\
18 \\
24\end{array}$ & $\begin{array}{ll}1 & \\
1 & 0 \\
3 & 4 \\
0 & 11 \\
10 & 10\end{array}$ & $\begin{array}{l}10 \\
0 \\
1 \\
11 \\
0\end{array}$ & 8 & $\begin{array}{l}3 \\
14 \\
21 \\
2\end{array}$ \\
\hline $\begin{array}{ll}0 & 1 \\
0 & 1 \\
11 & 1 \\
3 & 11 \\
21 & 2\end{array}$ & 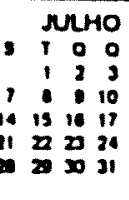 & $\begin{array}{l}3 \\
11 \\
11\end{array}$ & $\begin{array}{l}8 \\
5 \\
12 \\
18 \\
21\end{array}$ & $\begin{array}{ll}0 & 1 \\
3 & 11 \\
11 & 11 \\
11 & 11 \\
21 & 2\end{array}$ & 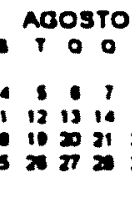 & $\begin{array}{l}3 \\
1 \\
15 \\
2 \\
2\end{array}$ & $\begin{array}{l}2 \\
2 \\
10 \\
20\end{array}$ & $\begin{array}{cc}0 & 1 \\
0 & 1 \\
1 & 18 \\
14 & 18 \\
21 & 20\end{array}$ & $\begin{array}{l}3 E \\
1 \\
11 \\
2 \\
2\end{array}$ & $\begin{array}{l}\text { TEM } \\
29 \\
210 \\
11 \\
11 \\
24 \\
0\end{array}$ & $\begin{array}{l}a R \\
0 \\
11 \\
11\end{array}$ & & $\frac{1}{13}$ \\
\hline
\end{tabular}




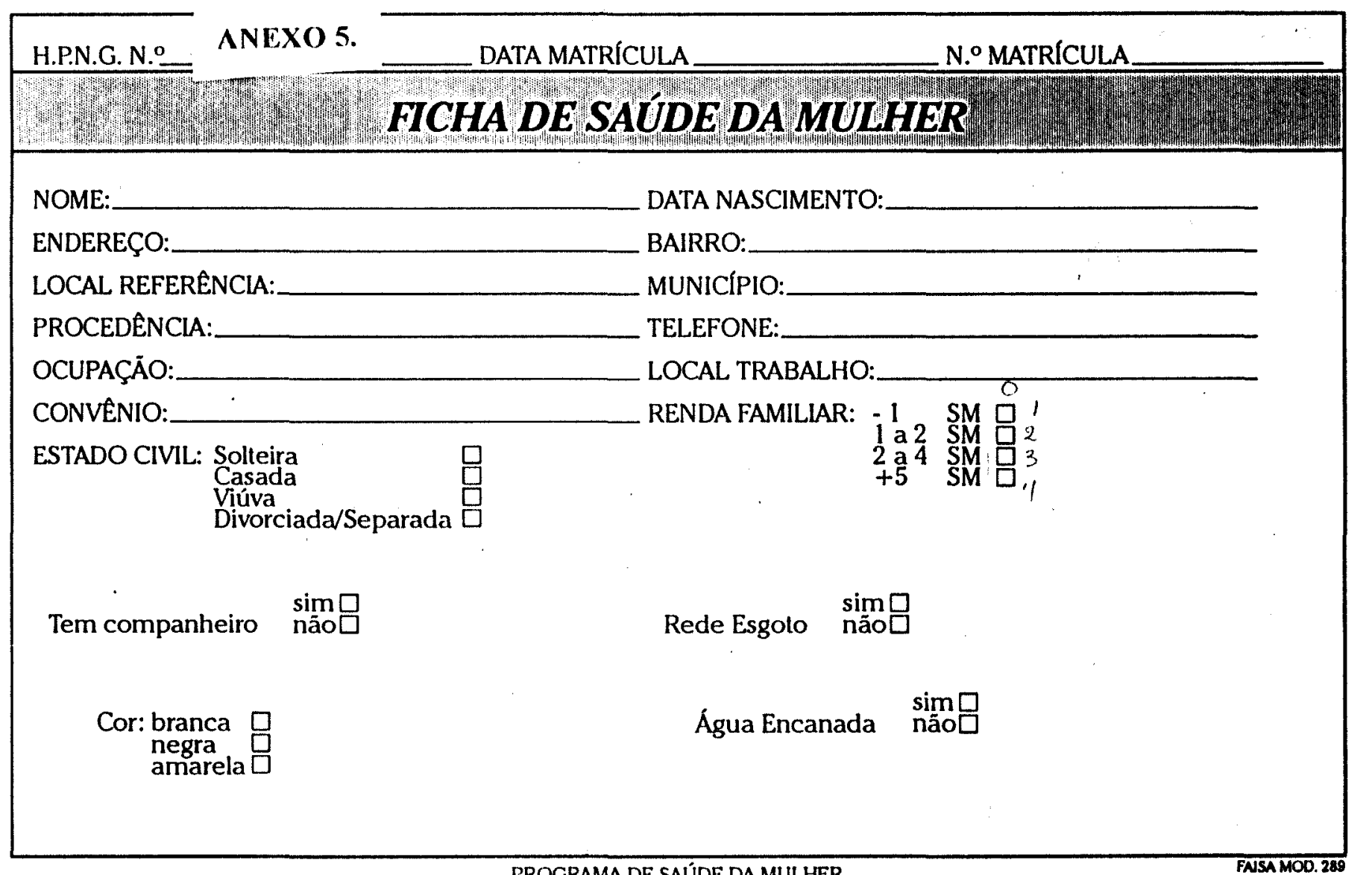




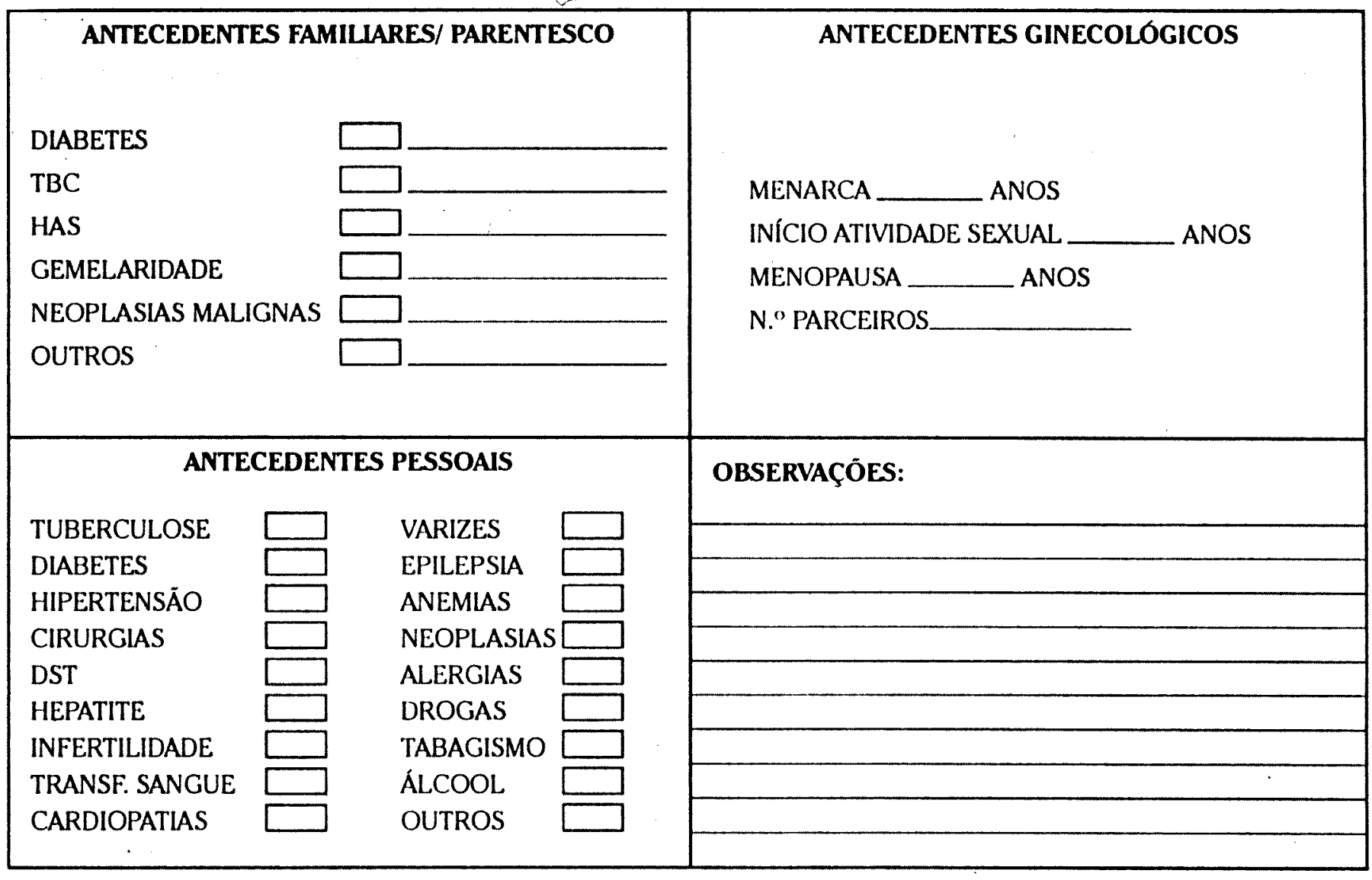




\begin{tabular}{|c|c|c|c|c|c|c|c|c|c|c|c|c|}
\hline \multicolumn{13}{|c|}{ ANAMNESE OBSTÉTRICA PREGRESSA } \\
\hline \multicolumn{3}{|c|}{ GRAVIDEZ } & \multirow{2}{*}{$\begin{array}{l}\text { PRÉ-NATAL } \\
\text { (LOCAL) }\end{array}$} & \multicolumn{3}{|c|}{ PARTO } & \multicolumn{2}{|c|}{$\begin{array}{l}\text { REVISAO } \\
\text { PUERPERAL } \\
\end{array}$} & \multirow[b]{2}{*}{$\begin{array}{l}\text { TEMPO } \\
\text { AMAMENTACAO }\end{array}$} & \multicolumn{3}{|c|}{ CONCEPTO } \\
\hline $\begin{array}{l}\text { GLSTAÇOEES } \\
\text { DATA }\end{array}$ & $\frac{\text { EVOLUCAO }}{A B}$ & & & DATA & TIPO & LOCAL & $\operatorname{SIM}$ & NÃO & & \multicolumn{2}{|c|}{ 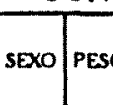 } & 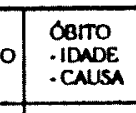 \\
\hline & & & & & & & & & & & & \\
\hline & & & & & & & & & & & & \\
\hline & & & & & & & & & & & & \\
\hline & & & & & & & & & & & & \\
\hline & & & & & & & & & & & & \\
\hline & & & & & & & & & & & & \\
\hline \multicolumn{13}{|c|}{ 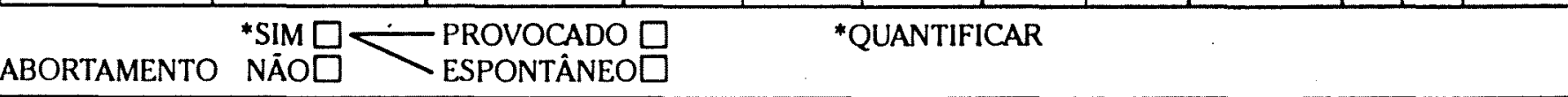 } \\
\hline \multicolumn{13}{|c|}{\begin{tabular}{|cc} 
& PLANEJAMENTO FAMILIAR \\
\end{tabular}} \\
\hline DATA & MÉTODO & \multicolumn{2}{|c|}{ QUEM INDICOU } & & \multicolumn{4}{|c|}{ INTERCORRÊNCIAS / CONDUTAS } & & \multicolumn{3}{|c|}{\begin{tabular}{l|l|l|}
\multicolumn{2}{|c}{ DATA } \\
INÍCIO & TÉRMINO \\
\end{tabular}} \\
\hline & & & & & & & & & & & & \\
\hline & & & & & & & & & & & & \\
\hline & & & & & & & & & & & & \\
\hline & & & & & & & & & & & & \\
\hline & & & & & & & & & & & & \\
\hline & & & & & & & & & & & & \\
\hline
\end{tabular}




\begin{tabular}{|c|c|c|c|c|}
\hline \multicolumn{4}{|c|}{ PREVENTIVO DE CÂNCER } & VACINAÇÃO CONTRA O TÉTANO \\
\hline \multicolumn{2}{|c|}{ CITOLOGIA CÉRVICO-VAGINAL } & \multicolumn{2}{|c|}{ EXAME DE MAMAS } & \multirow{6}{*}{$\begin{array}{l}\text { 1." Dose: } \\
\text { 2."a Dose: } \\
\text { 3." Dose: } \\
\text { Reforço: }\end{array}$} \\
\hline DATA & RESULTADO & DATA & RESULTADO & \\
\hline & & & & \\
\hline & & & & \\
\hline & & & & \\
\hline & & & & \\
\hline & & & & Observaçōes: \\
\hline & & & & \\
\hline & $\therefore \infty$ & & & \\
\hline & & & & \\
\hline & & & & \\
\hline & & & & \\
\hline & & & & \\
\hline & & & & \\
\hline & & & & $\cdots$ \\
\hline & & & & $\cdots$ \\
\hline e & & & & \\
\hline
\end{tabular}


F. A. I. S. A. ANEXO 6

CONSULTÓRIO N
H I G I E N E PRÉ - N A T A L

\section{ANAMNESE OBSTËTRICA ATUAL}

Data da $1^{a}$ Consulta Ulltima Menstruação

Celaléia

Caimbras

Miç̧ão

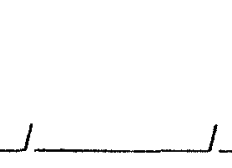
Vômitos Irritabilidade Corrimento Int. Agudas
MATRICULA Ne
Ordem da Gravidez

Apetite___________alorréia

Pert. Visuais

Edema

Mov. Felais

Prurido

Dor

Hemorragias

\section{EXAME FISICO GEAAL}

emperatura

Estado Geral

hucosas

Pele
Estatura

Const.

Gânglios
$\mathrm{FP}$

FC

Ap. Locomotor

Boca e Dentes

parelho Digestivo

parelho Respiratório

parelho Circulatório

Pulso

dema.

Varizes

Doloitos Físicos

istema Nervoso

Orgãos Sentidos

Psiquismo

Heóide Sist. Piloso

utrosdados

\section{EXAME OBSTÉTRICO}

lamas

bdome Forma

ulva

ero

hexos

acia: BE

elvigratia

Pigm.

Colostro Estrias

Vagina Tonturas Epigastralgia Defecação 
EVOLUÇÃO DA GRAVIDEZ

\begin{tabular}{|c|c|c|c|c|c|c|c|c|c|}
\hline Data & PESO & DA & Edema & $\begin{array}{c}\text { útero } \\
\text { (alt. circ) }\end{array}$ & Foco & Posição & Intercorrências & Tralamento & Médico \\
\hline & & & & & & & & & \\
\hline & & & & & & & & & \\
\hline & & & & & & & & & \\
\hline & & & & & & & & & \\
\hline & & & & & & & & & \\
\hline & & & & & & & & & \\
\hline & & & & & & & & & \\
\hline & & & & & & & & & \\
\hline & & & & & & & & & \\
\hline & & & & & & & & & \\
\hline & & & & & & & & & \\
\hline & & & & & & & & & \\
\hline
\end{tabular}

EXAMES COMPLEMENTARES

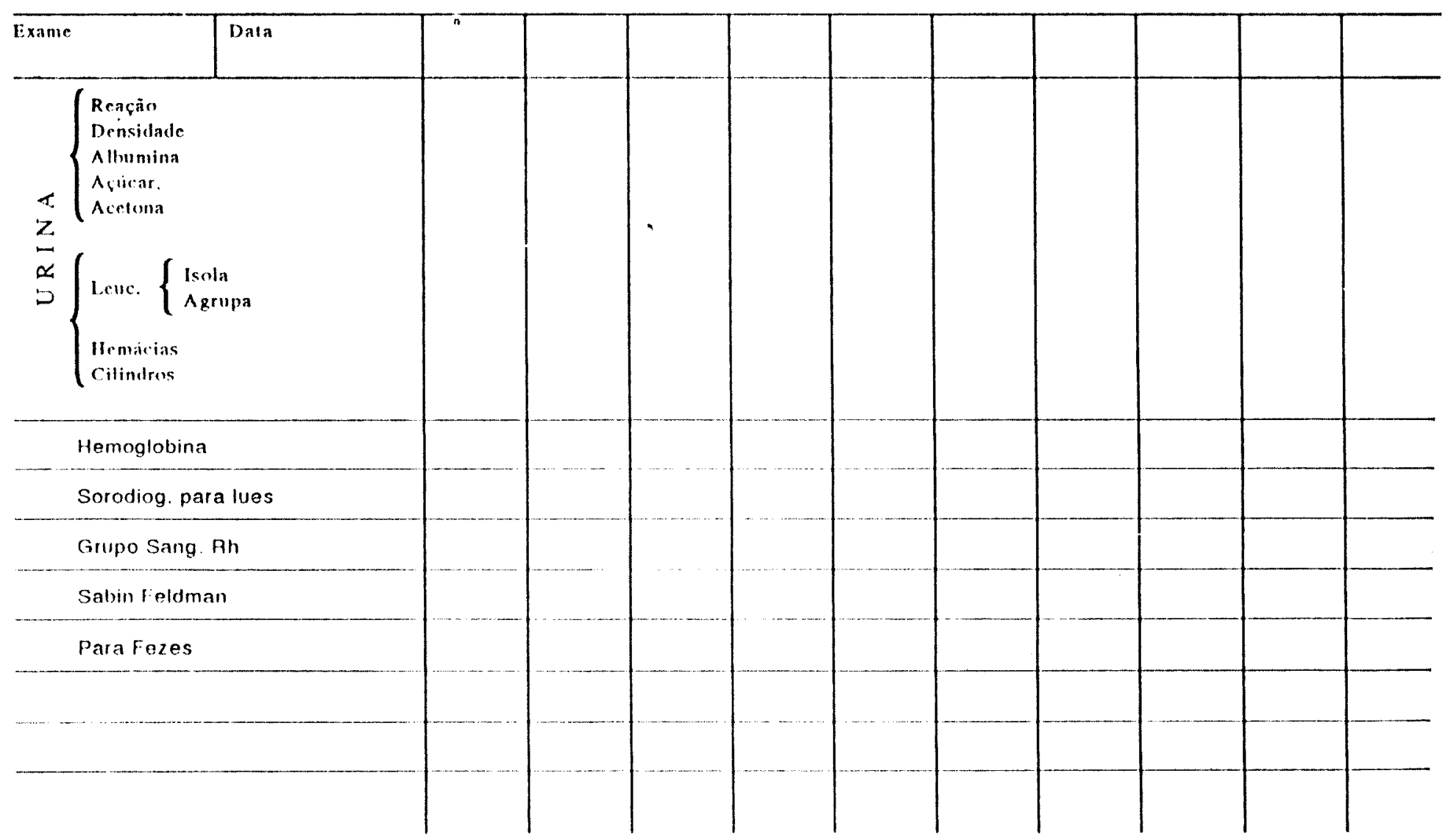




\section{ANEXO 7}

Anos escolares cursados por: gestante

chefe da familia

O que a senhora comeu ontem?

\begin{tabular}{|c|c|}
\hline ITEM & $\operatorname{sim}$ \\
\hline LEITE & - \\
\hline PĀO & \\
\hline OIJEIO & \\
\hline FRIOS & \\
\hline ARROZ & \\
\hline FEIIẢn & \\
\hline MACARRÃO & \\
\hline CARNE & \\
\hline PEIXE & \\
\hline ovn & \\
\hline FICAADO & \\
\hline FRANGO & \\
\hline SALSICHA LINGIJCA & \\
\hline FOLHAS VERDES & \\
\hline LECIMMES & \\
\hline FRIITAS & \\
\hline DOCES BOLO & \\
\hline BEBIDAS (alconl) & \\
\hline
\end{tabular}

Uso do sup'ilemento de ferro

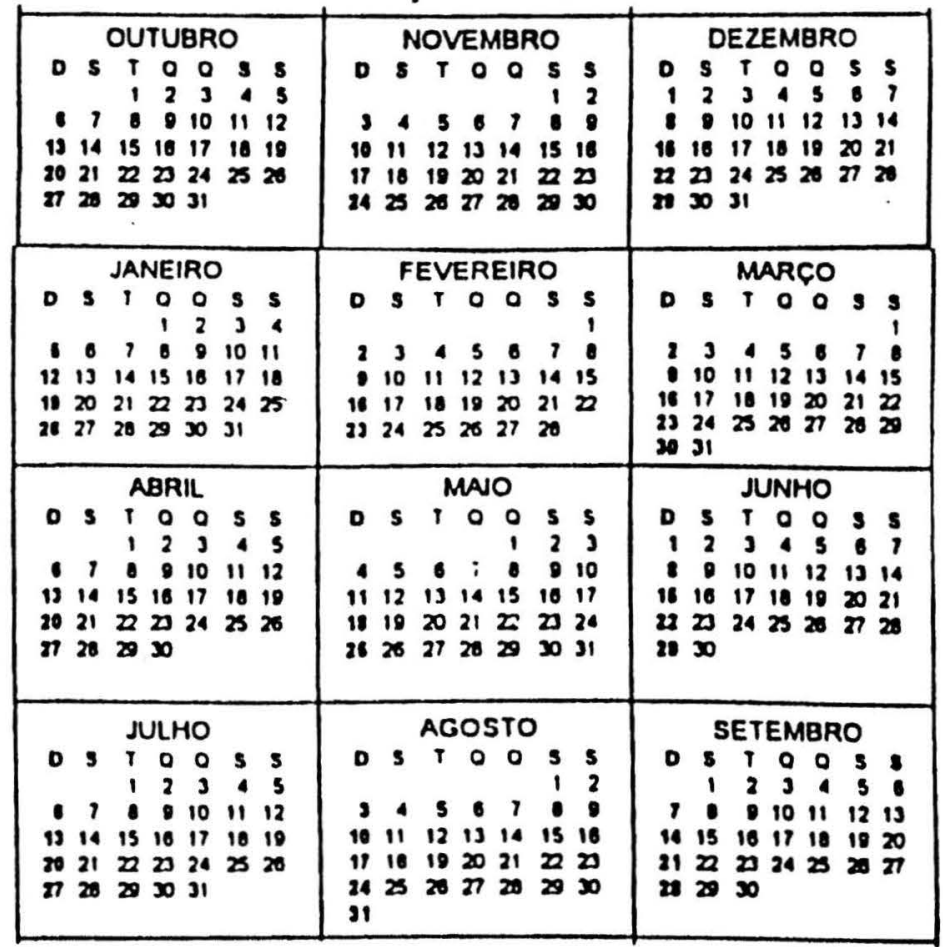


1997

Agosto

1997

\begin{tabular}{|c|c|c|c|c|c|c|}
\hline DOMINGO & SEGUNDA & TERÇA & QUARTA & QUINTA & SEXTA & SÁBADO \\
\hline & & & & & 1 & 2 \\
\hline 3 & 4 & 5 & 6 & 7 & 8 & 9 \\
\hline 10 & 11 & 12 & 13 & 14 & 15 & 16 \\
\hline 17 & 18 & 19 & 20 & 21 & 22 & 23 \\
\hline 24 & 25 & 26 & 27 & 28 & 29 & 30 \\
\hline 31 & & & & & & \\
\hline
\end{tabular}

1997

Setembro

1997

\begin{tabular}{|c|c|c|c|c|c|c|}
\hline DOMINGO & SEGUNDA & TERÇA & QUARTA & QUINTA & SEXTA & SÁBADO \\
\hline & 1 & 2 & 3 & 4 & 5 & 6 \\
\hline 7 & 8 & 9 & 10 & 11 & 12 & 13 \\
\hline 14 & 15 & 16 & 17 & 18 & 19 & 20 \\
\hline 21 & 22 & 23 & 24 & 25 & 26 & 27 \\
\hline 28 & 29 & 30 & & & & \\
\hline
\end{tabular}

\section{7}

Outubro

1997

\begin{tabular}{|c|c|c|c|c|c|c|}
\hline DOMINGO & SEGUNDA & TERÇA & QUARTA & QUINTA & SEXTA & SÁBADO \\
\hline & & & 1 & 2 & 3 & 4 \\
\hline 5 & 6 & 7 & 8 & 9 & 10 & 11 \\
\hline 12 & 13 & 14 & 15 & 16 & 17 & 18 \\
\hline 19 & 20 & 21 & 22 & 23 & 24 & 25 \\
\hline 26 & 27 & 28 & 29 & 30 & 31 & \\
\hline
\end{tabular}

\section{7}

Novembro

1997

\begin{tabular}{|c|c|c|c|c|c|c|}
\hline DOMINGO & SEGUNDA & TERÇA & QUARTA & QUINTA & SEXTA & SÁBADO \\
\hline & & & & & & 1 \\
\hline 2 & 3 & 4 & 5 & 6 & 7 & 8 \\
\hline 9 & 10 & 11 & 12 & 13 & 14 & 15 \\
\hline 16 & 17 & 18 & 19 & 20 & 21 & 22 \\
\hline 23 & 24 & 25 & 26 & 27 & 28 & 29 \\
\hline 30 & & & & & & \\
\hline
\end{tabular}

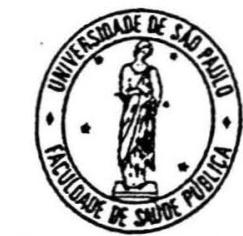

UNIVERSIDADE DE SÃO PAULO FACULDADE DE SAÚDE PÚBLICA DEPARTAMENTO DE NUTRIÇÃO NUPENS/USP

FAISA

ANEXO 8

\section{PROJETO:}

"INTERVENÇÃO NUTRICIONAL NO CONTROLE DA ANEMIA FERROPRIVA EM GESTANTES

\section{Mãe,}

A anemia é uma doença causada pela falta de ferro no organismo. Quando a gestante tem anemia ela se cansa facilmente, sente-se fraca, fica descorada e menos resistente à infecções. A anemia prejudica muito a qualidade da gestação e, portanto, a saúde do seu bebê que vai nascer, aumentando o risco de parto prematuros, baixo peso ao nascer e mesmo, de morte da criança antes do nascimento e nos seus primeiros dias de vida.

Praticamente todas as mulheres se tornam anêmicas quando engravidam porque, com o crescimento da criança, aumenta muito a necessidade de ferro. Para evitar que isso ocorra é necessário aumentar 0 consumo de ferro ingerindo um medicamento. Estamos fornecendo esse medicamento que deve ser tomado, de meia a uma hora antes da refeição, nos dias e na quantidade indicados pelos médicos do posto, a partir da data de entrega do frasco até 1 mês após o parto.

Marque neste calendário com um $X$ cada vez que tomar 0 remédio. Quando não tomar, marque o motivo. Traga o calendário quando vier ao Posto para marcarmos o próximo retorno. 


\section{6}

\section{Dezembro}

1996

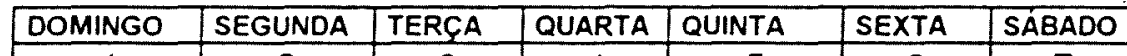

\begin{tabular}{|c|c|c|c|c|c|c|}
\hline 1 & 2 & 3 & 4 & 5 & 6 & 7 \\
\hline 8 & 9 & 10 & 11 & 12 & 13 & 14 \\
\hline 15 & 16 & 17 & 18 & 19 & 20 & 21 \\
\hline 22 & 23 & 24 & 25 & 26 & 27 & 28 \\
\hline 29 & 30 & 31 & & & & \\
\hline
\end{tabular}

\section{7}

Janeiro

1997

\begin{tabular}{|l|l|l|l|l|l|l|}
\hline DOMINGO & SEGUNDA & TERÇA & QUARTA & QUINTA & SEXTA & SÁBADO \\
\hline
\end{tabular}

\begin{tabular}{|c|c|c|c|c|c|c|}
\hline & & & 1 & 2 & 3 & 4 \\
\hline 5 & 6 & 7 & 8 & 9 & 10 & 11 \\
\hline 12 & 13 & 14 & 15 & 16 & 17 & 18 \\
\hline 19 & 20 & 21 & 22 & 23 & 24 & 25 \\
\hline 26 & 27 & 28 & 29 & 30 & 31 & \\
\hline
\end{tabular}

\section{7}

\section{Fevereiro}

1997

\begin{tabular}{|c|c|c|c|c|c|c|}
\hline DOMINGO & SEGUNDA & TERÇA & QUARTA & QUINTA & SEXTA & SÁBADO \\
\hline & & & & & & 1 \\
\hline 2 & 3 & 4 & 5 & 6 & 7 & 8 \\
\hline 9 & 10 & 11 & 12 & 13 & 14 & 15 \\
\hline 16 & 17 & 18 & 19 & 20 & 21 & 22 \\
\hline 23 & 24 & 25 & 26 & 27 & 28 & \\
\hline
\end{tabular}

\section{7}

\section{Março}

1997

\begin{tabular}{|l|l|l|l|l|l|l|}
\hline DOMINGO & SEGUNDA & TERÇA & QUARTA & QUINTA & SEXTA & SÁBADO \\
\hline
\end{tabular}

\begin{tabular}{|c|c|c|c|c|c|c|}
\hline & & & & & & 1 \\
\hline 2 & 3 & 4 & 5 & 6 & 7 & 8 \\
\hline 9 & 10 & 11 & 12 & 13 & 14 & 15 \\
\hline 16 & 17 & 18 & 19 & 20 & 21 & 22 \\
\hline 23 & 24 & 25 & 26 & 27 & 28 & 29 \\
\hline 30 & 31 & & & & & \\
\hline
\end{tabular}

1997

Abril

1997

\begin{tabular}{|l|l|l|l|l|l|l|}
\hline DOMINGO & SEGUNDA & TERÇA & QUARTA & QUINTA & SEXTA & SABADO \\
\hline
\end{tabular}

\begin{tabular}{|c|c|c|c|c|c|c|}
\hline & & 1 & 2 & 3 & 4 & 5 \\
\hline 6 & 7 & 8 & 9 & 10 & 11 & 12 \\
\hline 13 & 14 & 15 & 16 & 17 & 18 & 19 \\
\hline 20 & 21 & 22 & 23 & 24 & 25 & 26 \\
\hline 27 & 28 & 29 & 30 & & & \\
\hline
\end{tabular}

\section{7}

Maio

1997

\begin{tabular}{|l|l|l|l|l|l|l|}
\hline DOMINGO & SEGUNDA & TERCAA & QUARTA & QUINTA & SEXTA & SÁBADO \\
\hline
\end{tabular}

\begin{tabular}{|c|c|c|c|c|c|c|}
\hline & & & & 1 & 2 & 3 \\
\hline 4 & 5 & 6 & 7 & 8 & 9 & 10 \\
\hline 11 & 12 & 13 & 14 & 15 & 16 & 17 \\
\hline 18 & 19 & 20 & 21 & 22 & 23 & 24 \\
\hline 25 & 26 & 27 & 28 & 29 & 30 & 31 \\
\hline
\end{tabular}

\section{7}

\section{Junho}

\section{7}

\begin{tabular}{|c|c|c|c|c|c|c|}
\hline DOMINGO & SEGUNDA & TERÇA & QUARTA & QUINTA & SEXTA & SÁBADO \\
\hline 1 & 2 & 3 & 4 & 5 & 6 & 7 \\
\hline 8 & 9 & 10 & 11 & 12 & 13 & 14 \\
\hline 15 & 16 & 17 & 18 & 19 & 20 & 21 \\
\hline 22 & 23 & 24 & 25 & 26 & 27 & 28 \\
\hline 29 & 30 & & & & & \\
\hline
\end{tabular}

1997
\begin{tabular}{|c|c|c|c|c|c|c|}
\hline DOMINGO & SEGUNDA & TERÇA & QUARTA & QUINTA & SEXTA & SÁBADO \\
\hline & & 1 & 2 & 3 & 4 & 5 \\
\hline 6 & 7 & 8 & 9 & 10 & 11 & 12 \\
\hline 13 & 14 & 15 & 16 & 17 & 18 & 19 \\
\hline 20 & 21 & 22 & 23 & 24 & 25 & 26 \\
\hline 27 & 28 & 29 & 30 & 31 & & \\
\hline
\end{tabular}




\section{N Latex-Ferritina}

Campos de aplicación y objetivos

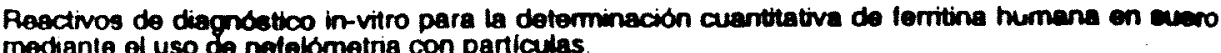

Significado dlagnósilico

La concentractón de lentina sérica está directamente relacionade con las reservas do hlorro en ol

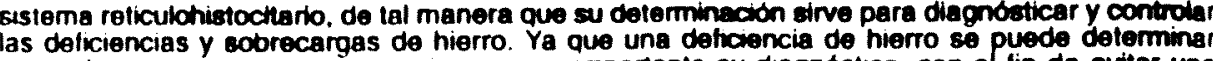
antes de que aparezca una anemia. es muy impontante su dagnóstico. con el fin de evitar una anemia ocasionada por desnutrición. Las reservas de hierro se juzgaban antes clinicamente por de saturación de la Iranslerrina (coeficiente oblenido del contenido de hierro serico y ye la capeca. dad tolal de lifación de hierro) o por medio de una investigación de la medula osea. Eslos melocis trenen el inconventente de no poder distinguir entre un agotamiento de las reservas de hierro y has be la delerminación de fermina como un método sensible y seguro para el reconocimienta dermpre. no de una deficiencia de hierro (2). Además. se puede tamosen conprot

En inflamaciones crónicas inlecciones, neoplasias y en insuficiencia renal crónica se encuentra un aumento del nivel de ferritina sérca. La correlación de fermtina en el suero y las reservas de herro

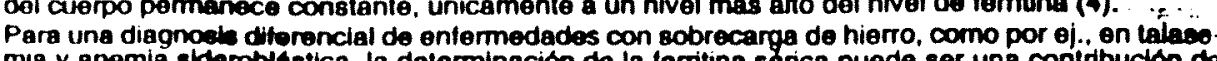
mia y anemia eltarobiastica, la delerminación de la lerritina sernce puede ser una conitibuclón de quelantes en enlermedades de sobrecarga de twerro.

Aumentos patolbgicoe de la concentración de tertitina se han oncontrado tamblén en carcinomís de ovario (6) y de conos (7), al igual que en beucemias y untomas (8,9). Junto con au uillidad cor ca como marcador tumoral para el lratamiento y el proceso de control de pacientes con tumores En lodos los casos se debe lener en cuenla que existe una diferencia on la concentración normal
de lermina en evero que depende de la edad y que es especifica del sexo. Principio del método

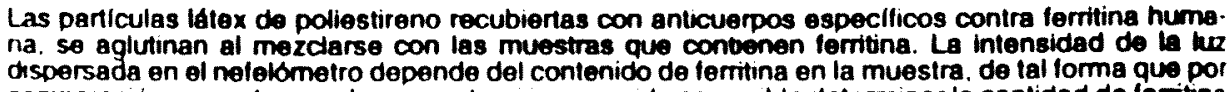
comparación con patrones de concentracion conocida es posible determinar la cantidad de lerritina

Reactivos

Contenldo del envase comerclal:

Kit de $N$ Lalex-Feritina ( $N^{\circ}$ de pedido OODD)

$3 \times$ para $3 \mathrm{ml}$ Reactivo $\mathrm{N}$ Lalex.Fermtina

$3 \times$ para $1 \mathrm{ml}$ Reactivo adicional A-N Ferritina

x para $3 \mathrm{ml}$ Reactivo adicional B-N Ferritina

$3 \times$ para $0.5 \mathrm{ml}$ Estándar $\mathrm{N}$ Feritina (humano)

$3 \times$ para $1 \mathrm{ml}$ Control I N Forritina (humano)

$3 \times$ para $1 \mathrm{ml}$ Control II N Ferritina (humeno)

Compoeletón:

El Resctivo $N$ Letex-Forrtina es un liofilizado de particulas de poliestireno recubiertas con un

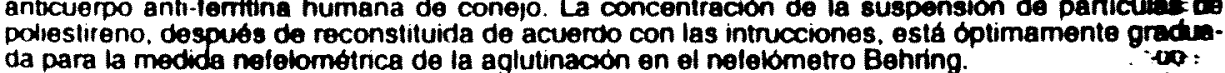
da para la medida nefelométrica de la aglutinación en el nelelómetro Behring.
El Reactivo ediclonal A-N Ferrilina está formado por una solución de suero de conejo coli ph-1 Ei Reectivo edkctonal B-N Forrtina está tomado por una solución de delergentes con pH repulaUna inazcla de las dos eoliciones adicionales sive para reducir las alteraciones ccasionadas por
los lactores reumatoveos. El estundar $N$ Fentitina es una mezcla de sueros humanos a los que se les añadio territina. E estandar presenta la concentración de lerntina dada en la etrqueta (en $\mu \mathrm{g} /$ ). La calibración se hace Los Controles N Fertitina son una mezcla de sueros humanos a los que se les ańadio ferritina numana. Los controles presentan la concentracion de lernitina dada en la etiquela.

Medio de coneervaclon:

Heactivos despues de la reconstitucion: Gentamicin $6.25 \mathrm{mg} /$

Amlolencin $0.625 \mathrm{mg}$

Azida de sodio $<1$ gn

Amtotencin $1.25 \mathrm{mgh}$

Heactivos adicconales: Azida de sodio $<1$ gl

Advertencisa y medidas de seguridad

2. En el manejo de diagnosticos in-vitro que comengan azida sódica debe observarse la siguiende regla: No ingerir y evitar contacto con la pret y mucosas. La azida sódica puede formar aztides Cada donación individual de sangre. destinada a la preparación del estandar N Ferritina o de los controles N Fenitina, ha sido sometida a pruebas para delectar el antigeno de la hepautis
(HBSAG). antitHCV y anti-HIV. Para la elaboración solo se utilizan donaciones con resultados negativos independ y na (por ê. suevos de pacientes) y productos (por ej. sueros estándar y de control) deben eer manipuladas con las procauciones necessanas. siquiendo las medidas de seguridad recomen-
dadas en caso de riesgo biologico. puesto que nunca se puede excluir completamente el peligro dadas en caso do riesgo biologico. puesto
de una contaminacion bactenana (10)

Preperacion de rescttros:

Reactivo N Latox-ferrtuna: Pesuspender el liofilizado contenido on un Irasco en $3.0 \mathrm{ml}$ de egue le. Cada dia. antes do ser usado.

Resctivos adicionnios N Forrilina: Pipelear $1 \mathrm{~m}$ del reactivo adicional B-N Ferritins en un Irasco det reactivo adicional A.N Fomitina: mezclar por agración sueve.

El estandar $N$ Ferttina y los controles $N$ Forrtente vienen listos para ser usadoe.

Estabillad y condictones do almacenamiento

Todos los componentes del lestkh, aun cerrados y conservados entre $+2 y+8^{\circ} \mathrm{C}$. 80 pueden untura

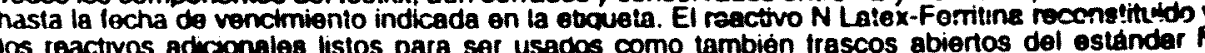
los reactivos adicionales listos para ser usados como también irascos abiertos del estander
Ferntana y de los controles $N$ Fernitina pueden ser uilizzdos durante 2 semanas. Frescos abiontos

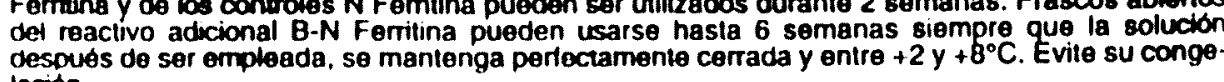

Mrterial edicionel neccearto:

Sisterne Noletomatrico de Behning

N onlivente. $N^{n}$ de pedido OUMT

Orros malenales venen descritos en el manual de operaciones del nelelómelro.

Material a Investlgar

Como malenal de investipacion se deben usar. on lo posible. muestras de suero numano ireacas imax. conservadas 8 dias ontre +2 y $+B^{\circ} \mathrm{C}$ ) o mivasiras congeladas. Las muestras se pueden toner

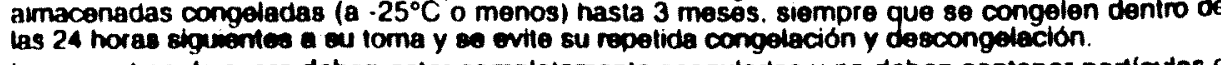
Las muesiras de suero deben estar comptelamente coaguladas y no deben contener particutas o Las mues tras de surero deben estar completarmen
restos de honna. despues de la contritugacion.

Las muestras de suero heremente lipemicas o las muestras congeladas. que presenten turtidiez después de su descongelaciod
(10 min a aprox $15000 \mathrm{~g})$.

\section{Método}

Procedimiento

1. Para una delallada inlomedión se aconeoja loer el manual de operacionas del neletometro

1. Para una det

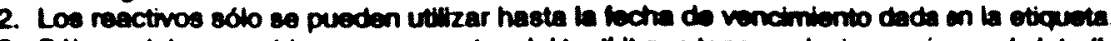

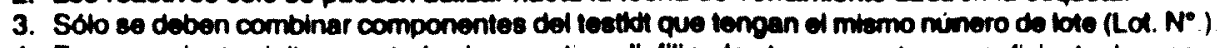

4. Es conventente vigllar, que todos los reactivos llolilizados longan un bermpo suficiente de recon

5. Los reactivos y las muestras tionon que cetar a lemperatura ambiento mes de ser usados

8. La modida de las muestras on of BNA y on el BN 100 se dobe electuar a la mama lemperatura Imax. $2^{\circ} \mathrm{C}$ de desviacion) en la que so realizo la curva de calloractún.

Equerma de olaboración para el netelómotro Behring (Teat- $N^{\circ}$ 50)

Todas las elapas son realizadas automáticamento por el aparalo.

25 ul Reactrvos adicionales N-Ferritina. lislos para of weo

80 ul Dilucion de la muestra, estandar o controles

$65 \mu \mathrm{N}$ diluyente

- pipetear en la cubeta
$40 \mu 1$ Reactivo $N$ Latex-Ferritina

- pipetar en la cubela, egitar

- medir la señal después de 12 min

Preparación de le curva de roterenola:

La concentración de ferrtina humana del estandar N Fortina viene dada en la etiguela. En a ne con ol $N$ dilupente: $1: 20,1: 40,1: 80,1: 160,1: 300$

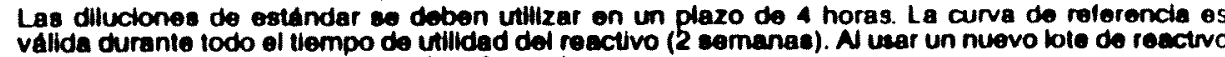
se do hacer una nueva curva de reterencla.

Modida de las muestrase de peclemese:

Las muestras de pacientes se dillyyen automáticamente 1 : 5 con $\mathrm{N}$ dilicyente y deben usarse dentro Advertencle:

Si las sehales de las muestras de suero se encuentran por luera de le curva de relerencia se debe una cuantificacion (viene integrada en el soltware).

Control de calldad interno:

Para controlar la exactitud y la precisión de la determinación cuantitativa de femtina con of nelelo. metro Behring. Se debe medir con cada serie de muestras los controles $N$ Fernitina. Los coniroles se deben tratar y calcular como las muestras de pacientes. El valor teonco de los controtes se debe Catculo de los resuttados del andilis:

Los resultados se calculan automáticamente mediante una lunción log-togit

Limitaclones y fuentes de error:

Las alleraciones causadas por los tactores reumáticos se disminuyen usando los reactivos adicie

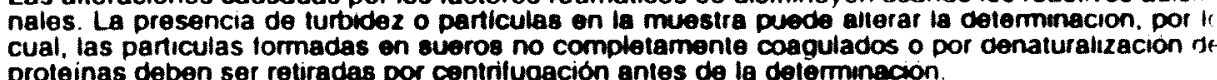
Muestras ahamenle lipermicas deben ser aclaradas por cenlillugación (10 min a $15000 \times$ g).

Valores de referencla

La concentración de lemitina en suero de personas clinicamente sanas depende de la edad y de Sexo y presenta un rango de dusperción muy ampito. Es cordon umblical contiene entre 100 a $250 \mu g$ h. En los dos prime.

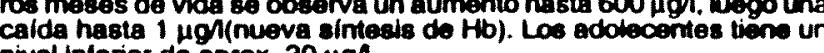

$26 \cdot 306 \mu \mathrm{gn}$
$7-130 \mu \mathrm{g}$

Hombres

Mujeres(postmenopausia): $\quad 27-298 \mu \mathrm{gh}$

omar como valores intormativos. Cada laboratono debe de lener sus propios valores de reterencia

Características del test

Rango de modida y eonsibilloded:

El rango de relerencia del reactivo N Lalex-Ferrilina eslá comprendido entre 5 y $320 \mu g /$ para una La sensiblidad se fija con el limine infertor de la curva de relerencia y depende de la conceniracio de lerritina en el estandar. Un limitio tipico de delecctón para lerritina es de 5 ugh en diluciones de Eapecificidad:

Leterminacion es especlfica para fertitine.

Precisión y reproduclbillided:

Con el kit N Latex-Ferritina se midheron 5 concentraciones dilerenles de fermina laprox. 5. 15.30

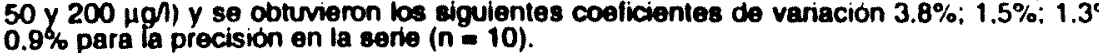
Con otras 5 concentraciones de lerritina (aprox. $5.30,45,60$ y 160 ug/l) se encontraron coeficiente Comparación de mbiodos:

44 muestras de sueros (concentraciones de lerritina de hasta aprox $200 \mu 9 /$ ) fueron comparadas con ef kh $N$ Latex. Ferritina (y) y con un inmunoensayo similar existente en el comercio $(x)$ y analiza
das. Al comparar los resultados, por análisis de regresión lineal, se obluvo la siguiente linea de

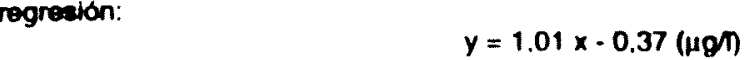

\[ y=1.01 \times-0.37(\mu g / n) \]
Al comparar con un radioinmunoensayo existenie en el comercio el análisis de regresión lineal dic,

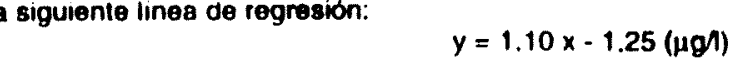

Nola:

Los valores dados para las caracteristicas del test representan valores florcos y no se deben toma:

Literatura

1. Fairbanks VF. Laboratory teating for iron status. Hoepital Practice 26 (Supptement 3): 17.24 (1991

2. Burns ER. Goldberg SN. Lawrence CH. Wenz B. Clinical utility or serum tesis tor ron deficienc
in hospitaized patients. Am J Clin Pathol 93: 240-245 (1990).

3. Cook JD. Skikne BS. Lymch SR. Serum lenttin in the evaluation of anemia. In: Albertin A. editor. Padic
immunoassay of Hormones. Proteins and Enzrmes. ExcorptaMedica. Amsterdam 1880: 239.248.

4. Jacobs A. Palh FRC. Worwood M. Ferritin in serum: Clinical and bioctiemical implications. N

5. Hershko $C$. Koniin AM. Loria A. Serum territin and mean corpuscular voturne measurement in me

6. Yuan CC. $\mathrm{Na} \mathrm{HT}$. Yeh SH, Chen SS, Heu DS. Ho CH. Hyperterntemema in ovanan cancer. J

6. Fuarod Med 33: 193-195 (1988).

7. Marcus DM. Zinberg N. Measurement of senum lerritin by radioummunoassav: Results in norma'

8. Domer MH Abel U. Fritze $D$. Hodgkin's Disease. Cancer $52: 2308-2312$ (1863)

9. Aulbert E. Schmidt CG. Ferritin - A turnor marker in myelold loukemia. Cancer Delect Prev B

0. Biosalety in Microbiological and Biomedical Laboratories. U.S. Department of Health and HU
man Services. Washingion 1993 (HHS Publication No. (COC) 93-8395)

Fabricante: Behningwerko AG

D-35001 Maturos 


\section{ANEXO 10. FERRO TRANSFERRINA \\ Somente para \\ uso in vitro

DEFINICAO

O teste executado no soro identifica o nivel de Ferro ligado a

Translerrina que o transporta para a medula ossea.

\section{PATOFISIOLOGIA}

O Forro usado na sintese de Hemoglobina. Apos a ingestáo o Ferro absorvido dentro do intestino e se liga com a Transferrina a qual o transporta a medula óssea, onde a Hemoglobina fabricada Quando os niveis de Ferro estáo diminuidos a TIBC tambem esta diminuida, quando os niveis de Ferro estáo aumentados a TIBC tambem estard

\section{SIGNIFICADO CLINICO}

Vide bula Ferro - Mótodo Colorimetrico

\section{INTERFERÉNCIAS}

Vide bula Ferro - Metodo Colorimetrico

\section{METTODO}

Colorimetrico de Ponto Final

Este Kit deve ser usado em conjunto com o Kit de Ferro - Metodo Colorimetrico da LABORLAB.

\section{LINEARIDADE E ESTABILIDADE DA REACAO}

Vide bula Ferro - Metodo Colorimétrico.

\section{COMPOSIÇAO DO KIT}

Reativo Saturante - CAT 01801

Soluçáo establlizada de Fe III, equivalente a $1 \mathrm{mg} / \mathrm{dt}$

Volume $=30 \mathrm{~mL}$

Reatlvo Adsorvente - CAT 01802

Carbonato de Magnesio $50 \times 80 \mathrm{mg}$

50 copsulas

\section{MATERIAL NAO FORNECIDO (NECESSARIO)}

Vide bula Ferto - Metodo Colorimetrico

Tubos de centriluga (Kahn)

VIDA ÚTIL E ARMAZENAMENTO

O Kit e estavel a temperatura ambiente ate a dala de vencimento impressa na caixa

\section{AMOSTRA}

Vide bula Ferro - Melodo Colorimetrico.

\section{TÉCNICA}

\section{A - SATURACAO DA TRANSFERRINA}

Em um tubo de Kahn, colocar $500 \mu \mathrm{L}$ de soro e $500 \mu \mathrm{L}$ de Reativo Saturante, homogeneizar e deixar em repouso por 5 minutos a $37 \mathrm{C}$. Após, colocar o conteúdo de uma capsula de Reativo Adsorvente no lubo. Tampar agltar por 5 minutos a temperatura amblente.

A agitaça deve ser vigorosa e em sentido longitudinal.

Centrifugar 10 a 15 minutos a 3 ou $4 \times 1000 \mathrm{rpm}$, ate obter um sobrenadante limpido ou com a opalescencia propria do soro.

\section{B - COLORIMETRIA}

Em 3 Tubos de ensajo marcados: B (Blank), P (Padrảo) - D (Desconhecido), colocar com micropipeta:

$\begin{array}{lccc} & B & & \text { D } \\ \text { Agua deionizada } & 500 \mu \mathrm{L} & - & - \\ \text { Padrao } & - & 500 \mu \mathrm{L} & - \\ \text { Sobrenadanle } & - & - & 500 \mu \mathrm{L}\end{array}$

- agregar os reativos do KH Ferro - Metodo Colorimetrico. como indicado na tecnica do mesmo.

\section{CALCULOS}

Corrigir as leituras e efoluar os calculos de mesma maneira que na dosagem do Ferto Colorimbtrico, multiplicando o resultado final por 2 (Fator de diluiça do soro)

Habitualmento a determinaço do Ferro Strico se realiza juntamento com a dranterrine (nesto caso inicier a Saturacto de Transterina 30 minutos antes) e o possivel informar 3 valores: Forro Serico. Transferina - Saturaça \% que calculada da seguinte forma:

$$
\text { SaturaçAo \% }=\frac{\text { Forio Sorico } \mu \mathrm{g} / \mathrm{dL}}{\text { Transterrina } \mu \mathrm{g} / \mathrm{dL}} \times 100
$$

VALORES DE REFERENCIA

Transforina (TIBC) $\quad-250: 400 \mu g / d L$

Saturacho de Transtertina = 20 . $55 \%$

\section{OBSERVAÇOES}

- A agitaça insuficiente produz valores falsamente aumentados de Transferrina.

- A concentraço de Fe lli no Reativo Saturante e $10 \times$ maior que - do Reativo Padráo, portanto, náo medir esse Reativo com a mesma micropipela useda com os Desconhecidos e Reativo Padráo. Podo-so utilizar uma pipela de $1 \mathrm{~mL}$ para medir o Reativo Saturante, pois essa medida nso o critica.

\section{APRESENTACAO}

Kit suficiente para processar 50 amostras de soro

\section{BIBLIOGRAFIA}

1-Dixon, K. - Ann. Clin.Biochem 10/5:127 (1973)

2.ICSH-AM J.Clin Palh .56/4.543 (1971) 


\section{CATN. 01700}

Somente para

uso in vitro

\section{FERRO MÉTODO COLORIMÉTRICO}

DEFINICAO

O teste executado no soro sanguineo para identificar o nivel do metal, necessário que está presente em diminutas quantidades no corpo humano.

PATOFISIOLOGIA

O Ferro utilizado na sintese da Hemoglobina. Após a ingestáo o Ferro absorvido no intestino ligado a Translerrina que o transporta para a medula óssea onde a Hemoglobina é fabricada. SIGNIFICADO CLINICO

Valores elevados - Anemia hemolitica perniciosa, deficiéncia de acido tolico. intoxicaços por chumbo. insuficiencia hepatica. talassemia, deficiencia de piridoxina.

Valores baixos- Anemia Ferropriva, cancer gastrointestinal, cancer do seio. insuficiencia renal crónica, úcera peptica, gravidez (20 a 40 semanas) recem-nascido com pouco peso.

INTERFERENCIAS

Valores lalsamente elevados - Suplemento de Ferro, anticoncepcional oral, hemolise.

METODO

Colorimélrico de Ponto Final

LINEARIDADE E ESTABILIDADE DA REAÇAO

A reaça o linear at $500 \mu \mathrm{g} / \mathrm{dL}$

A cor final da reaçáo es estável entre 6 e 20 minutos

\section{COMPOSICAO DO KIT}

Reatlvo Padrato - CAT 0170

Soluça de lons de $\mathrm{Fe}$ lit, equivalente a $100 \mu \mathrm{g} / \mathrm{dL}$

Volume $=20 \mathrm{~mL}$

Reativo PBTS - CAT 01702

Soluçáo estabilizada de Piridil

Bis-fenil Triazina Sultonato $=50 \mathrm{mmol} / \mathrm{L}$

Volume $=7 \mathrm{~mL}$

Reatlvo Tamplo CAT 01703

Soluço de succianato $=0.25 \mathrm{mmol} / \mathrm{L}, \mathrm{pH}=3,7$

Volume $=200 \mathrm{~mL}$

Reatlvo Redutor CAT 01704

Ampola contendo Acido Mercaploacético a $70 \%$

Volume $=3 \mathrm{~mL}$

ATENCAO: O Reativo Redutor em contato com a pele causa graves quelmaduras.

MATERIAL NAO FORNECIDO (NECESSARIO)

Agua deionizada (vide IMPORTANTE)

Espectrofotómetro ou colorimetro.

Micropipetas o pipetas capazes de medir os volumes indicados na tecnica. (vide IMPORTANTE)

Tubos de ensaios para o aparelho a ser utllizado.(vide IMPORTANTE)

\section{PREPARACAO DO REATIVO TAMPAOIREOUTOR}

Transferir o conteudo da Ampola do Reativo Redutor para o Frasco do Reativo Tampao (verter o conteudo da ampola diretamente sobre o Reativo Tampao), tampar o frasco, homogeneizar por inversao.

Anotar no rólulo a data da preparaço.

O Reativo Tampéo/Redutor estável por 1 ano refrigerado.

Levá-lo a 18-30 C antes de usar.

VIDA ÜTIL E ARMAZENAMENTO

O Kit estavel a temperatura ambiente até a data do seu vencimento impressa na caixa.

IMPORTANTE

LIMPEZA DO MATERIAL

Todo o material a ser usado na técnica deve estar livre de Ferro Deve-se deixar o mesmo submerso em uma soluçâo de Acido Cloridrico p.a a $10-15 \%$ por 6 horas, apos, eliminar a acidez com

Reg.M.S $n^{0} 10246810020$

LABORLAB S/A PRODUTOS PARA LABORATORIOS Estr.dos Romeiros, 2369

Fone: (011) 7298-4421 (Central de Atendimento ao Cliente) numerosas lavagens com agua deionizada (livre de Ferro). Secar o material a no máximo $80 \mathrm{C}$. em estantes de aço inox ou revestidas de plástico.

O material assim tratado deve ser utillzado exclusivamente na determlnaça de Ferro.

AGUA DEIONIZADA

E fundamental o uso de água absolutamente livre de Ferro, tanto na lavagem do material como na utilizada no Blank de Reativos.

O ideal agua delonizada com condulividade menor que O.O2yiohms.

VALORES DE BLANKS ACEITAVEIS

A leitura do Blank de Reativos em Absorbancia não deve ser superior a 0.150 , a água delonizada deverá ter uma desprezivel contribuiço nesta leitura.

Para controlar esse Blank recomenda-se ler um Blank de Reativos (2 mL de Tampáo/Redutor $+0.5 \mathrm{~mL} \mathrm{H} 2 \mathrm{O}+1$ gota do Reativo PBTS), contra um Blank de Tampáo $(2,5 \mathrm{~mL}$ de Tampâo/Rodutor +1 gota do Reativo PBTS). A leltura do Blank de Reatlvos deverh ser menor ou lgual leltura do Blank de Tampao, caso contrario substituir a dgua delonizada por outra de qualldade comprovada.

AGITACAO DOS TUBOS

Os lubos devem ser agitados suavemente, sem inverte-los para evitar contamineçoes.

AMOSTRA

Unicamente soro obtido da maneira usual, livre de hemolise e de glóbulos vermelhos. Os anticoagulantes interterem na reaçáo.

O paciente deve estar em jejum e a coleta deve ser felta sempro no mesmo horário (prelerencialmente pela manha), pois, flutuaçoes fisiologicas sáo significativas durante o dia.

TÉCNICA

Em 3 tubos de ensaio previamente preparados(vide IMPORTANTE). marcados B(Blank), P(Padrâo) D D(Desconhecido)colocar:

Agua deionizada

(vide IMPORTANTE

Padráo

Soro

Tampáo/Redutor

$\begin{array}{ccc}8 & P & D \\ 500 \mu \mathrm{L} & - & - \\ - & 500 \mu \mathrm{L} & - \\ - & - & 500 \mu \mathrm{L} \\ 2 \mathrm{~mL} & 2 \mathrm{~mL} & 2 \mathrm{~mL}\end{array}$

Homogenizar suavemente (sem inverter). Vide IMPORTANTE. Ler a

Absorbancla do Tubo D (Blank de Soro BD), em Espectrofotometro a $560 \mathrm{~nm}$ ou em Colorimetro com filtro verde $(540-560 \mathrm{~nm})$, zerando o aparelho com água delonizada.

Colocar, mantendo o frasco conta-gotas em posição vertical, UMA GOTA do Reativo PBTS em cada tubo.

Misturar imediatamente cada tubo e ler todos eles em $560 \mathrm{~nm}$ entre 6 a 20 minutos, zerando o aparetho com água delonizada.

CALCULOS

Corrigir as leituras $P \in D$. subtraindo os Blanks correspondentes:

$$
\begin{aligned}
& P-B=P \text { (corrigida) } \\
& D \cdot(B+B D)=D \text { (corrigida) } \\
& \text { Ferro } \mu g / d L=D \text { (comiglda) } \times 1 \\
& \text { Onde: } \quad f=100 \mu \mathrm{g} / \mathrm{dL} \\
& \text { P(corrigida) }
\end{aligned}
$$

VALORES DE REFERENCIA

De 60 até $160 \mu \mathrm{g} / \mathrm{dL}$ com a seguinte média de valores:

Homens $=114,6 \mu \mathrm{g} / \mathrm{dL}$

Mulheres $=103,3 \mu \mathrm{g} / \mathrm{dL}$

APRESENITACAO: KIT Bunciente para 100 reacoes.

BIBLIOGRAFIA: Dixon K - Ann.Clin.Biochem 10/5:127 (1973) ICSH - AM.J.Clin.Path.56/4:543 (1971). 